LUIZ FILIPE DE ALMEIDA TOVAR FARO

\title{
TÉCNICAS PARA GARANTIA DE QUALIDADE FIM-A-FIM EM SERVIÇOS DE TELECOMUNICAÇÕES DIGITAIS
}

Dissertação apresentada à Escola Politécnica da Universidade de São Paulo para a obtenção do título de Mestre em Engenharia Elétrica

São Paulo 
LUIZ FILIPE DE ALMEIDA TOVAR FARO

\title{
TÉCNICAS PARA GARANTIA DE QUALIDADE FIM-A-FIM EM SERVIÇOS DE TELECOMUNICAÇÕES DIGITAIS
}

\author{
Dissertação apresentada à Escola Politécnica da \\ Universidade de São Paulo para obtenção do \\ título de Mestre em Engenharia \\ Área de Concentração: \\ Sistemas Digitais \\ Orientador: \\ Prof. Dr. Edison Spina
}

São Paulo 


\section{FICHA CATALOGRÁFICA}

Faro, Luiz Filipe de Almeida Tovar

Técnicas para garantia de qualidade fim-a-fim em serviços de telecomunicações digitais / L.F.A.T. Faro. -- São Paulo, 2007. $162 \mathrm{p}$.

Dissertação (Mestrado) - Escola Politécnica da Universidade de São Paulo. Departamento de Engenharia de Computação e Sistemas Digitais.

1.Administração da qualidade 2.Telecomunicações 3.Desenvolvimento de produtos 4.Modelos organizacionais 5.Convergência tecnológica I.Universidade de São Paulo. Escola Politécnica. Departamento de Engenharia de Computação e Sistemas Digitais Il.t.

São Paulo 


\section{AGRADECIMENTOS}

A meus pais, sem os quais nada disto seria possível, cujo carinho e compreensão se mostraram fundamentais durante esta jornada.

À Milena, pela paciência, compreensão e dedicação durante todos estes anos.

Ao meu orientador Edison Spina, cuja confiança na minha visão inicial para o Mestrado e paciência quase infinita foram instrumentais para a conclusão desta Dissertação.

Aos professores Edson Gomi e Denis Gabos, minha Banca de Qualificação, cujos comentários certeiros ajudaram a especificar melhor este trabalho.

A Moacyr Martucci pelo incentivo a iniciar o programa de Mestrado.

A Carlos Pingarilho, Jorge Leonel e Pedro Pedini, pelo incentivo constante, compreensão e flexibilidade em relação à minha disponibilidade.

A Eduardo Cardoso e Rodrigo Parreira pelo apoio durante todo 0 trabalho e em especial durante a publicação do artigo técnico.

A Petre Dini, a toda a equipe da IARIA e ao comitê técnico do ICDS 07, cujos comentários durante a elaboração e apresentação do artigo técnico suscitaram novas direções para este trabalho.

A todos que, direta ou indiretamente, contribuíram para a conclusão desta Dissertação. 


\section{RESUMO}

Este trabalho apresenta um conjunto de conceitos, ferramentas e metodologias que, se aplicados em conjunto, permitem às entidades responsáveis por desenvolver e oferecer serviços de telecomunicações atender melhor às expectativas dos seus clientes.

Esse conjunto de ferramentas foi criado a partir da identificação e seleção de conceitos e metodologias desenvolvidos originalmente para serem aplicados em diversas atividades: produção fabril, projeto de produtos para consumo massificado, gestão de redes de telecomunicações, gestão empresarial e outros. As ferramentas selecionadas incluem conceitos das áreas de Gestão da Qualidade Total, dos trabalhos do TeleManagement Forum e da Fundação Nacional da Qualidade.

Os conceitos e metodologias selecionados foram então posicionados sobre um conjunto de mapas e diagramas que visam representar a interação entre consumidores, seus prestadores de serviço e as entidades que desenvolvem serviços para estes.

Assim, este trabalho parte de uma ampla gama de conhecimentos originários de diversas disciplinas diferentes e propõe uma maneira de integrá-los de forma otimizada para aplicação em serviços de telecomunicações.

Palavras-chave: Administração da qualidade. Telecomunicações. Desenvolvimento de produtos. Modelos organizacionais. Convergência tecnológica. eTOM. QFD. NGOSS. Seis Sigma. 


\begin{abstract}
This work presents a set of concepts, tools and methodologies that, if applied together, allow telecommunications service providers and developers to better fulfill their customers' expectations.

This set of tools was created by identifying and selecting concepts and methodologies originally developed for deployment on different industries: manufacturing, consumer goods development, communications network management, corporate management and so on. The selected tools include concepts from Total Quality Management, the works of the TeleManagement Forum and the models developed by the Brazilian National Foundation for Quality (FNQ).

These selected concepts and methodologies were then positioned over a set of conceptual maps and diagrams that aim to model the interaction between consumers, their service providers and the entities that develop services for the later.

As such, this work starts from a broad range of techniques that come from very different knowledge fields and proposes a way to integrate them in an optimized set for application on the telecommunications industry.
\end{abstract}

Keywords: Quality management. Telecommunications. Product development. Organizational models. Technology convergence. eTOM. QFD. NGOSS. Six Sigma. 


\section{LISTA DE FIGURAS}

Figura 1 - Modelo de Qualidade de Serviços ............................................. 17

Figura 2 - Abrangência do trabalho..................................................... 19

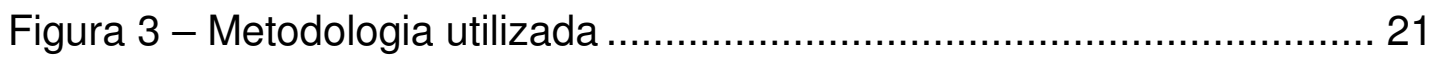

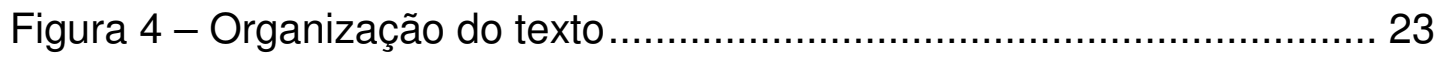

Figura 5 - Modelo de Kano para requisitos dos consumidores ................... 27

Figura 6 - Papéis no Modelo de Referência de e-business do TMForum ... 32

Figura 7 - Modelo de Referência de e-business do ponto de vista do

Consumidor 35

Figura 8 - Relacionamento oferta-demanda entre Provedor de Serviços e

Consumidor 35

Figura 9 - Partes interessadas e seus relacionamentos no modelo proposto 36

Figura 10 - Necessidades de ferramentas das partes interessadas ........... 40

Figura 11 - Evolução da organização da produção...................................... 44

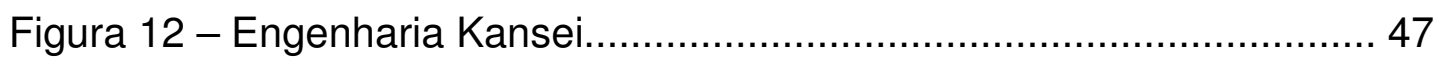

Figura 13 - Ciclo PDCA de melhoria contínua …….................................. 50

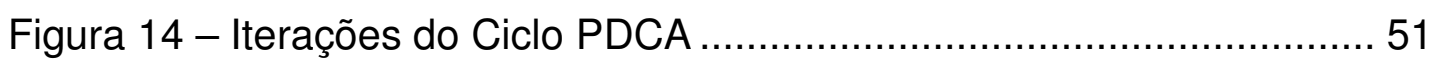

Figura 15 - Exemplo de uso do Ciclo PDCA: implantação da Norma de

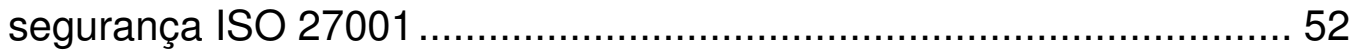

Figura 16 - Ciclo DMAIC de melhoria contínua e controle estatístico de processos 56

Figura 17 - Níveis de maturidade de um Provedor de Serviços, segundo o

TMForum 58

Figura 18 - Abrangência do programa NGOSS........................................ 59

Figura 19 - Componentes Arquiteturais do programa NGOSS ................... 61

Figura 20 - Perspectivas e Dimensões do NGOSS Lifecycle ........................ 63

Figura 21 - Metodologia SANRR ........................................................ 66

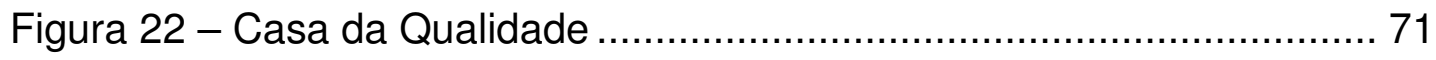


Figura 23 - Exemplo de Casa da Qualidade preenchida.............................. 74

Figura 24 - Maximum Value Table ...................................................... 77

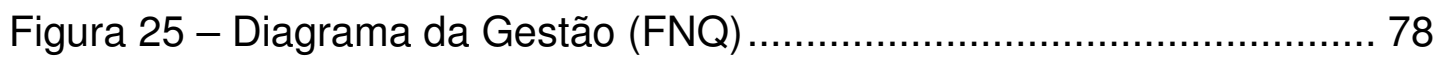

Figura 26 - Critérios de Excelência da FNQ.......................................... 81

Figura 27 - Fundamentos x Critérios de Excelência da FNQ ...................... 83

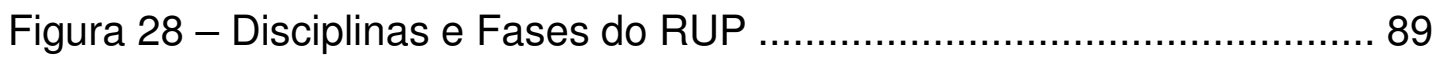

Figura 29 - Processo de Desenvolvimento "em cascata".......................... 90

Figura 30 - Processo de Desenvolvimento iterativo ................................... 91

Figura 31 - Processo RUP de Gestão da Implantação ............................... 92

Figura 32 - Modelo de Processos - ITIL ................................................. 95

Figura 33 - Áreas de conhecimento do PMBoK ................................... 100

Figura 34 - TMForum - Visão, Missão e Iniciativas ................................. 105

Figura 35 - Evolução dos modelos de processos de gestão de serviços de

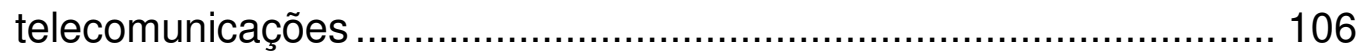

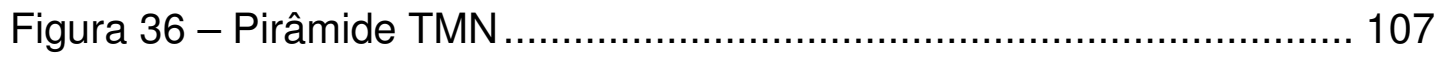

Figura 37 - TOM - Telecom Operations Map....................................... 109

Figura 38 - Conceitos do eTOM: Partes interessadas e Macro-agrupamentos de Processos .................................................................................... 113

Figura 39 - Conceitos do eTOM: Produto, Serviço, Recurso ………….... 116

Figura 40 - eTOM - Visão de Nível 0 .............................................. 117

Figura 41 - Decomposição do processos de Nível 0 de Estratégia, Infraestrutura e Produto ....................................................................... 118

Figura 42 - Decomposição do processos de Nível 0 de Operações ......... 120

Figura 43 - Decomposição do processo de Nível 0 de Gestão Empresarial

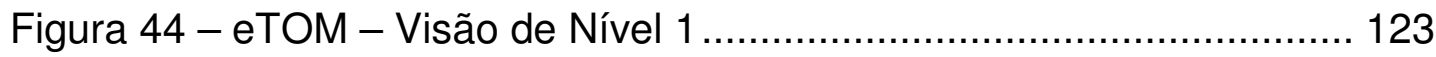

Figura 45 - eTOM - Visão de Nível 2 .................................................... 125

Figura 46 - Entendimento da Cadeia de Prestação de Serviços dentro do

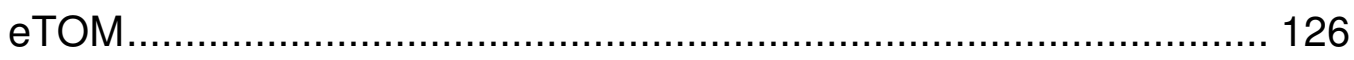

Figura 47 - Cadeia de Prestação de Serviços ............................................ 127

Figura 48 - Escopo de Atuação de Desenvolvedores e Provedores na

Cadeia de Prestação de Serviço ...................................................... 128 
Figura 49 - Mapeamento Ferramentas x Necessidades x Partes Interessadas

Figura 50 - Mapeamento Ferramentas x Cadeia de Prestação de Serviços

Figura 51 - Provedores: Diagrama da Gestão x eTOM 137

Figura 52 - Provedores: DMAIC x eTOM 138

Figura 53 - Provedores: Voice Of Customer x eTOM.............................. 139

Figura 54 - Provedores: Kansei e House of Quality x eTOM .................... 140

Figura 55 - Provedores: Kaizen e PDCA x eTOM …………………....... 141

Figura 56 - Provedores: RUP x eTOM …………………………..... 142

Figura 57 - Provedores: SANRR x eTOM ………………………....... 143

Figura 58 - Provedores: NGOSS Implementation Model x eTOM............. 144

Figura 59 - Provedores: Seis Sigma x eTOM....................................... 145

Figura 60 - Ferramentas para Provedores de Serviço x eTOM ................. 146

Figura 61 - Desenvolvedores: Voice Of Customer x eTOM ...................... 148

Figura 62 - Desenvolvedores: Kansei, House of Quality, Maximum Value

Table e Visitas Gemba x eTOM......................................................... 149

Figura 63 - Desenvolvedores: RUP x eTOM ………............................ 150

Figura 64 - Desenvolvedores: NGOSS Implementation Model x eTOM ... 151

Figura 65 - Ferramentas para Desenvolvedores de Serviço x eTOM ....... 152 


\section{LISTA DE TABELAS}

Tabela 1 - Relacionamentos entre partes interessadas e ferramentas necessárias.

Tabela 2 - Necessidades internas de Desenvolvedores e Provedores de

Serviço 39

Tabela 3 - Ferramentas selecionadas do Lean Thinking e TQM............... 45

Tabela 4 - Comparação entre TQM e Seis Sigma ................................. 53

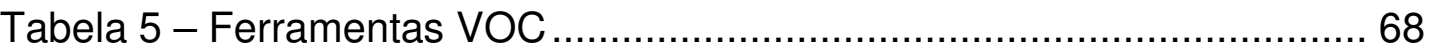

Tabela 6 - Ferramentas selecionadas ............................................. 101

Tabela 7 - Ferramentas identificadas para cada relacionamento entre as partes interessadas ...................................................................... 102 


\section{LISTA DE ABREVIATURAS}

ASQ American Society for Quality (Sociedade Americana para a Qualidade)

COBIT Control Objectives for Information and related Technology (Objetivos de Controle para a Informação e Tecnologias relacionadas)

DMAIC Define, Measure, Analyze, Improve, Control (Definir, Medir, Analisar, Implementar / Melhorar, Controlar)

eTOM enhanced Telecom Operations Map

FAB Fulfillment, Assurance \& Billing (Entrega, Garantia de Qualidade e Cobrança - termo do eTOM)

FNQ Fundação Nacional da Qualidade

ICT Information and Communication Technology (Tecnologia da Informação e Comunicações)

ISACA Information Systems Audit and Control Association (Associação para Auditoria e Controle de Sistemas de Informação)

ISO International Organization for Standardization

IT Information Technology (Tecnologia da Informação)

ITGI IT Governance Institute (Instituto de Governança de TI)

ITIL IT Infrastructure Library (Biblioteca de Infra-estrutura de TI)

ITSMF IT Service Management Forum (Fórum de Gestão de Serviços de TI)

ITU International Telecommunications Union (União Internacional de Telecomunicações)

NGOSS Next Generation Operation Support Systems (Sistemas de Suporte à Operação de Próxima Geração)

OSI/NM OSI/Network Management Forum

OSS Operation Support Systems (Sistemas de Suporte à Operação)

PMBoK Project Management Body of Knowledge (Corpo de Conhecimento em Gerenciamento de Projetos) 
PMI Project Management Institute (Instituto de Gerenciamento de Projetos)

QFD Quality Function Deployment (Desdobramento da Função Qualidade)

QoS Quality of Service (Qualidade de Serviço)

QoE Quality of Experience (Qualidade de Experiência)

RUP Rational Unified Process

SANRR Scope, Analyze, Normalize, Rationalize, Rectify

SID Shared Information Data Model

SIP Strategy, Infrastucture \& Product (Estratégia, Infra-estrutura e Produto termo do eTOM)

SLM Service Level Management (Gestão de Nível de Serviço)

TI Tecnologia da Informação

TMForum TeleManagement Forum

TMN Telecommunications Management Network

TOM Telecom Operations Map

TQM Total Quality Management (Gestão da Qualidade Total)

VOC Voice Of Customer (Voz do Consumidor) 


\section{SUMÁRIO}

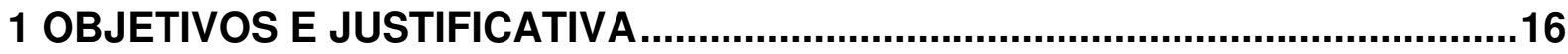

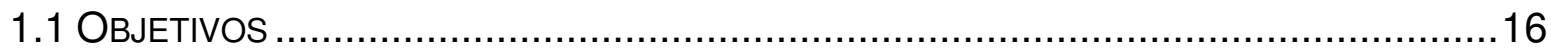

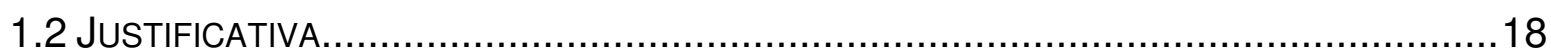

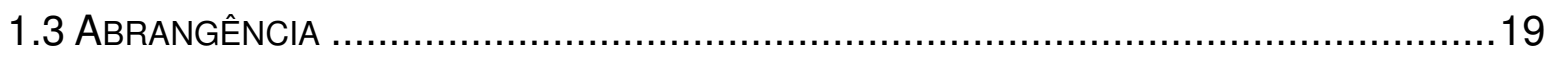

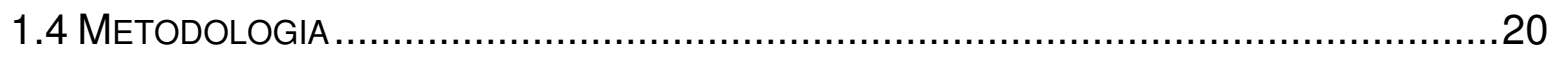

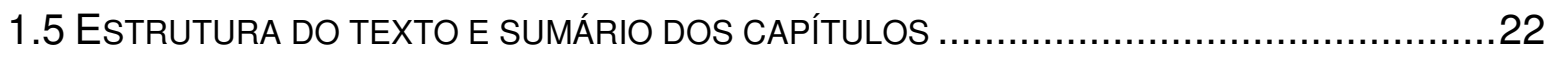

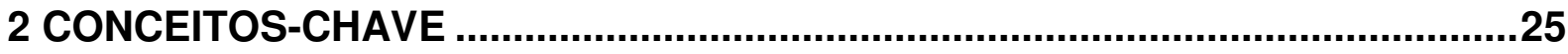

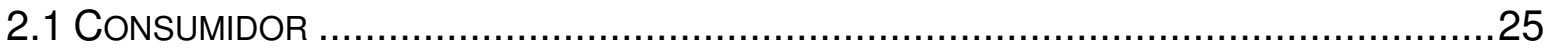

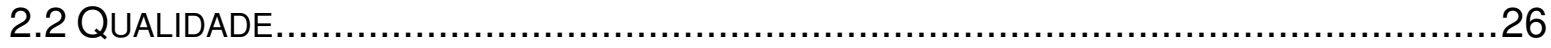

2.3 SERVIÇO DE TELECOMUNICAÇÕES ............................................................28

3 PARTES INTERESSADAS E SUAS NECESSIDADES ......................................29

3.1 PARTES INTERESSAdAS (StAKEHOLDERS) ................................................29

3.1.1 O Modelo de Referência do TMForum para e-business............................29

3.1.1.1 Definição e Objetivos..........................................................29

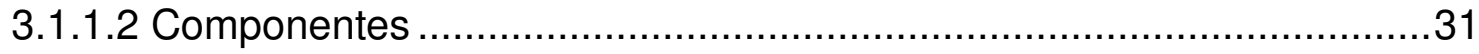

3.1.2 Proposta: Modelo de referência com ênfase em requisitos e design de

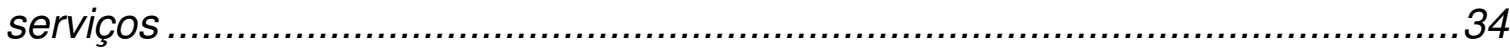

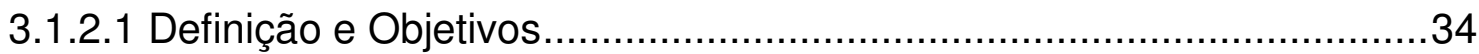

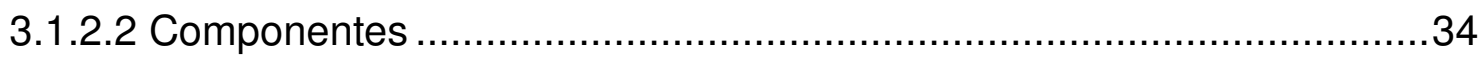

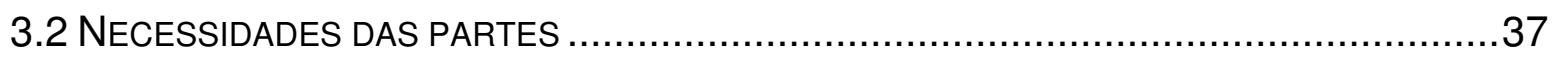

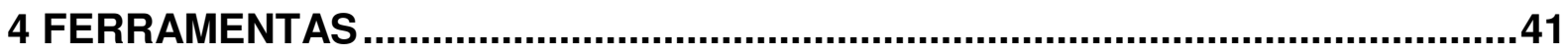

4.1 LEAN ThinkING E TOtAL QUALITY MANAGEMENT ........................................ 41

4.1.1 Kansei Engineering ............................................................. 46

4.1.2 Kaizen ................................................................................. 48

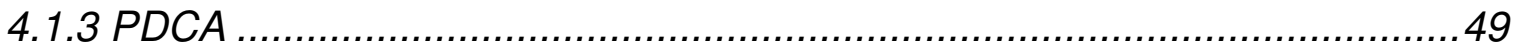

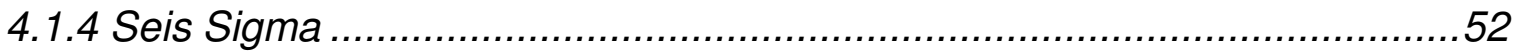

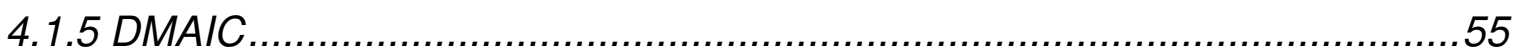

4.2 Programa NGOSS (NEW Generation OSS) .......................................... 57 


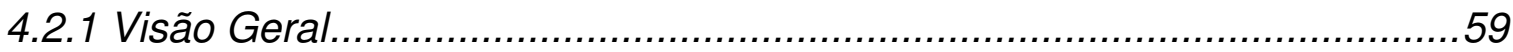

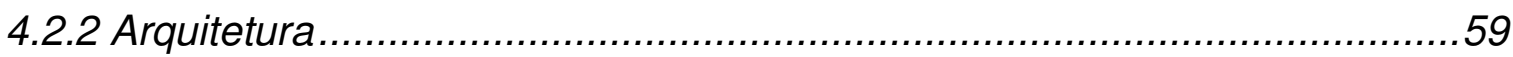

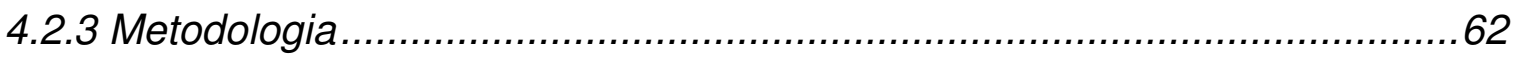

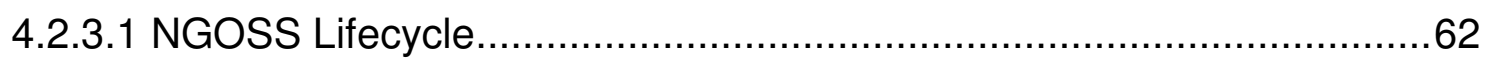

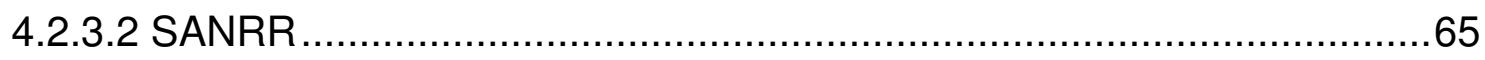

4.3 Metodologia QFD (Quality Function DePLOYMENT) ....................................66

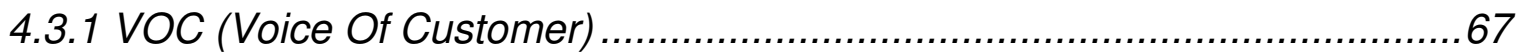

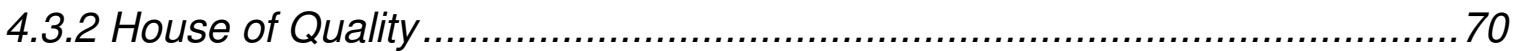

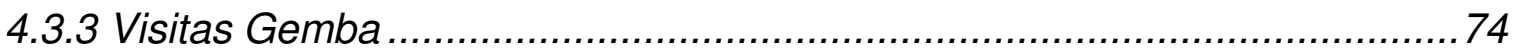

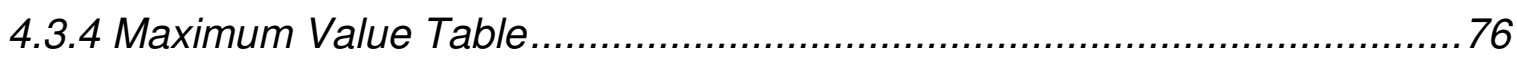

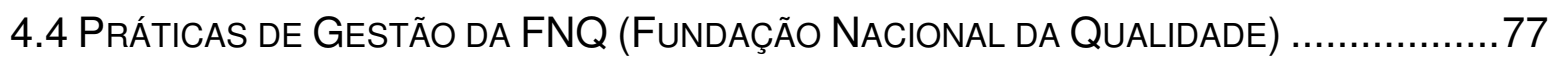

4.4.1 Melhores práticas do RUP (Rational Unified Process) ..............................83

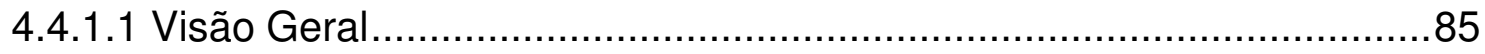

4.4.1.2 Práticas interessantes para o desenvolvimento de Serviços de

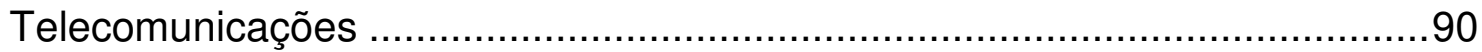

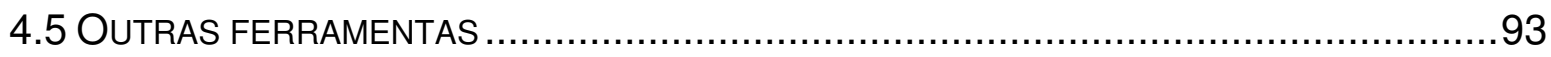

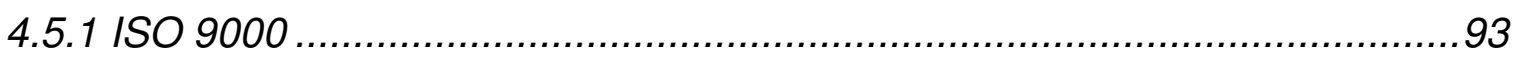

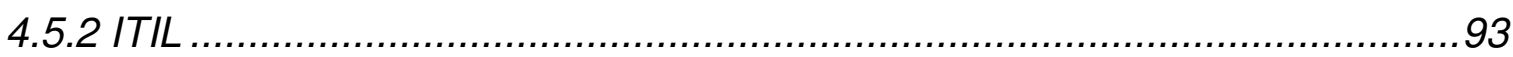

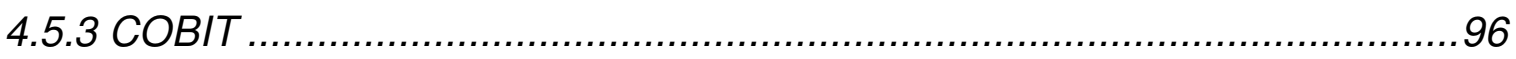

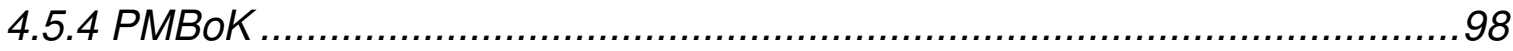

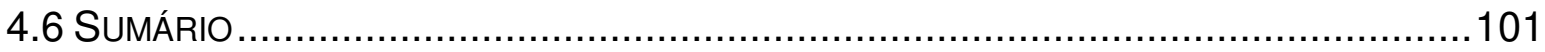

5 O MODELO DE PROCESSOS E A CADEIA DE PRESTAÇÃO DE SERVIÇOS DE TELECOMUNICAÇÕES ..............................................................................103

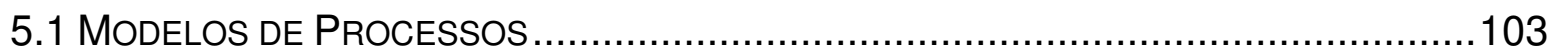

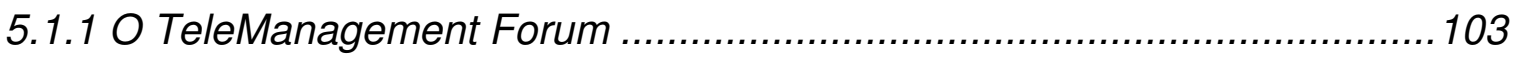

5.1.2 Evolução dos modelos de processos em Telecomunicações ..................106

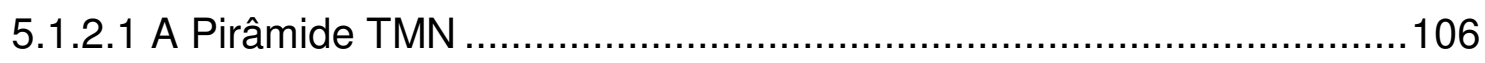

5.1.2.2 TOM - Telecom Operations Map ……….................................109

5.1.2.3 eTOM - enhanced Telecom Operations Map..................................112

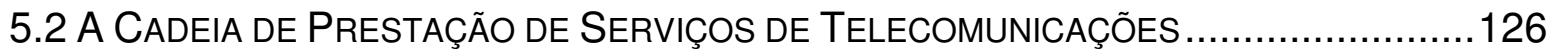

\section{MAPEAMENTO DE FERRAMENTAS NA CADEIA DE PRESTAÇÃO DE}

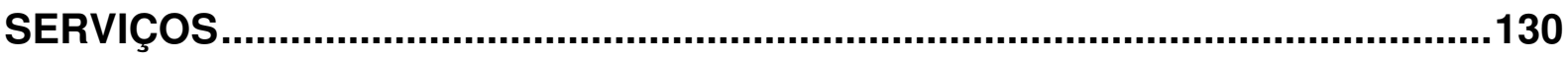

6.1 Mapeamento no mOdelo de Relacionamento entRe StakeHolders .............130 
6.2 Mapeamento na Cadeia de PrestaçÃo de Serviços ...................................132

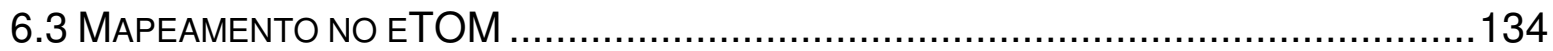

6.3.1 Ferramentas para Provedores de Serviços ....................................... 134

6.3.2 Ferramentas para Desenvolvedores de Serviços................................147

7 CONSIDERAÇÕES FINAIS .........................................................................153

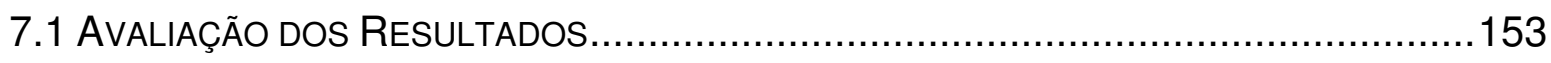

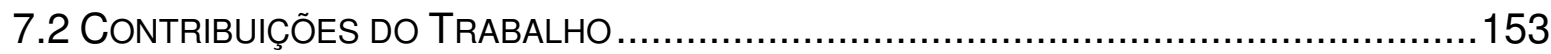

7.3 TRABALHOS FUTUROS .......................................................................... 154

LISTA DE REFERÊNCIAS ...............................................................................156 


\section{OBJETIVOS E JUSTIFICATIVA}

\subsection{Objetivos}

Deseja-se apresentar uma "caixa de ferramentas" para garantir que a "voz do consumidor" seja ouvida e levada em consideração em todos os elos da cadeia de prestação de serviços em telecomunicações, ou seja, que estes serviços sejam prestados com a máxima qualidade na ótica do Consumidor.

Por "caixa de ferramentas" entende-se um conjunto de técnicas, metodologias e frameworks que abordem a prestação de serviços de maneira fim-a-fim: da concepção do serviço à sua entrega final ao usuário.

Por "voz do consumidor" entende-se os anseios, demandas e expectativas dos usuários finais dos serviços de telecomunicações - ou seja, os requisitos destes usuários em sua forma original.

Formalmente, considerando o modelo de Qualidade de Serviços proposto por Parasuraman, Zeithaml e Berry em 1985 e comentado por Hegedus em [1], existem cinco gaps na qualidade de serviços (Figura 1):

- Gap 1: discrepância entre o que a empresa acredita que o consumidor espera e a expectativa real deste;

- Gap 2: discrepância entre o produto que a empresa entende que deve fornecer e o produto que é desenvolvido;

- Gap 3: discrepância entre o produto que foi especificado e o que é efetivamente produzido;

- Gap 4: discrepância entre aquilo que a empresa entende que é necessário incorporar ao produto e aquilo que ela comunica ao mercado;

- Gap 5: discrepância potencial entre o serviço esperado e o percebido do ponto de vista do consumidor. Os fatores determinantes para o serviço esperado pelo consumidor incluem a comunicação boca a boca (Word Of 
Mouth - WOM), necessidades pessoais, experiências anteriores e comunicações externas do fornecedor de serviço.

O objetivo final deste trabalho é auxiliar os Provedores de Serviço a sanar o gap 5: garantir que o serviço percebido pelo consumidor seja o mais próximo possível das suas expectativas. Para cumprir estes objetivos, serão propostas ferramentas e metodologias para lidar com os gaps 1, 2 e 3 - não é objetivo deste trabalho debater as técnicas de Comunicação e Publicidades necessárias para atenuar o gap 4.

\section{CONSUMIDOR}

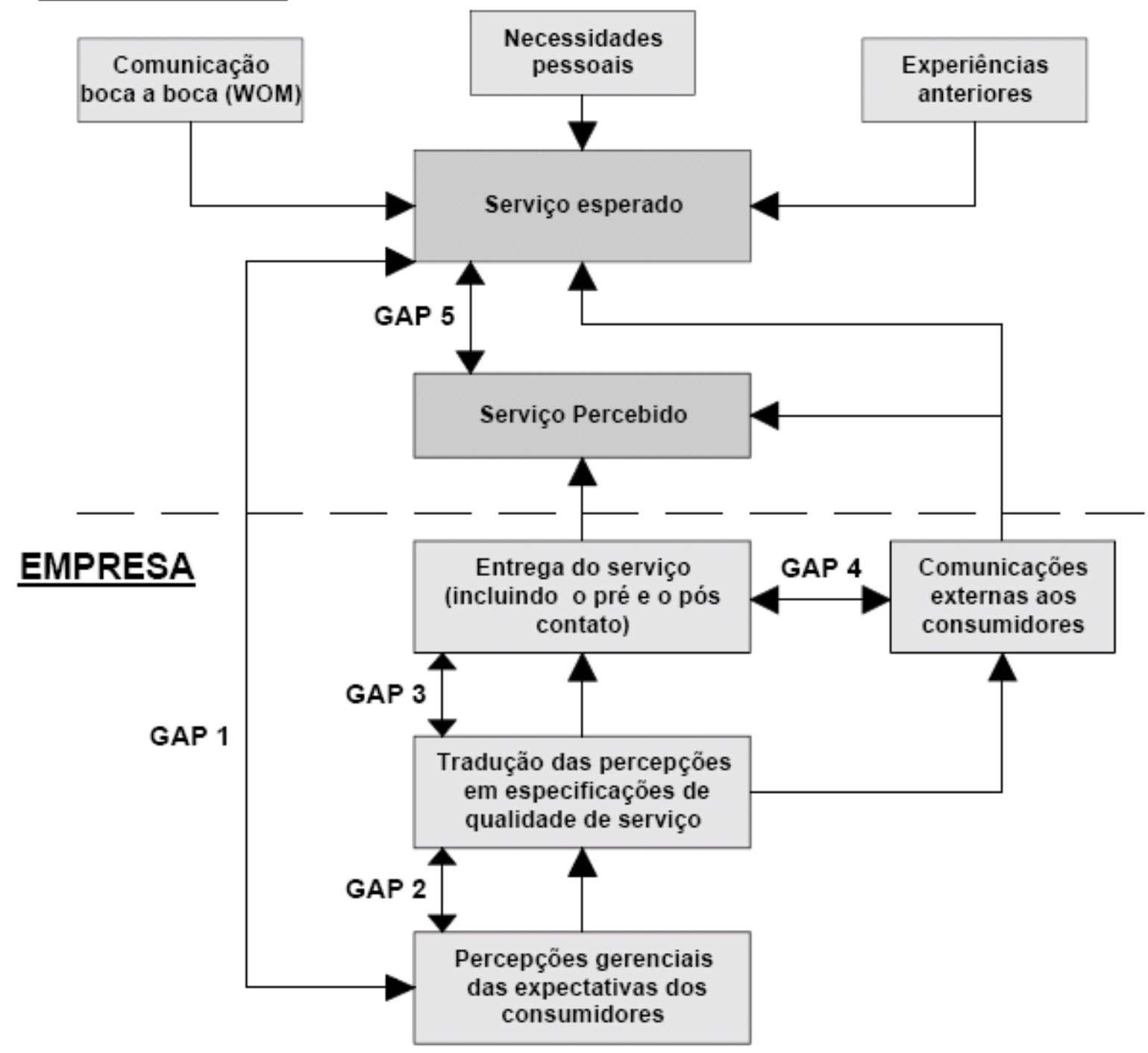

Figura 1 - Modelo de Qualidade de Serviços 
Em sua forma final, este trabalho consistirá em um conjunto de recomendações tanto para os Desenvolvedores quanto para os Provedores de Serviço, notadamente as Operadoras de Telecomunicações. Este conjunto será representado na forma de um mapeamento das ferramentas que irão permitir ao Provedor de Serviços reconhecer, assimilar em seus processos e, finalmente, atender às demandas e expectativas dos consumidores por meio de seus serviços.

Nenhuma restrição será feita sobre a natureza dos serviços prestados; ao contrário, serão realizados esforços especiais para que as técnicas propostas se apliquem aos chamados Serviços Convergentes, que combinam características de diversos serviços hoje independentes (comunicação de voz fixa e móvel, comunicação de dados fixa e móvel, distribuição de música, vídeo e programação de televisão entre outros).

Adicionalmente, esta dissertação também objetiva trazer para o meio acadêmico um conjunto de conceitos, metodologias e frameworks hoje amplamente divulgados e aplicados no mercado de telecomunicações. Com isto espera-se facilitar o trabalho de futuros pesquisadores, disponibilizando uma introdução estruturada a conceitos do mercado de telecomunicações consolidada num único documento.

\subsection{Justificativa}

Este trabalho nasceu do contato do autor com o dia-a-dia das áreas de Operação dos principais Provedores de Serviços de Telecomunicações do Brasil. Deste convívio veio a constatação de que falta aos Provedores uma "caixa de ferramentas" para garantir a Qualidade de Serviço do ponto de vista do principal interessado: o Consumidor.

Para corroborar esta constatação, abundam dados que atestam a insatisfação do usuário com a qualidade dos serviços atuais [2][3][4][5]. Além disso, a crescente sofisticação da demanda [6] e dos serviços [7] se coloca como um grande desafio aos Provedores de Serviço - em especial, os Serviços 
Convergentes prestados sobre Redes Heterogêneas [7] são particularmente complexos no que tange à gestão da expectativa e da satisfação do Consumidor.

\subsection{Abrangência}

Considere-se uma matriz bidimensional cujos eixos sejam formados por uma visão em camadas de um serviço de telecomunicações (como a Pirâmide de Gerenciamento de Serviços definida pelo ITU.T [8]) e por um ciclo genérico de gestão de serviços em 3 etapas (Concepção, Implementação e Disponibilização / Operação).

Nesta matriz é possível delinear a abrangência do presente trabalho da seguinte maneira: toda a cadeia de gestão de um serviço de telecomunicações será contemplada e o foco da análise estará na camada de Serviços e, eventualmente, serão abordadas questões de negócios.

Figura 2.

Esta definição da abrangência do trabalho está representada graficamente na

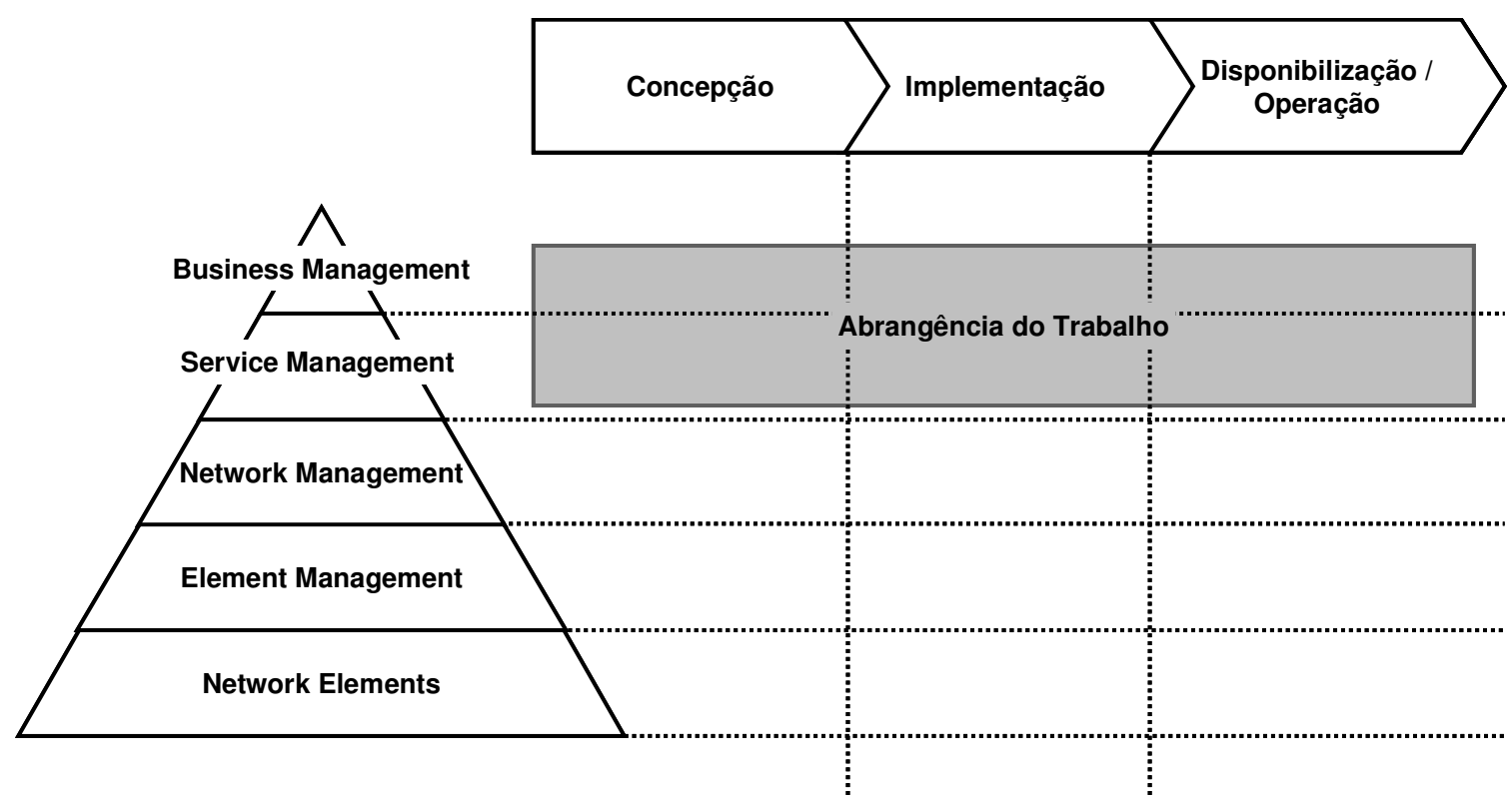

Figura 2 - Abrangência do trabalho

O público alvo deste trabalho são as entidades responsáveis por conceber, implementar, disponibilizar e operar os serviços, ou seja, os Desenvolvedores e 
os Provedores de Serviço (esta distinção será detalhada e explorada posteriormente neste texto).

\subsection{Metodologia}

Para criar a "caixa de ferramentas" objetivada, os seguintes passos genéricos foram identificados:

- Identificar as partes interessadas (stakeholders) relevantes, seus papéis e inter-relacionamentos

- Identificar as técnicas, ferramentas, metodologias e frameworks aplicáveis a cada um desses relacionamentos

- Selecionar o framework de processos de negócio mais adequado para descrever a cadeia de prestação de serviços de telecomunicações

- Mapear as técnicas identificadas no framework de processos de negócio selecionado

Esta metodologia encontra-se representada graficamente na Figura 3. 


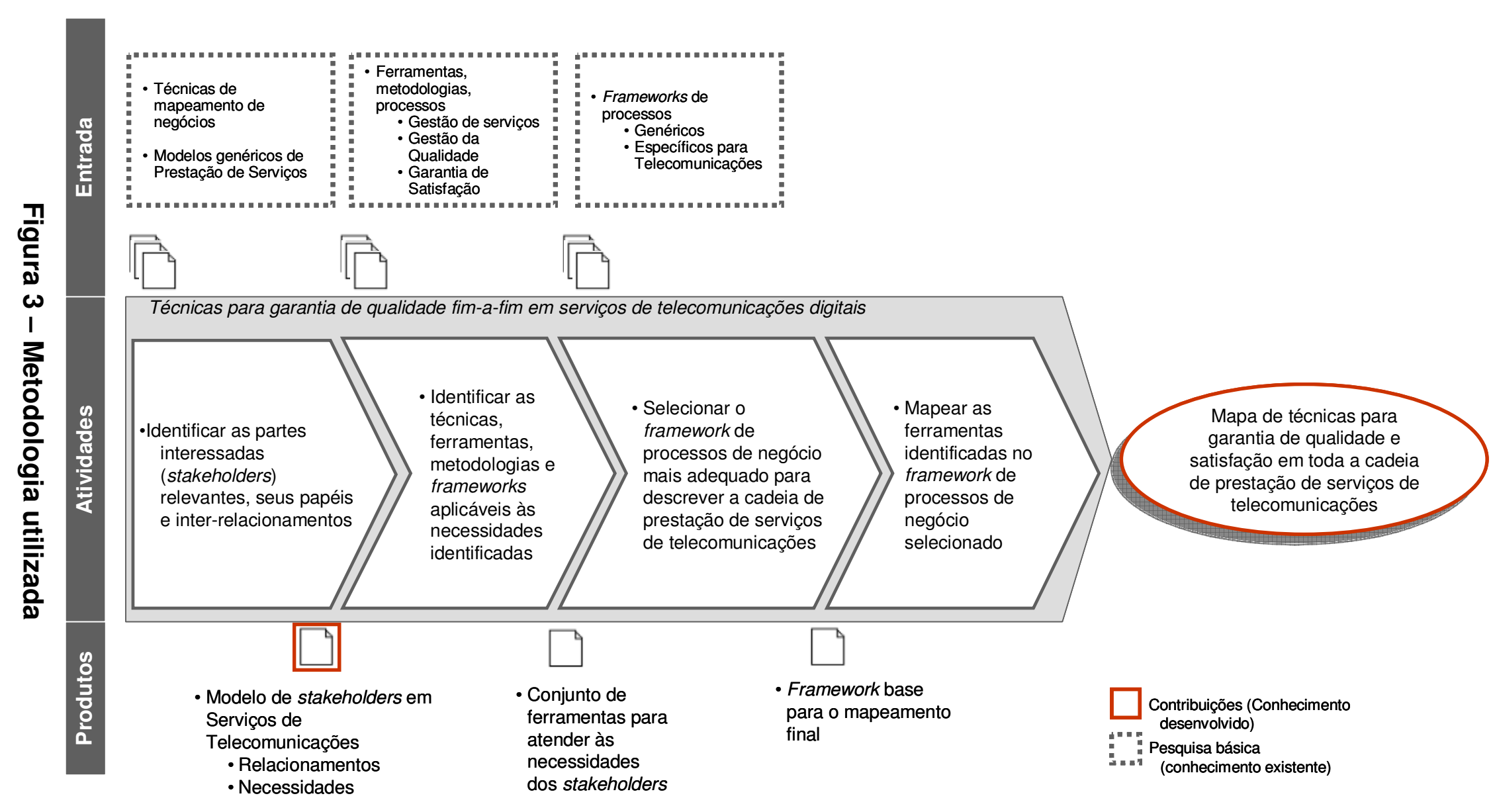


Adicionalmente, será construído um Estudo de Caso, aplicando a um Provedor

de Serviços típico as técnicas identificadas da maneira sugerida no mapeamento.

\subsection{Estrutura do texto e sumário dos capítulos}

O trabalho está dividido em 7 capítulos (Figura 4). 
Técnicas para garantia de qualidade fim-a-fim em serviços de telecomunicações digitais

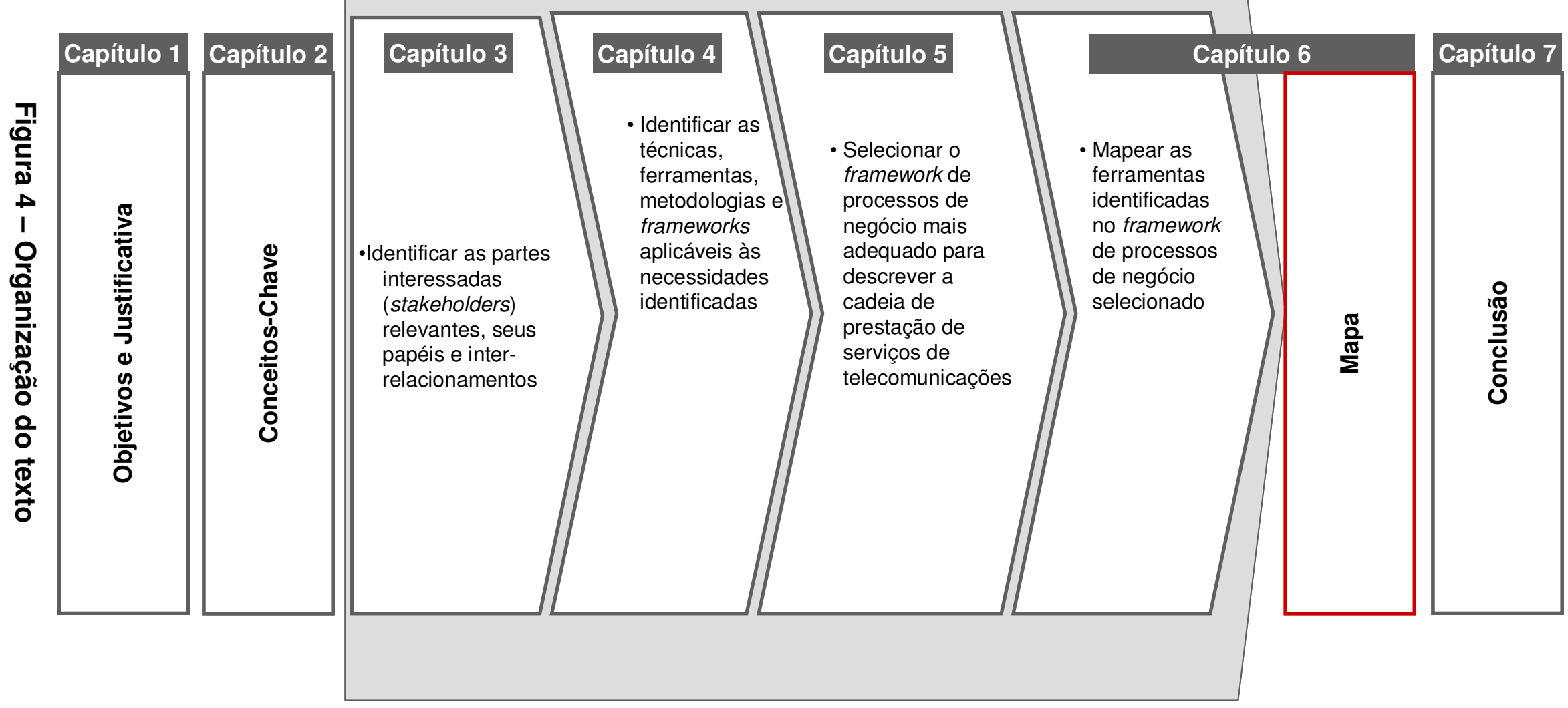


- Capítulo 1 - Objetivos e Justificativa

- Compreende a presente introdução, explicitando o objetivo, motivação e metodologia do trabalho

- Capítulo 2 - Conceitos-Chave

- Apresenta a definição formal de alguns conceitos-chave que serão utilizados em toda a Dissertação

- Capítulo 3 - Partes interessadas e suas necessidades

- Apresenta a identificação das partes interessadas (stakeholders) relevantes, seus papéis e inter-relacionamentos

- Capítulo 4: Ferramentas

- Aqui se identificam e conceituam as técnicas, ferramentas, metodologias e frameworks aplicáveis aos relacionamentos apresentados no Capítulo 4

- Capítulo 5: Cadeia de prestação de serviços em Telecomunicações

- Descreve o trabalho de seleção e apresentação do framework de processos de negócio mais adequado para descrever a cadeia de prestação de serviços de telecomunicações

- Capítulo 6: Mapeamento de ferramentas na cadeia de prestação de serviços

- Apresenta o mapeamento das técnicas identificadas no Capítulo 5 no framework de processos de negócio selecionado no Capítulo 6

- Capítulo 7: Considerações Finais

- Apresenta as considerações finais sobre o trabalho 


\section{CONCEITOS-CHAVE}

O presente trabalho tem por objetivo apresentar um conjunto de ferramentas para garantir que a voz do consumidor seja levada em consideração em todos os elos da cadeia de prestação de serviços em telecomunicações.

Assim, é essencial estabelecer definições de trabalho para os conceitos de Consumidor, Qualidade e Serviços de Telecomunicações.

\subsection{Consumidor}

Figura central neste texto, o Consumidor (também chamado Usuário final ou Cliente no decorrer do trabalho) é definido de maneira similar por diversas instituições:

- Definição da União Européia [9]: Consumidor é a pessoa física que faz negócios sem fins profissionais;

- Definição tradicional da língua portuguesa [10]: Consumidor é aquele ou aquilo que consome, ou ainda, aquele que compra para gastar em uso próprio;

- Definição da American Society for Quality (ASQ): Consumidor é qualquer um para o qual a organização fornece produtos ou serviços;

- Definição do TeleManagement Forum, focada em serviços de comunicação e informação [11]: Consumidor é o responsável por solicitar, usar e pagar pelos serviços / produtos. Esta definição é explorada em maiores detalhes no capítulo 3 e na seção 5.1.2.3

Neste trabalho, entende-se o Consumidor como definido pelo TeleManagement Forum: aquele que solicita, usa e paga pelos serviços de telecomunicações, podendo tratar-se de pessoa física ou jurídica. 


\subsection{Qualidade}

Dado o objetivo do presente trabalho, é necessário entender de que se trata esta "Qualidade" que se deseja garantir. Diversas entidades definem o termo Qualidade de diferentes maneiras:

- Definição da ISO [12]: Grau no qual um conjunto de características inerentes satisfaz a requisitos;

- Definição tradicional [10]: Numa escala de valores, propriedade que permite avaliar e, consequentemente, aprovar, aceitar ou recusar, qualquer coisa;

- Definição da ASQ [13] [14]: Termo subjetivo para o qual cada pessoa possui uma definição particular. Em contextos técnicos, Qualidade pode ter dois significados: 1. as características de um produto ou serviço que the permitem satisfazer necessidades explícitas ou implícitas, 2. um produto ou serviço sem quaisquer deficiências.

Um entendimento mais moderno é a proposta de Kano [16]: um modelo bidimensional de Qualidade. Nesse modelo, a qualidade pode ser do tipo "tem que ser" ou do tipo "atraente". O primeiro tipo é próximo da definição da ISO: um produto de boa qualidade "tem que" atender aos requisitos do consumidor. $\mathrm{O}$ segundo tipo, a qualidade atraente, é composto pelas características que o consumidor iria adorar - mas ainda não descobriu.

De acordo com a ASQ [15], "satisfazer o consumidor significa fornecer o que é necessário quando é necessário"; assim, esse modelo bidimensional de qualidade requer um modelo igualmente bidimensional de necessidades ou requisitos. Esse modelo, também proposto por Kano, está ilustrado na Figura 5 (adaptada de [16]). 


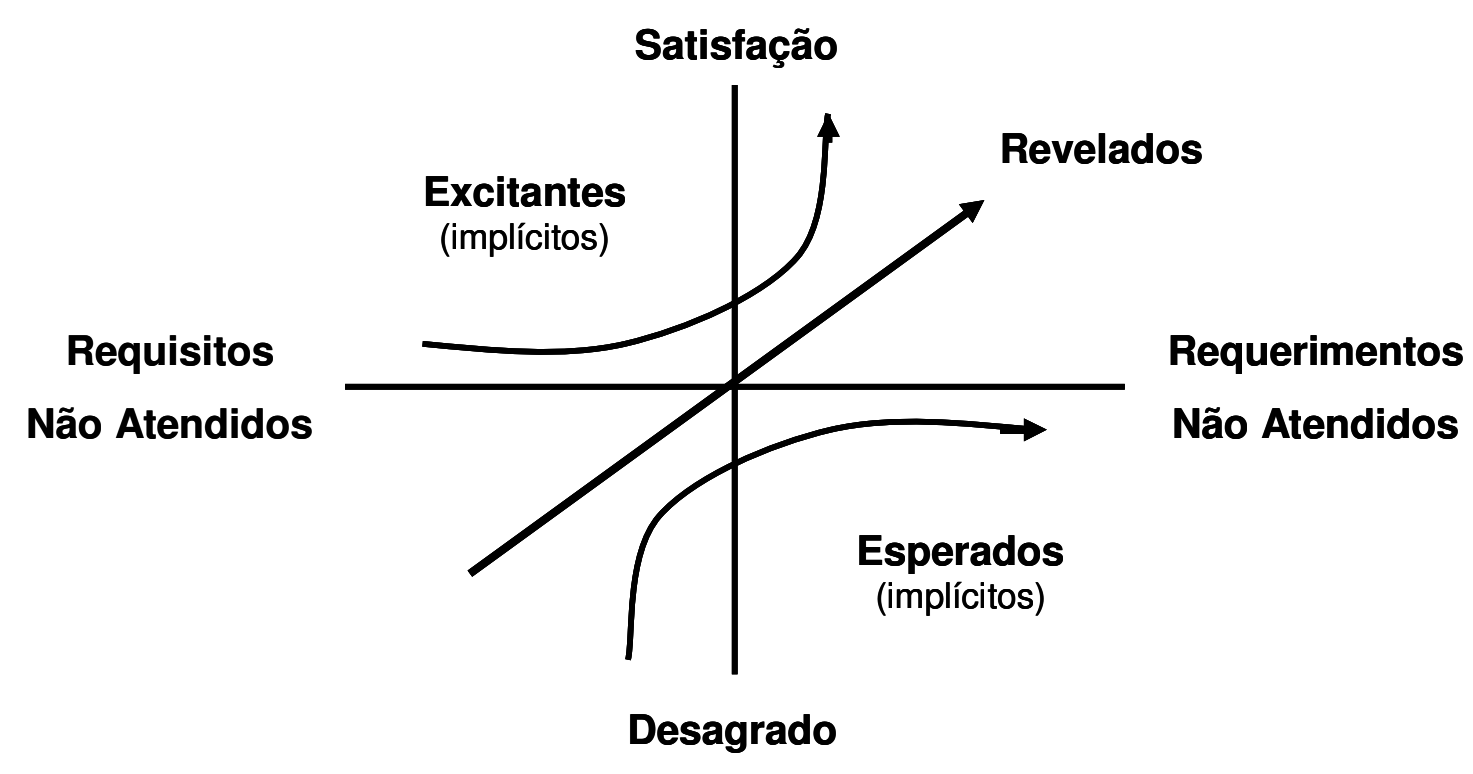

Figura 5 - Modelo de Kano para requisitos dos consumidores

Os requisitos propostos por Kano [16], [17] são:

- Requisitos Revelados são aqueles diretamente listados pelos consumidores quando perguntados sobre quais os seus desejos. Estes requisitos satisfazem (ou desagradam) proporcionalmente à sua presença (ou ausência) no produto ou serviço.

- Requisitos Esperados são em geral tão básicos que o consumidor se esquece deles - até que o produto ou serviço deixem de atendê-los. Requisitos Esperados são expectativas básicas sem as quais o produto pode deixar de ter valor: sua ausência desagrada muito o consumidor. Da mesma forma, quando atendidos, estes requisitos mal são notados por ele. Assim, estes requisitos devem ser atendidos a todo o custo.

- Requisitos Excitantes são difíceis de descobrir, pois estão além das expectativas do consumidor. Sua ausência em um produto não desagrada, mas sua presença excita o consumidor. Como os consumidores não conseguem formalizar estes requisitos, é dever dos Desenvolvedores e Provedores de Serviços identificá-los e explorá-los.

Este modelo bidimensional é bastante dinâmico na medida em que para o consumidor, o que é Excitante hoje é Esperado amanhã. 
O entendimento de Qualidade utilizado neste trabalho é o do modelo apresentado aqui: a característica de um produto de ser capaz tanto de atender quanto de surpreender, ou excitar, o consumidor.

\subsection{Serviço de Telecomunicações}

O conceito de Serviço utilizado neste trabalho é o conceito de Produto do TMForum, apresentado na seção 5.1.2.3.1.1: um Serviço é desenvolvido pelo Provedor de Serviço para ser comercializado como parte dos seus Produtos. Um mesmo Serviço pode ser incluído em múltiplos produtos.

Assim, ao discutir o Serviço que um consumidor recebe, estamos na verdade nos referindo ao que o TMForum chama de Produto, ou seja, a visão do consumidor sobre a oferta de um Provedor de Serviços. 


\section{PARTES INTERESSADAS E SUAS NECESSIDADES}

Neste capítulo serão desenvolvidos os passos apresentados na primeira fase da Metodologia (seção 0), conduzindo-se uma análise de alto nível baseada nos relacionamentos entre as partes interessadas (stakeholders).

\subsection{Partes interessadas (Stakeholders)}

O objetivo desta seção é identificar as partes interessadas (stakeholders) relevantes ao estudo, seus papéis e inter-relacionamentos. A adoção de um modelo de referência para as partes interessadas é fundamental para a posterior identificação das ferramentas mais adequadas a otimizar o relacionamento entre estas partes.

A base para este estudo serão os trabalhos realizados pelo TeleManagement Forum [18], entidade de reconhecida influência no cenário global de telecomunicações, a pesquisa realizada e as idéias desenvolvidas durante a construção da presente dissertação e a experiência do autor como profissional do setor.

\subsubsection{O Modelo de Referência do TMForum para e-business}

\subsubsection{Definição e Objetivos}

Compreendendo a evolução do ambiente de prestação de serviços de comunicação em direção à Convergência Tecnológica e de Serviços [7], o TeleManagement Forum (TMForum) [18] propôs um modelo de referência para categorizar todas as partes interessadas. Este modelo, apresentado na versão 6 
do enhanced Telecom Operations Map (eTOM) [11], recebeu o nome de ebusiness Reference Model.

Antes de descrever este modelo, é importante conhecer a definição utilizada pelo TMForum para o conceito de e-business.

Para o TMForum, e-business é "a interação entre parceiros de negócio com o auxílio da Tecnologia da Informação" [11]. Como tal, e-business se refere não somente a comprar e vender bens e serviços através da Internet, mas também a prestar assistência aos consumidores e a colaborar com todos os parceiros envolvidos no negócio. Assim, toda a empresa que utiliza a Tecnologia da Informação (e, notadamente, a Internet) para se tornar mais eficiente, produtiva e competitiva está conduzindo e-business.

Nesta visão, o ambiente de e-business pode ser entendido como comunidades de organizações complementares operando em conjunto para criar novas entidades de negócio. As características intrínsecas da Tecnologia da Informação tornam estas entidades especialmente flexíveis, permitindo-lhes reajustar-se a novas realidades de mercado com velocidade muito superior à de entidades cujos processos de negócios não se caracterizam como e-business.

Ao propor o seu Modelo de Referência para e-business, o TMForum declara estar respondendo à necessidade dos Provedores de Serviço de Telecomunicações de integrar seus frameworks de negócios, tecnologia e processos e, em especial, à necessidade de integrar seus processos de ebusiness aos processos de negócio tradicionais. $\mathrm{Na}$ visão da entidade, esta necessidade tem 3 principais motivadores:

- Atender às expectativas do consumidor, movendo-se para uma abordagem que privilegie o relacionamento com este, aumentando sua fidelidade ao Provedor de Serviços e o valor que este representa para a empresa;

- Assegurar que ganhos de produtividade possam continuar a ser obtidos, num processo de melhoria contínua;

- Oferecer um rol de produtos e serviços cada vez mais amplo, tarefa que em serviços de Telecomunicações é especialmente dependente da integração de processos. 
Destes 3 motivadores, o primeiro (atender às expectativas do consumidor) é o que mais encontra ressonância com os objetivos deste trabalho, justificando o presente estudo do Modelo de Referência de e-business do TMForum.

\subsubsection{Componentes}

O Modelo de Referência de e-business do TMForum foi estruturado a partir do entendimento dos relacionamentos entre as partes interessadas, já que na definição de apresentada e-business representa a operação de redes de relacionamento de grande complexidade. Além disso, o entendimento de que a entidade formada pelo Provedor de Serviços e seus parceiros de negócio deve ter a performance de uma empresa única: para tal, é necessário enfocar o relacionamento entre as partes, otimizando-os, no lugar de adotar uma abordagem hierárquica ou funcional (mais adequada ao estudo de processos intra-empresa).

Ao estudar os diversos relacionamentos existentes na cadeia de prestação de serviços de telecomunicações, o TMForum identificou 5 papéis desempenhados pelas diversas organizações engajadas numa relação de e-business (Figura 6 , retirada de [11]). 


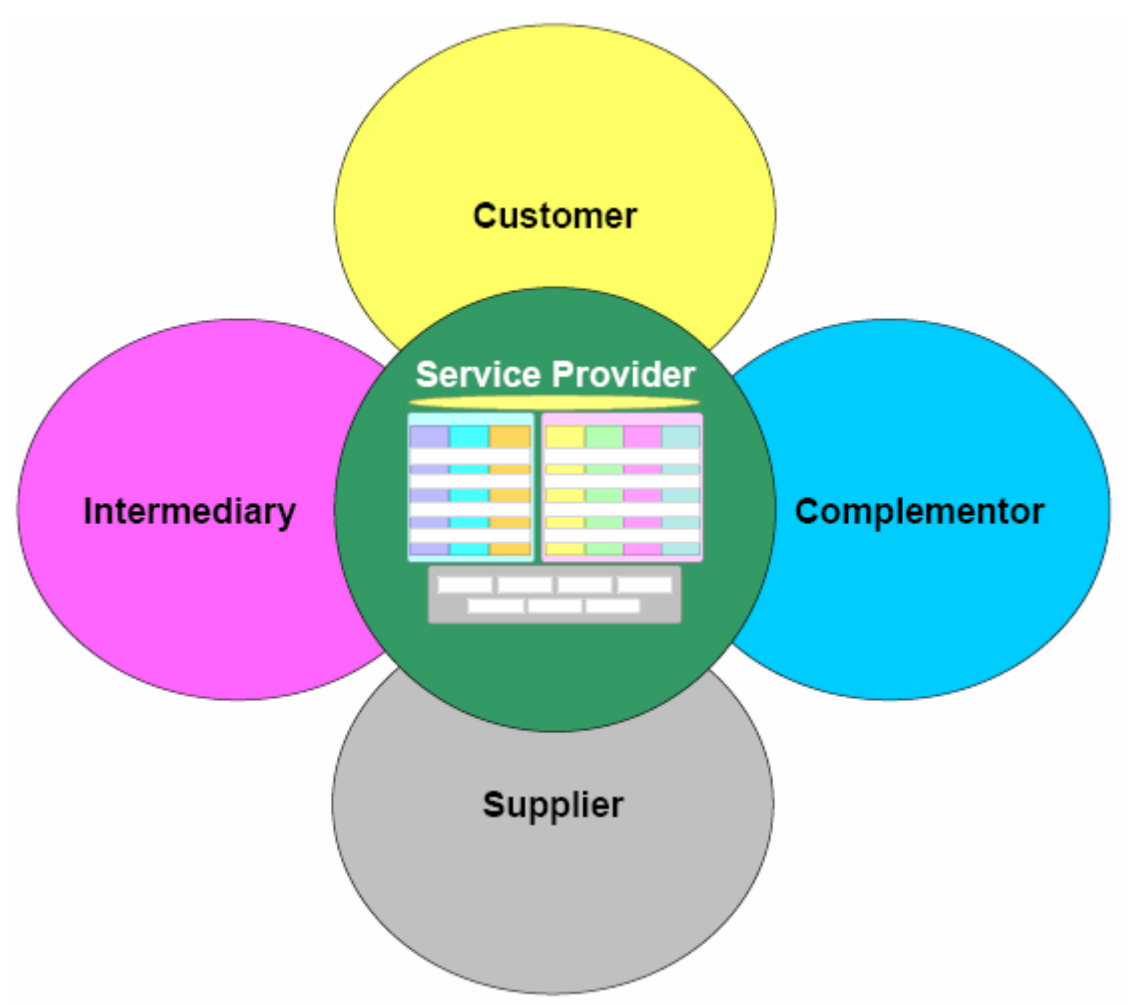

Figura 6 - Papéis no Modelo de Referência de e-business do TMForum

A seguir descreve-se a definição do TMForum para cada um dos papéis identificados:

- Customer (Consumidor): é o responsável por solicitar, usar e pagar pelos serviços / produtos. O Consumidor pode representar um usuário final, onde os serviços prestados são consumidos, ou um atacadista que revende estes serviços. Em alguns casos, o Consumidor pode ser subdividido em dois papéis adicionais: o Subscriber (Assinante), responsável pelo contrato e pagamentos e o End User (Usuário Final), que realmente utiliza os serviços prestados.

- Service Provider (Provedor de Serviços): apresenta uma visão integrada dos produtos / serviços para o Consumidor. É a interface contratual com este, e é responsável por vender e cobrar o serviço, bem como por prestar todo o tipo de assistência e suporte para o Consumidor. O Provedor de Serviço pode fornecer todo o serviço diretamente ou pode subcontratar parte dele (ou mesmo todo ele) de terceiros (na tão discutida prática da Terceirização), mantendo o papel de se relacionar com o Consumidor em todos os níveis. 
Para o Consumidor, o Provedor de Serviços é a única interface existente, em todos os momentos.

- Complementary Provider (Provedor Complementar): estende o produto do Provedor de Serviço, oferecendo funcionalidades ou capacidades adicionais (mas não fundamentais) que o complementam ou adicionam valor a ele. $\mathrm{O}$ Provedor Complementar atua em parceria com o Provedor de Serviços, e pode possuir um relacionamento direto com o Consumidor. Um exemplo de Provedor Complementar é um provedor de conteúdo (Ex.: notícias sobre futebol) acessível a partir do serviço de acesso a dados prestado por uma Operadora Móvel.

- Intermediary (Intermediário): oferece um serviço para o Provedor de Serviços ou para o Consumidor. No ambiente globalizado em que os modelos de e-business são desenvolvidos, o papel do Intermediário ganhou bastante importância. Em geral os Intermediários oferecem funções específicas dentro da cadeia de valor do e-business, como vendas, pagamento eletrônico ou autenticação. Exemplos típicos: uma equipe de vendas local em um mercado onde o Provedor de Serviços não possui presença ou conhecimento; um ambiente eletrônico em que os Consumidores podem localizar os Provedores de Serviço mais adequados (um modelo de Intermediário conhecido como e-marketplace).

- Supplier (Fornecedor): fornece ao Provedor de Serviços hardware, software, serviços e soluções completas. Estes são combinados pelo Provedor de Serviços, a fim de compor o serviço oferecido ao Consumidor. Este relacionamento é bastante importante, pois a capacidade de entrega do Fornecedor impacta diretamente as atividades do Provedor de Serviço.

Por fim, o TMForum observa que as empresas podem assumir múltiplos papéis em diferentes cadeias de valor. No ambiente de rápidas mudanças do ebusiness, esses papéis e relacionamentos podem ter uma duração bastante curta quando comparados aos relacionamentos tradicionais do mercado de telecomunicações. 


\subsubsection{Proposta: Modelo de referência com ênfase em requisitos e design de serviços}

Aqui se discute com maior profundidade a criação do Modelo de Referência apresentado em [19] e utilizado para estruturar a discussão de técnicas e metodologias para orientar os processos de uma operadora de telecomunicações em direção aos seus clientes.

\subsubsection{Definição e Objetivos}

Dado seu objetivo e ênfase na satisfação do Consumidor, a relação entre este e o Provedor de Serviço é a mais importante deste trabalho. Assim, para efeito do estudo e mapeamento de técnicas a realizar, não serão consideradas todas as partes interessadas definidas pelo Modelo de Referência de e-business apresentado em 3.1.1 - ao invés disso, será proposto e utilizado um novo modelo de relacionamento entre stakeholders que privilegia a interação entre Provedor de Serviço e Consumidor em dois ângulos: oferta e demanda.

\subsubsection{Componentes}

Inicialmente, partiu-se do Modelo de Referência de e-business do TMForum e seus papéis fundamentais (Figura 6). Devido à ênfase que se deseja dar à relação entre Consumidor e Provedor de Serviço, adotou-se o ponto de vista do usuário final: para este, só existe o Provedor de Serviço (Figura 7). Adicionalmente, o relacionamento que realmente nos interessa é a relação oferta-demanda (Figura 8). 


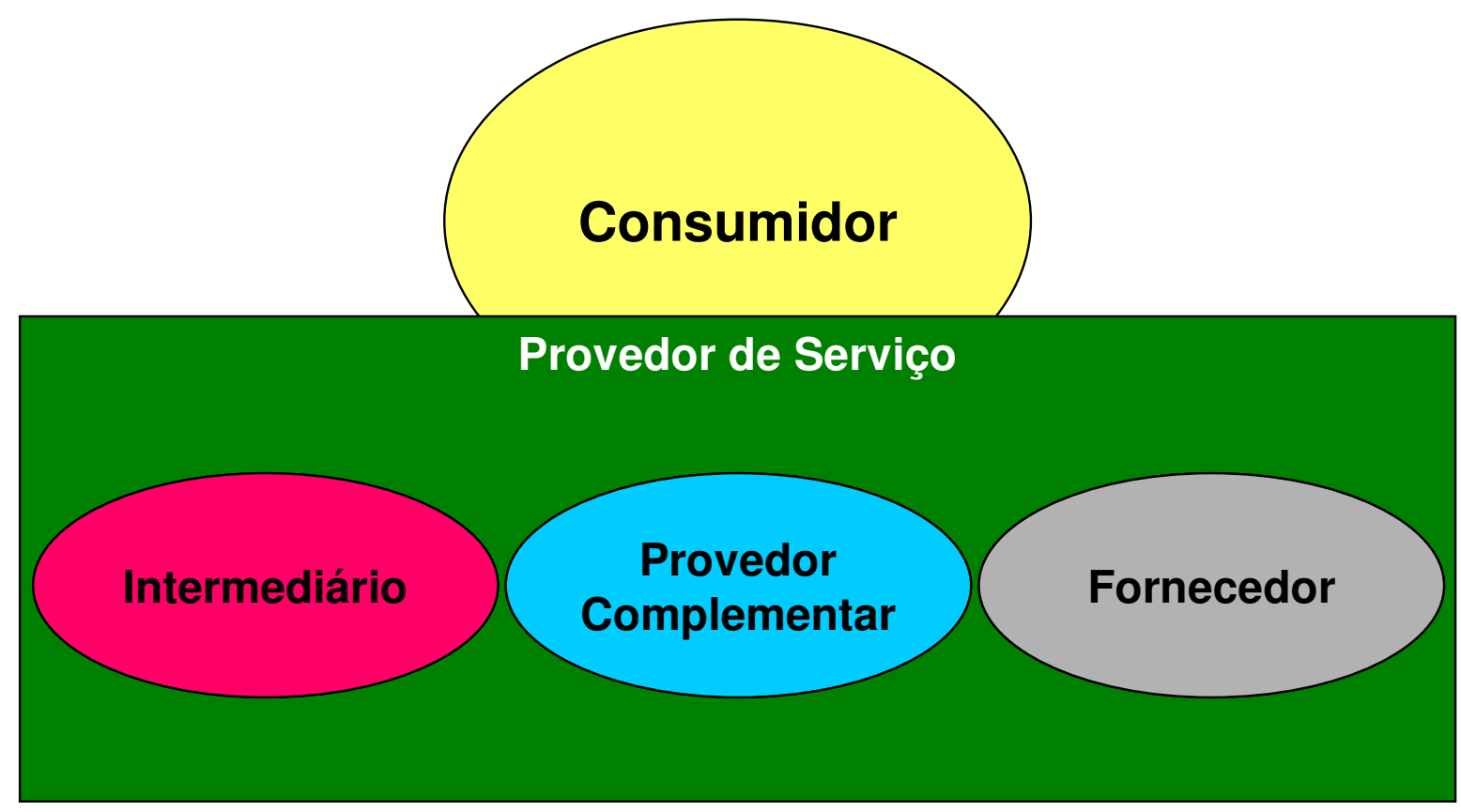

Figura 7 - Modelo de Referência de e-business do ponto de vista do Consumidor

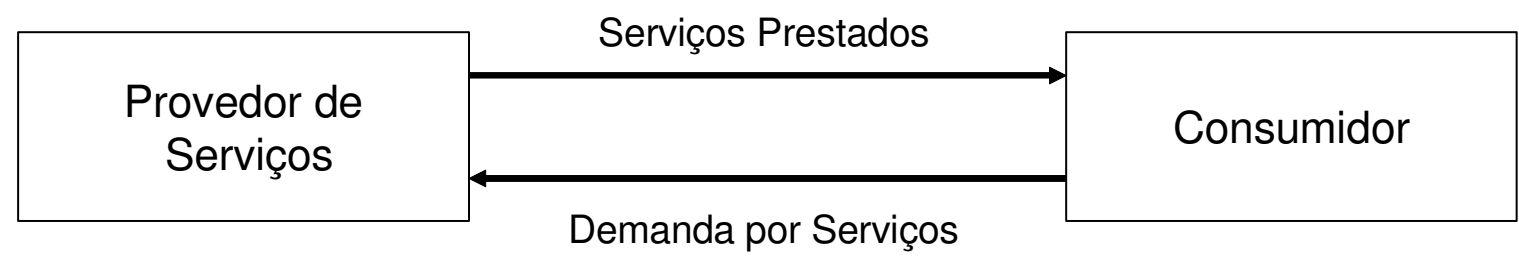

Figura 8 - Relacionamento oferta-demanda entre Provedor de Serviços e Consumidor

Ao reconhecer que a interação entre Provedor de Serviço e Consumidor se dá tanto em relação à oferta quanto à demanda, optou-se por dividir o papel do Provedor de Serviço em dois sub-papéis: o Desenvolvedor de Serviços, pelo lado da demanda, responsável pela criação de um novo serviço e pela maior parte da captura de requisitos junto ao Consumidor, e o Provedor de Serviços, do lado da oferta, responsável por levar ao Consumidor os serviços propriamente ditos. O relacionamento entre estas partes torna-se então mais complexo: o Consumidor tem demandas (necessidades, anseios, desejos) que se tornam os Requisitos com os quais o Desenvolvedor de Serviços trabalha. 
Este entrega estes serviços ao Provedor de Serviços, que por sua vez os oferece ao Consumidor (Figura 9).

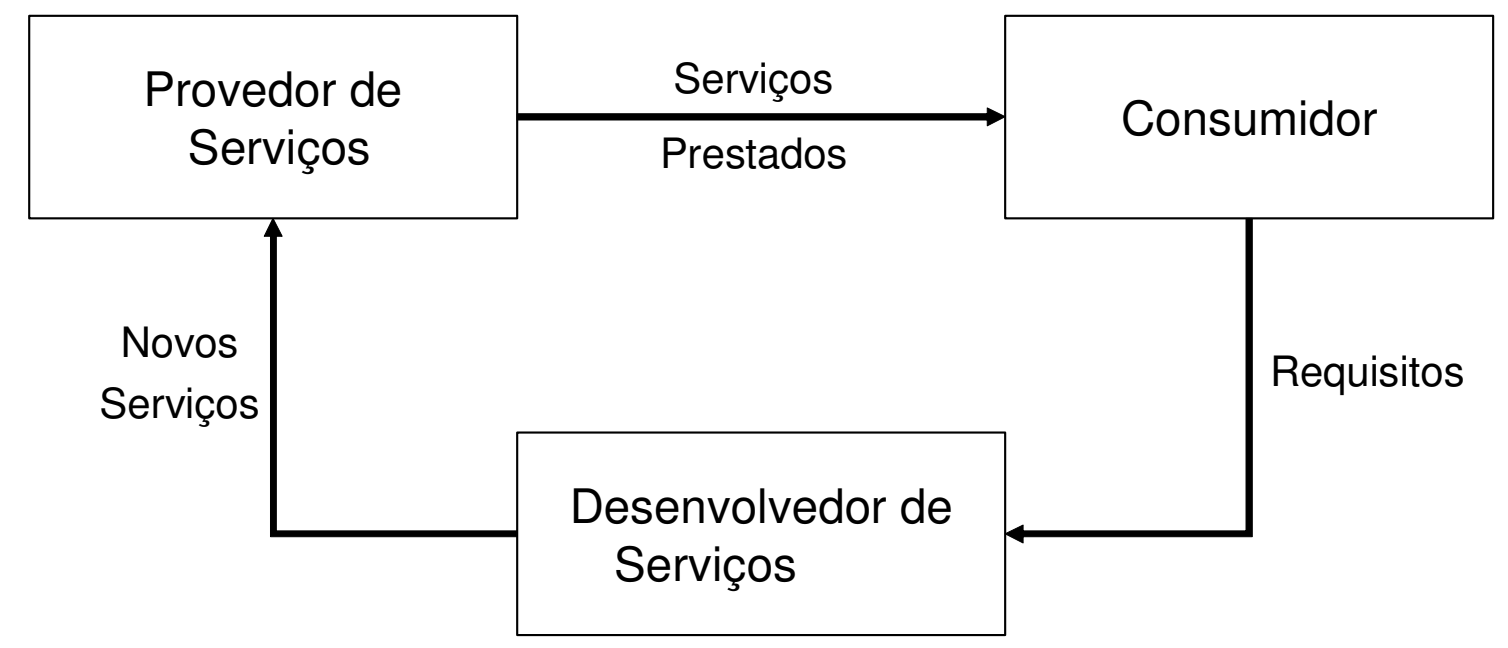

Figura 9 - Partes interessadas e seus relacionamentos no modelo proposto

No modelo proposto, as partes interessadas são assim definidas:

- Consumidor: definido exatamente como no Modelo de Referência de ebusiness do TMForum (vide 3.1.1) ). O Consumidor compra serviços do Provedor de Serviços ou recebe ofertas e serviços gratuitos. O Consumidor pode ser Pessoa Física, Jurídica ou entidade de outra espécie;

- Desenvolvedor de Serviços: desenvolve novos serviços de acordo com os requisitos do Consumidor. Suas atividades incluem desenvolvimento e customização de hardware e software, geração, formatação e agregação de conteúdo, conversão de mídias e o que quer que seja necessário para trazer um novo serviço de telecomunicações para o público. A relação entre Desenvolvedores e Provedores de Serviços é do tipo "n-para-n": um Desenvolvedor de Serviços pode (e em geral o faz) atender diversos Provedores, e um Provedor de Serviços pode trabalhar (e em geral trabalha) com diversos Desenvolvedores. O Desenvolvedor de Serviços pode ser um Provedor de Serviços, mas existem diversas entidades independentes que atuam desenvolvendo serviços a serem ofertados pelos Provedores: Integradores de Sistemas e Fornecedores de hardware e software em geral atuam como Desenvolvedores de Serviços. Adicionalmente, estas entidades 
podem fazer toda a prestação do serviço em nome do Provedor, atuando como um grupo funcional "terceirizado"; esta situação, muito comum na oferta de Provedores de Serviço de Telefonia Móvel, tende a se tornar cada vez mais comum [20].

- Provedor de Serviços: também definido como em 3.1.1. Promove, vende e entrega os serviços desenvolvidos pelos Desenvolvedores de Serviços aos Consumidores, sendo responsável por esta entrega de maneira fim-a-fim: do recebimento do pedido à cobrança do Consumidor. De maneira simplificada, a definição alternativa do TMForum para o Provedor de Serviços também se aplica: "uma Empresa que vende Serviços de Informação e / o Comunicação para terceiros".

\subsection{Necessidades das partes}

O objetivo desta seção é identificar as necessidades das partes interessadas em cada um dos relacionamentos apontados no modelo de referência proposto. Estas necessidades irão orientar a busca de técnicas, ferramentas, metodologias e frameworks aplicáveis a cada um desses relacionamentos.

A partir do entendimento dos relacionamentos entre as partes interessadas ilustradas na Figura 9, é possível determinarem-se as necessidades de cada parte em relação à otimização de um dado relacionamento. Aqui, entenda-se "otimização" como "maior alinhamento às expectativas do Consumidor, visando à maximização da sua satisfação".

Como o objetivo deste trabalho é oferecer a Provedores e Desenvolvedores de Serviço as ferramentas necessárias para reconhecer, assimilar em seus processos e atender às demandas e expectativas dos Consumidores, as ferramentas serão identificadas e descritas sob a ótica de quem cria ou presta o serviço (e não sob a ótica de quem o consome).

O resultado da análise dos relacionamentos e interações indicados na Figura 9 encontra-se na Tabela 1, a seguir. 


\section{Tabela 1 - Relacionamentos entre partes interessadas e ferramentas necessárias}

\begin{tabular}{|c|c|c|c|c|}
\hline $\mathrm{De}$ & Para & $\begin{array}{l}\text { Natureza da } \\
\text { interação / } \\
\text { Informação } \\
\text { transmitida }\end{array}$ & Descrição & Ferramentas necessárias \\
\hline 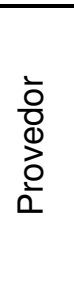 & 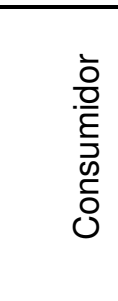 & $\begin{array}{l}\text { Serviços } \\
\text { prestados }\end{array}$ & $\begin{array}{l}\text { Serviços entregues pelo } \\
\text { Provedor ao Consumidor; } \\
\text { esta interação é a razão } \\
\text { de ser do Provedor de } \\
\text { Serviços }\end{array}$ & $\begin{array}{l}\text { Ferramentas que } \\
\text { assegurem a entrega } \\
\text { perfeita de um dado produto } \\
\text { ao consumidor }\end{array}$ \\
\hline 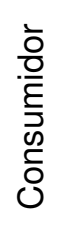 & $\begin{array}{l}\overline{0} \\
\text { D } \\
0 \\
\text { o } \\
\text { வ }\end{array}$ & Feedback & $\begin{array}{l}\text { Consumidor realimenta o } \\
\text { Provedor de Serviços com } \\
\text { a sua percepção sobre o } \\
\text { serviço que recebe }\end{array}$ & $\begin{array}{l}\text { Ferramentas de captura de } \\
\text { feedback, capazes de } \\
\text { capturar a verdadeira "voz } \\
\text { do consumidor" }\end{array}$ \\
\hline $\begin{array}{l}\frac{\bar{o}}{.0} \\
\frac{0}{5} \\
0 \\
\frac{0}{0} \\
0\end{array}$ & 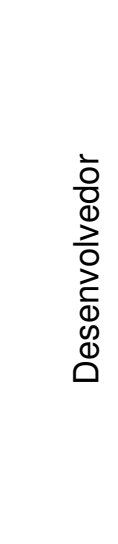 & $\begin{array}{l}\text { Requisitos e } \\
\text { demandas por } \\
\text { novos } \\
\text { serviços }\end{array}$ & $\begin{array}{l}\text { Consumidor manifesta } \\
\text { (em geral indiretamente) } \\
\text { suas demandas, anseios } \\
\text { e necessidades. Cabe ao } \\
\text { Desenvolvedor de } \\
\text { Serviços capturar estas } \\
\text { demandas e materializá- } \\
\text { las na forma de novos } \\
\text { serviços }\end{array}$ & $\begin{array}{l}\text { Ferramentas para captura } \\
\text { das necessidades dos } \\
\text { Consumidores, que } \\
\text { permitam aos } \\
\text { Desenvolvedores ouvir a } \\
\text { "voz do consumidor". }\end{array}$ \\
\hline 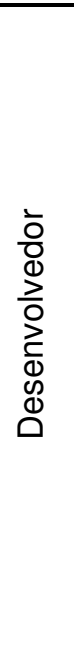 & $\begin{array}{l}\overline{0} \\
\text { D } \\
\text { o } \\
\text { ㄴ }\end{array}$ & $\begin{array}{l}\text { Novos } \\
\text { serviços } \\
\text { recém-criados }\end{array}$ & $\begin{array}{l}\text { O Desenvolvedor de } \\
\text { Serviços passa o novo } \\
\text { serviço desenvolvido para } \\
\text { o controle do Provedor de } \\
\text { Serviço, que se torna } \\
\text { responsável por levá-lo } \\
\text { para o mercado }\end{array}$ & $\begin{array}{l}\text { Ferramentas que } \\
\text { assegurem uma transição } \\
\text { suave do ambiente de } \\
\text { desenvolvimento para o de } \\
\text { produção e que as } \\
\text { características do serviço, } \\
\text { modeladas de acordo com } \\
\text { as expectativas do } \\
\text { Consumidor, não sejam } \\
\text { alteradas ou distorcidas na } \\
\text { transição para o Provedor. }\end{array}$ \\
\hline
\end{tabular}


Além da necessidade das ferramentas identificadas na Tabela 1, identificam-se também duas outras áreas que necessitam de técnicas para garantir o correto tratamento da "voz do Consumidor": os processos internos dos Provedores e dos Desenvolvedores de Serviços. Estas necessidades encontram-se descritas na Tabela 2, a seguir.

\section{Tabela 2 - Necessidades internas de Desenvolvedores e Provedores de Serviço}

\begin{tabular}{|c|c|c|}
\hline Área & Descrição & Ferramentas necessárias \\
\hline $\begin{array}{l}\text { Processos internos } \\
\text { do Desenvolvedor } \\
\text { de Serviços }\end{array}$ & $\begin{array}{l}\text { Processos de negócio do } \\
\text { Desenvolvedor de Serviços. Dada } \\
\text { a ênfase na satisfação do } \\
\text { Consumidor, ênfase será dada aos } \\
\text { processos operacionais, } \\
\text { diretamente ligados à modelagem } \\
\text { e criação de novos serviços. Para } \\
\text { todos os efeitos, estes podem ser } \\
\text { considerados similares ao de uma } \\
\text { Fábrica de Software }\end{array}$ & $\begin{array}{l}\text { Dada a ênfase na perspectiva do } \\
\text { Consumidor, as ferramentas } \\
\text { necessárias são as que possibilitam } \\
\text { converter as suas demandas } \\
\text { (imprecisas, informais, subjetivas) } \\
\text { em requisitos (precisos, formais, } \\
\text { objetivos) }\end{array}$ \\
\hline $\begin{array}{l}\text { Processos internos } \\
\text { do Provedor de } \\
\text { Serviços }\end{array}$ & $\begin{array}{l}\text { Processos de negócio do Provedor } \\
\text { de Serviços. Compreendem todo o } \\
\text { framework do eTOM [11] }\end{array}$ & $\begin{array}{l}\text { Ferramentas que permitam a } \\
\text { melhoria contínua dos processos } \\
\text { do eTOM, tornando-os cada vez } \\
\text { mais orientados à perspectiva do } \\
\text { Consumidor }\end{array}$ \\
\hline
\end{tabular}

Um resumo das interações detalhadas e das necessidades identificadas nas tabelas anteriores pode ser encontrado na Figura 10, utilizando as partes interessadas identificadas no modelo de referência proposto em $3.1 .2 \mathrm{e}$ apresentado em [19]. 


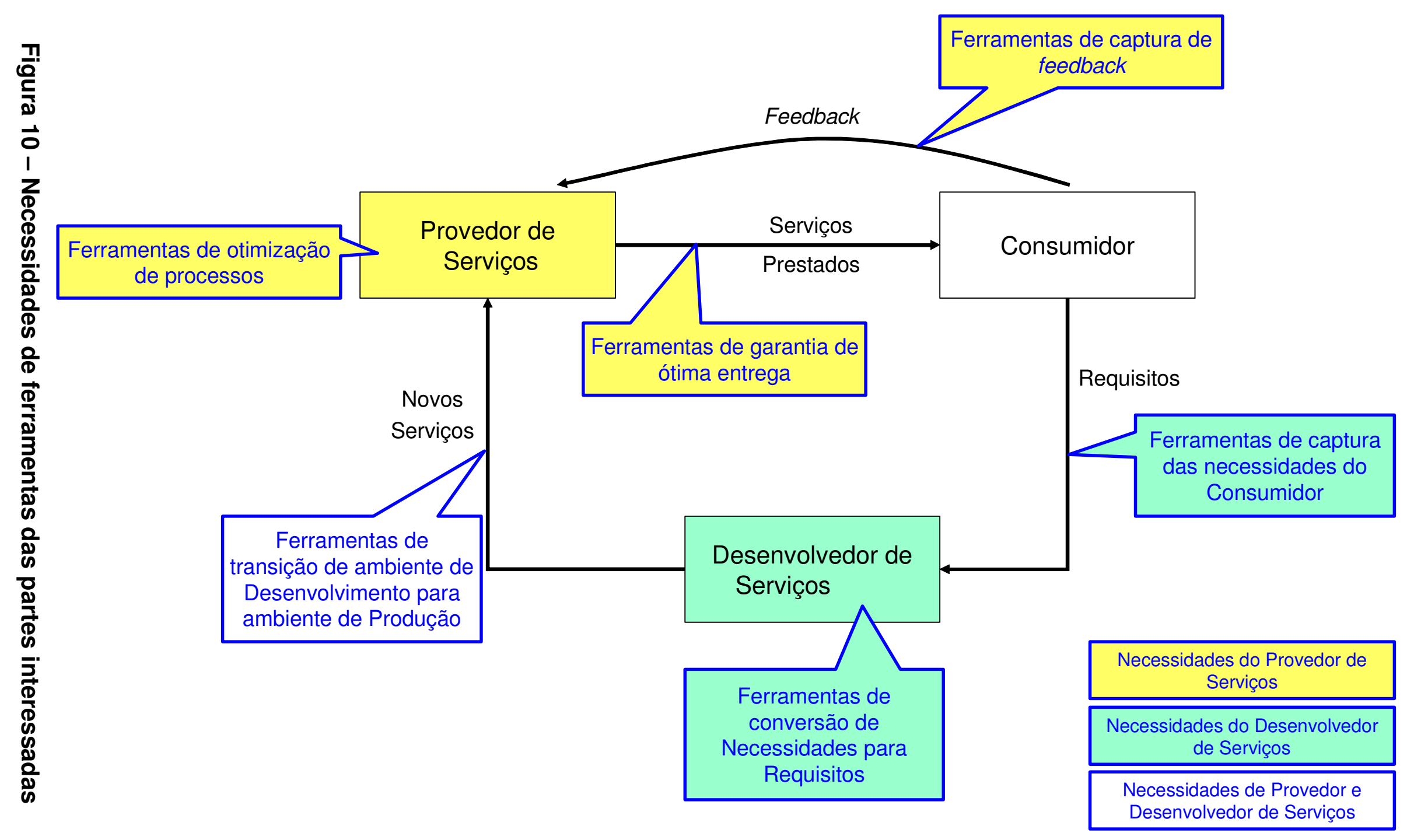




\section{FERRAMENTAS}

O objetivo desta seção é identificar as técnicas, ferramentas, metodologias e frameworks aplicáveis a cada um dos relacionamentos identificados, atendendo às necessidades sumarizadas na Figura 10.

A fim de identificar as ferramentas mais apropriadas para responder a cada uma das necessidades já apontadas, efetuou-se uma pesquisa que envolveu desde os campos da Gestão de Serviço e Gestão da Qualidade aos domínios dos Fatores Humanos e Human Centered Design. Esta pesquisa esteve sempre orientada às necessidades de Desenvolvedores e Provedores de Serviço e resultou na escolha de 5 grandes conjuntos de práticas ou disciplinas:

- Lean Thinking e Total Quality Management

- Progama NGOSS (New Generation OSS)

- Metodologia QFD (Quality Function Design)

- Práticas de Gestão da FNQ (Fundação Nacional da Qualidade)

- Melhores práticas do RUP (Rational Unified Process)

Dentro destes conjuntos, selecionaram-se as técnicas mais relevantes para o segmento de telecomunicações em geral e para as necessidades de Desenvolvedores e Provedores de Serviços em especial.

A seguir encontra-se uma breve descrição de cada disciplina, a razão para sua seleção e as ferramentas, práticas, conceitos e metodologias selecionados como mais relevantes.

\subsection{Lean Thinking e Total Quality Management}

A título de contextualização, serão brevemente revisitados os conceitos e a história dos sistemas produtivos que levaram à criação das ferramentas que serão utilizadas neste trabalho. 
Para efeitos desta dissertação, consideramos o Lean Thinking e o Total Quality Management como metodologias equivalentes; de fato, ambos propõem conceitos muito próximos, diferindo apenas em sua origem. Enquanto o Lean Thinking se baseia em idéias e experimentos desenvolvidos no Japão, o TQM tem uma "herança" eminentemente ocidental. No entanto, houve uma "polinização cruzada" entre essas duas escolas de pensamento, de modo que para o nosso enfoque ambas podem ser consideradas como um conjunto único de ferramentas e práticas de trabalho.

Womack e Jones definem o Lean Thinking ("pensamento enxuto") como [21]:

Uma maneira de especificar o que tem valor, alinhar as ações que
agregam valor na melhor seqüência possível, executar essas ações sem
interrupção sempre que alguém as solicitar e executá-las com eficiência
cada vez maior. Em resumo, o "pensamento enxuto" é enxuto porque
oferece uma maneira de fazer cada vez mais com cada vez menos -
menos esforço humano, menos equipamentos, menos tempo e menos
espaço - enquanto se aproximando cada vez mais de fornecer aos
consumidores exatamente o que eles desejam. O primeiros passos para a criação do modelo de produção Lean foram dados por Henry Ford, que em 1913 uniu os conceitos de atividades padronizadas, ferramentas interoperáveis e transporte de componentes para criar o que ele denominou de "produção em fluxo" (flow production). A principal limitação desse sistema de produção não era a produtividade, mas a impossibilidade de oferecer variedade ao consumidor.

Nos anos 30, e mais especificamente após a II Guerra Mundial, Kiichiro Toyoda, Taiichi Ohno e outros profissionais da Toyota desenvolveram uma série de inovações simples que alteraram significativamente o modelo de produção desenvolvido por Ford, oferecendo tanto os benefícios da produção em fluxo quanto a variedade de produtos que os clientes demandavam. A este novo modelo se deu o nome de Toyota Production System (Sistema Toyota de Produção).

Os engenheiros que desenvolveram o Sistema Toyota de Produção concluíram que ao dimensionar os equipamentos para o volume de produção estritamente necessário, introduzir máquinas capazes de monitorarem seu próprio desempenho e garantir a qualidade da sua produção, alinhar estas máquinas 
por processo e não por função, torná-las flexíveis para que pudessem ser reconfiguradas para produzir diferentes tipos de peças e garantir que cada elo do processo de produção fosse capaz de informar ao elo anterior das suas necessidades de materiais, seria possível obter baixo custo, alta variedade, alta qualidade e rápidos tempos de resposta a mudanças nas demandas do consumidor [21], [22].

Esta rápida história dos modelos de produção fabril encontra-se sumarizada na Figura 11. 


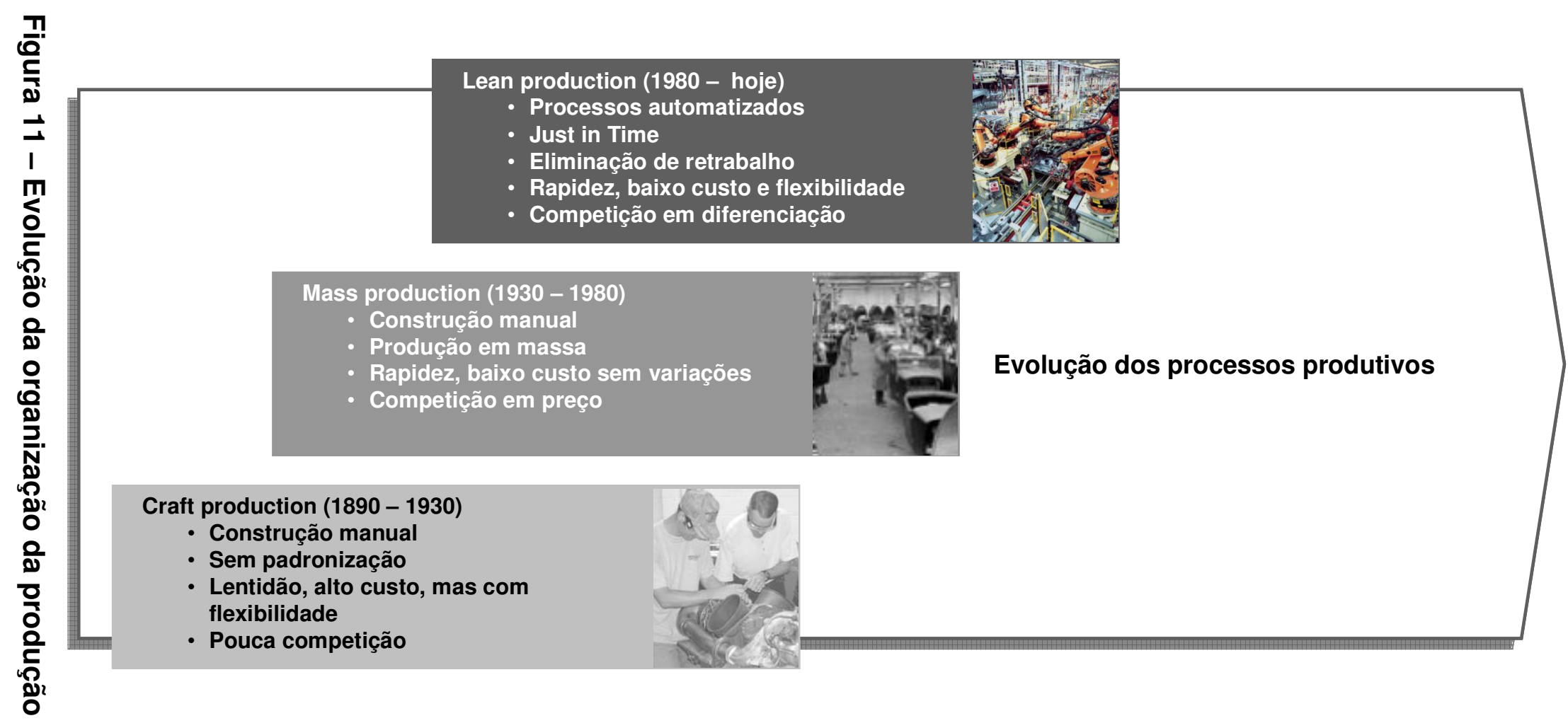


Em [21], o Lean Thinking é sumarizado em 5 princípios fundamentais:

- Especificar o valor desejado pelo cliente

- Identificar a cadeia de valor para cada produto, criticando e examinando cada um dos elos desta cadeia em busca de desperdícios ou atividades que não agregam valor ao produto

- Fazer o produto "fluir" continuamente, sem interrupções, através dos passos que realmente agregam valor a ele

- Introduzir o conceito de "produção puxada" nesse fluxo, ou seja, garantir que a demanda do passo atual "puxe" a produção do passo

- Gerenciar o processo com foco na perfeição, ou seja, de maneira que o número de passos e a quantidade de tempo e informação necessários caiam continuamente

A cada um desses princípios corresponde uma ou mais ferramentas selecionadas para detalhamento neste trabalho

Tabela 3).

Tabela 3 - Ferramentas selecionadas do Lean Thinking e TQM

\begin{tabular}{cll}
\hline Princípios & Ferramenta & Origem \\
\hline 1 & Kansei Engineering & Lean Thinking \\
$2,3,4$ & Kaizen & Lean Thinking \\
3,4 & PDCA & TQM \\
4 & DMAIC & TQM \\
5 & Seis Sigma & TQM \\
\hline
\end{tabular}




\subsubsection{Kansei Engineering}

Criado na década de 70 pelo Prof. Mitsuo Nagamachi, da Hiroshima International University, no Japão, o termo Kansei Engineering ("Engenharia Kansei", em tradução livre) se refere a um método de desenvolvimento de produtos que visa capturar os aspectos mais intangíveis das demandas dos consumidores [23].

O princípio guia da Engenharia Kansei é a orientação ao consumidor, centrada na simples noção de que quando um consumidor deseja adquirir algo ele já tem em mente uma espécie de sentimento ou imagem (kansei, em japonês). Se este sentimento puder ser implementado em um produto, o consumidor ficará mais satisfeito. Assim, o objetivo primário da Engenharia Kansei é traduzir o kansei do consumidor em parâmetros de projeto objetivos e diretamente aplicáveis à engenharia de produto [23]. Adicionalmente, o método também mostra como o design de um produto afeta o kansei que o consumidor desenvolve a respeito do mesmo.

Segundo o seu criador, a Engenharia Kansei foi desenvolvida para atender a 3 requisitos [24]:

- Como entender precisamente o kansei do consumidor

- Como refletir esse kansei no design de um produto

- Como sistematizar as práticas de design orientado ao kansei do consumidor

O método Kansei encontra-se representado na Figura 12, adaptada de [25]. 


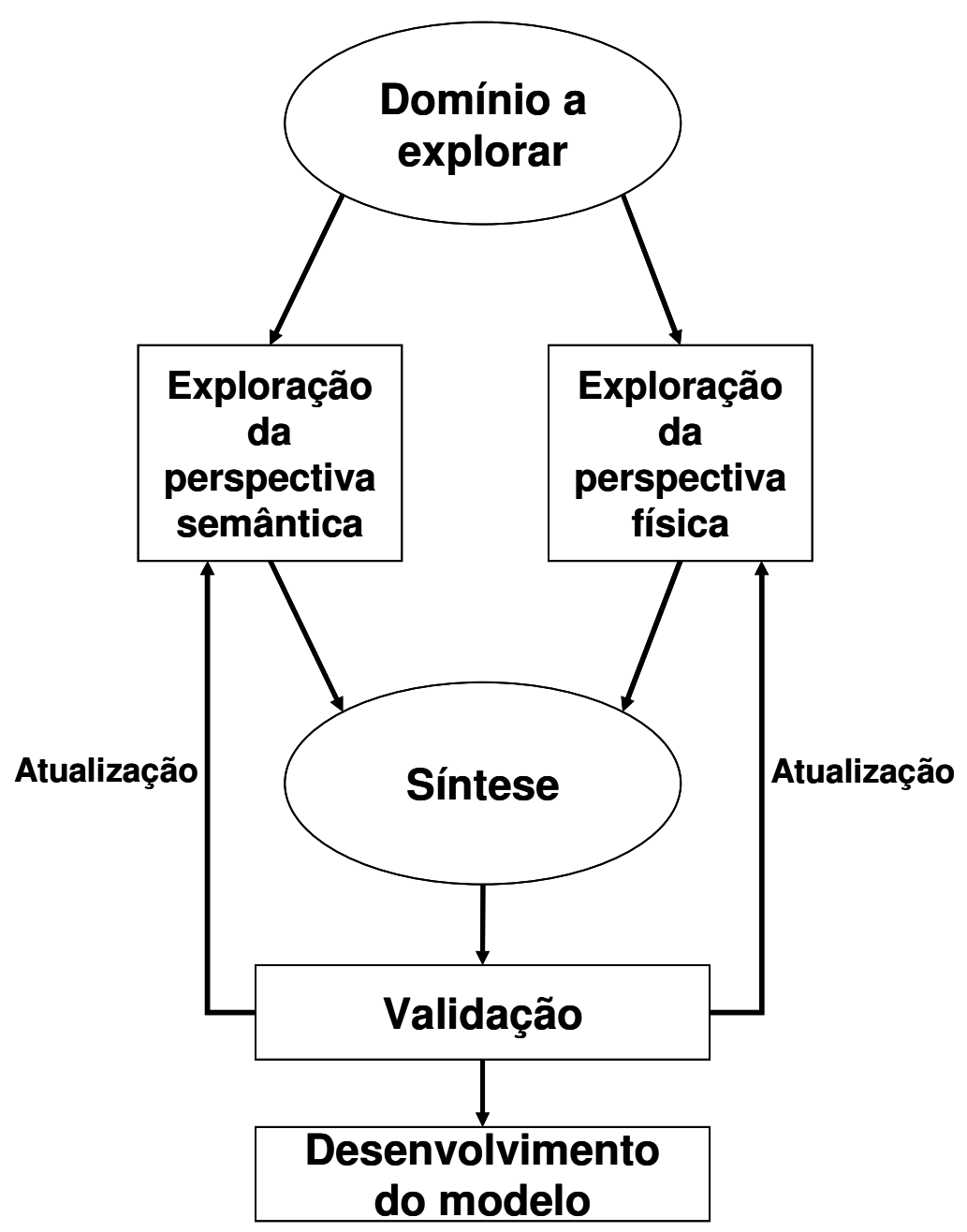

Figura 12 - Engenharia Kansei

A idéia básica é descrever a imagem de um produto a partir de duas perspectivas: a semântica (palavras que o consumidor associa ao kansei que ele tem do produto) e a física (propriedades, características e funcionalidades de um produto, de um ponto de vista totalmente objetivo).

Estas duas descrições geram respectivamente um conjunto de palavras e um conjunto de propriedades. A seguir, estes conjuntos são fundidos na fase de Síntese, cujo resultado é um mapeamento que indica quais propriedades físicas geram cada impacto semântico (e portanto afetam diretamente o kansei do consumidor). Este mapeamento faz da Síntese a fase mais importante da metodologia da Engenharia Kansei. 
Após a Síntese é possível conduzir um Teste de Validação, em um processo iterativo que visa aperfeiçoar o entendimento das dimensões semântica e física do produto em relação ao consumidor.

Quando o resultado dessa interação é considerado satisfatório um modelo é construído, formalizando a correlação entre as propriedades físicas e a descrição semântica do produto. Este modelo é então utilizado como subsídio pela equipe responsável por desenvolver o produto, pois auxilia enormemente o entendimento dos requisitos do consumidor.

\subsubsection{Kaizen}

Segundo o Lean Institute [21], o Kaizen é a "Melhoria contínua de um fluxo completo de valor ou de um processo individual, a fim de se agregar mais valor com menos desperdício." [27]. A própria palavra "Kaizen" vem do japonês Kai (mudança) e Zen (bom) - ou "mudança para melhor".

Além desta ênfase na melhoria contínua, é importante ter em mente que o Kaizen suporta e fortalece a melhoria por meio da inovação, ou seja, o foco contínuo na melhoria gera rupturas ou saltos de produtividade na empresa [28]. Ainda segundo [27]:

Há dois níveis de kaizen (Rother e Shook 1999): 1.Kaizen de sistema ou de fluxo, que enfoca no fluxo total de valor. Dirigido ao gerenciamento.

2.Kaizen de processo, que enfoca em processos individuais. Dirigido a equipes de trabalho e líderes de equipe.

Para efeito do mapeamento pretendido, entende-se o Kaizen como a metodologia genérica de melhoria contínua aplicada tanto aos níveis estratégicos quanto aos níveis operacionais da prestação de serviço. Neste sentido, o Kaizen é entendido aqui muito mais como uma postura ou filosofia direcionada a mudar a forma de pensar dos profissionais de uma empresa [29] do que como uma abordagem prática de melhoria contínua. 
Para implementar a filosofia Kaizen em geral utiliza-se o ciclo PDCA [28], descrito a seguir.

\subsubsection{PDCA}

O Ciclo PDCA, originalmente chamado de Método de Melhorias, foi desenvolvido nos anos 30 pelo estatístico Walter A. Shewhart, em seu livro Economic Control of Quality of Manufactured Product. Nesta obra, Shewhart apresenta o PDCA como um ciclo de controle estatístico de processos que pode ser repetido continuamente sobre qualquer processo ou problema.

Nos anos 50, o especialista em qualidade W. Eduards Deming ficou mundialmente famoso ao aplicar o PDCA no Japão, popularizando o método e dando origem a uma nova forma de se pensar em gestão da qualidade [30].

O nome da metodologia vem das iniciais das suas quatro etapas (Figura 13) [30]:

- Plan (Planejar): estabelecer os objetivos (metas) e os processos necessários para atingi-los - ponto fundamental, "não existe PDCA sem metas" [30]. Deming enfatizava a importância de documentar nesta fase as melhorias esperadas, sem o quê torna-se difícil validar a eficácia das processos propostos.

- Do (Executar): implementar os processos planejados.

- Check (Verificar): monitorar e avaliar os processos e resultados em relação aos objetivos propostos na fase inicial.

- Act (Atuar): aplicar ações corretivas que tornem o resultado mais próximo dos objetivos propostos. Isto significa rever todas as fases (Planejar, Executar, Verificar, Atuar), modificando-as para melhorá-las antes da próxima iteração. 


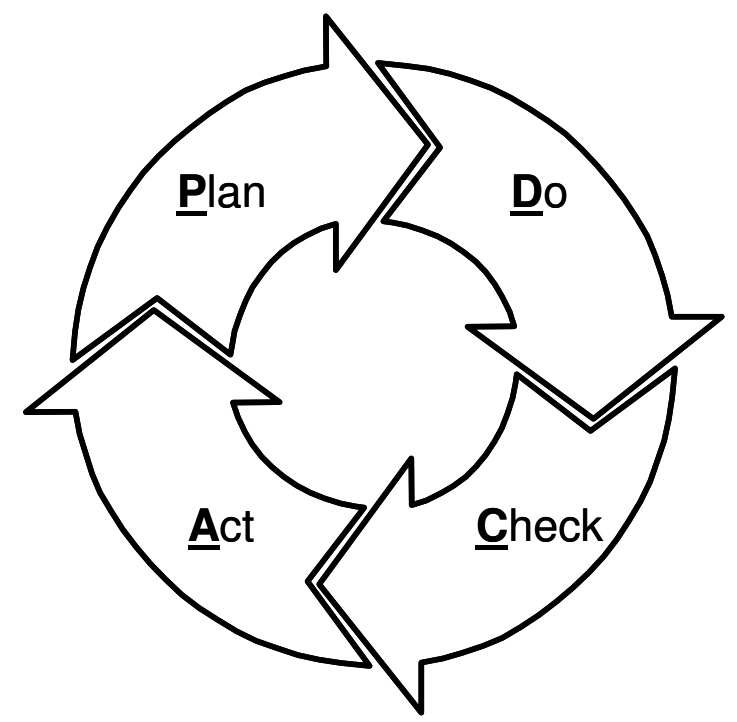

Figura 13 - Ciclo PDCA de melhoria contínua

Como já foi mencionado em 4.1.2, o PDCA é uma implementação prática do Kaizen, incorporando totalmente a sua filosofia de melhoria contínua. Assim, o PDCA deve ser implementado repetidamente, tão rápido quanto possível, numa espiral ascendente que converge para a meta pretendida. Esta abordagem se baseia no entendimento de que conhecimento e capacitação são sempre limitados, mas que melhoram no decorrer do processo. De maneira similar, em geral as informações necessárias para se atingir melhoria em um processo não estão disponíveis. Assim, ao invés de permanecer num estado de inação por falta de conhecimento, capacitação ou informação, é melhor se aproximar iterativamente da meta, melhorando esta aproximação a cada iteração (Figura 14). 
Iteração 3

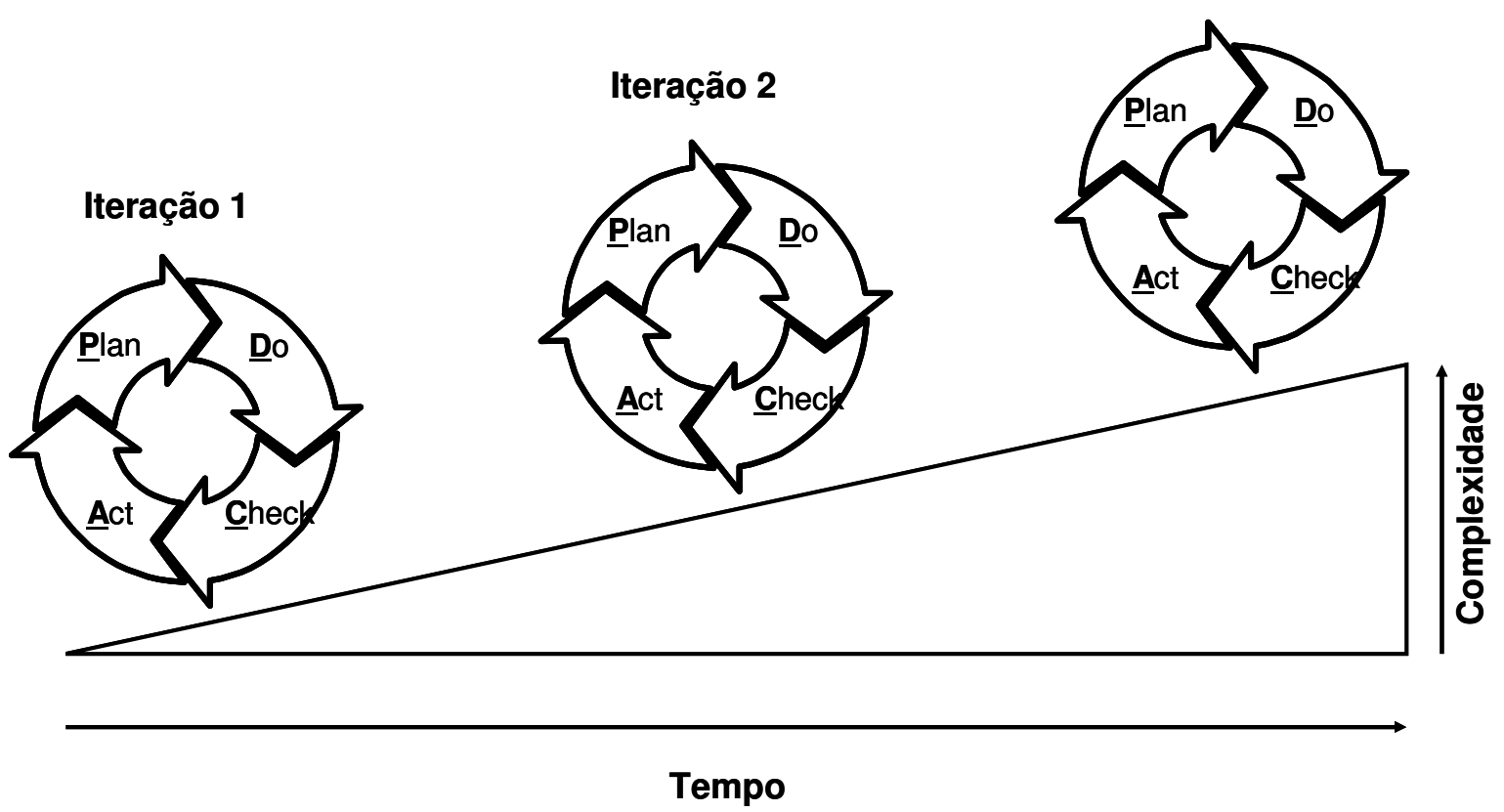

Figura 14 - Iterações do Ciclo PDCA

A força do PDCA está em sua simplicidade. Apesar de fácil de ser compreendido, em geral o PDCA é difícil de ser implementado em definitivo, devido a uma série de problemas das organizações e seus membros: complacência, distração, falta de foco, falta de comprometimento, mudanças de prioridade não planejadas, falta de recursos e que tais.

A importância do PDCA para este trabalho também deriva da sua aplicabilidade a um grande número de atividades. Segundo [31], o PDCA pode (e deve) ser utilizado:

- Como um modelo para melhoria contínua;

- Ao iniciar um novo projeto de melhoria;

- Ao desenvolver ou melhorar um processo, produto ou serviço;

- Ao definir um processo de trabalho repetitivo ou iterativo;

- Ao planejar uma iniciativa de coleta e análise de dados para descobrir e priorizar problemas e suas causas raízes;

- Ao implementar qualquer mudança. 
Por esta grande versatilidade, o ciclo PDCA é o processo padrão para implementação de diversas normas ISO [32]; apenas a título de exemplo, a Figura 15 ilustra a aplicação do Ciclo PDCA à implantação da Norma ISO 27001, referente aos requisitos de segurança em tecnologia da informação [33].

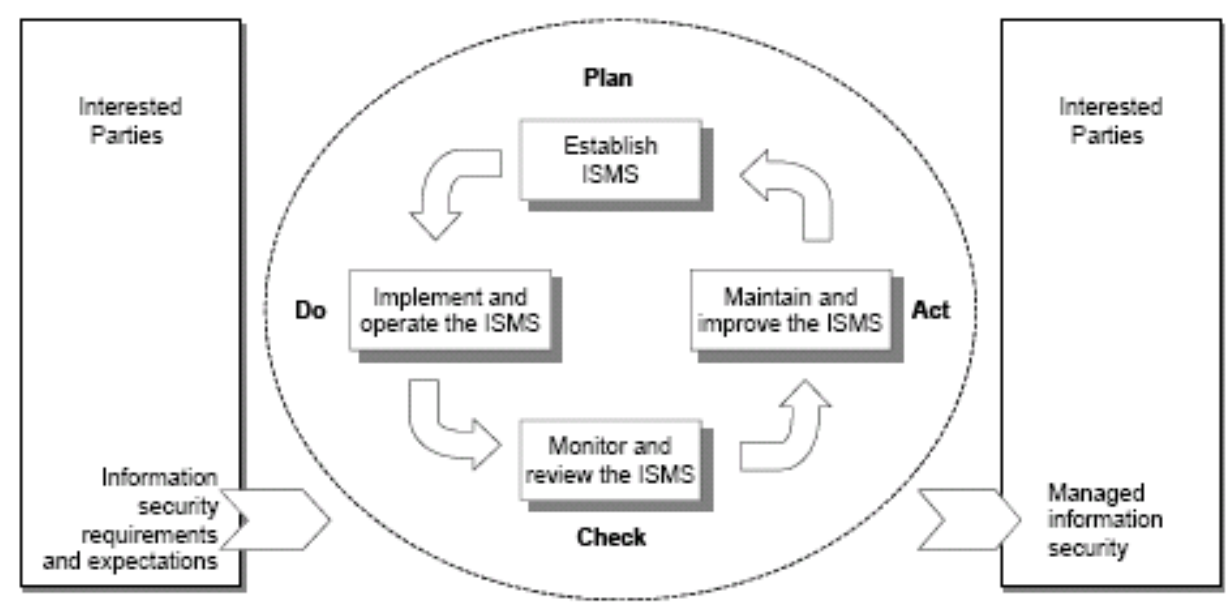

Figura 15 - Exemplo de uso do Ciclo PDCA: implantação da Norma de segurança ISO 27001

Adicionalmente, como veremos a seguir, o ciclo PDCA também está presente na metodologia Seis Sigma de gestão da qualidade, com o nome de DMAIC.

\subsubsection{Seis Sigma}

O Seis Sigma é um conjunto de práticas originalmente desenvolvido pela Motorola [34] para sistematizar a melhoria contínua de processos, com foco na eliminação de defeitos. Embora originalmente aplicado pela Motorola a processos de produção de bens em grande escala, a aplicação do Seis Sigma pela GE na GE Capital demonstrou a adequação da metodologia à indústria de serviços [35]. Segundo TRAD, 2006 apud PANDE, 2000 [36]: "Os ganhos potenciais do Seis Sigma são igualmente significativos (se não maiores) em organizações de serviço e em atividades de não-manufatura assim como são em ambientes 'técnicos"; daí o valor do Seis Sigma para o presente trabalho. 
No Seis Sigma defeitos são definidos como unidades que não fazem parte da população desejada - esta definição generalista permite que a metodologia seja aplicada a diferentes processos e segmentos de mercado, contribuindo para a presença do Seis Sigma em muitas iniciativas de TQM.

Apesar dessa proximidade, o Seis Sigma ainda guarda importantes diferenças em relação ao TQM, notadamente o uso intenso de ferramentas estatísticas e o envolvimento de um corpo de profissionais especializados em qualidade. Estas semelhanças e diferenças estão resumidas na Tabela 4, retirada de TONINI, 2006 apud FOLARON, 2003 [37].

Tabela 4 - Comparação entre TQM e Seis Sigma TQM Seis Sigma

\begin{tabular}{|c|c|c|}
\hline Semelhanças & $\begin{array}{l}\text { - } \text { Focado no Cliente } \\
\text { - } \quad \text { Impulsionado por líderes } \\
\text { - } \text { Orientado aos processos } \\
\text { - } \text { Gerenciamento pelos fatos } \\
\text { - } \quad \text { Trabalho em equipe }\end{array}$ & $\begin{array}{ll}\text { - } & \text { Focado no Cliente } \\
\text { - } & \text { Impulsionado por líderes } \\
\text { - } & \text { Orientado aos processos } \\
\text { - } & \text { Gerenciamento pelos fatos } \\
\text { - } & \text { Metodologia definida } \\
\text { - } & \text { TrabalC) } \\
\text { - } & \\
\end{array}$ \\
\hline Diferenças & $\begin{array}{l}\text { - } \text { Análise estatística básica } \\
\text { - } \text { Tarefa de todos } \\
\text { - } \text { Projetos identificados de baixo } \\
\text { para cima } \\
\text { - } \text { Carteira de ferramentas } \\
\text { - } \text { Custo da má qualidade } \\
\text { - } \text { Desencadeado nos processos }\end{array}$ & $\begin{array}{l}\text { - } \text { Análise estatística avançada } \\
\text { - } \text { Tarefa de especialistas } \\
\text { - } \text { Projetos identificados pela } \\
\text { estratégia empresarial } \\
\text { - Uso estruturado de } \\
\text { - } \text { Viés na linha base } \\
\text { - Desencadeado por projetos }\end{array}$ \\
\hline
\end{tabular}


De fato, a ênfase em aspectos quantitivos e o uso intenso de ferramentas estatísticas são as características que diferenciam o Seis Sigma de outras abordagens de melhoria de processos. Segundo TRAD, 2006 apud WERKEMA, 2002 [36]:

É possível definir Seis Sigma como uma estratégia gerencial disciplinada e altamente quantitativa que tem como objetivo aumentar drasticamente a lucratividade das empresas por meio da melhoria da qualidade de produtos e processos e do aumento da satisfação de clientes e consumidores.

O próprio nome Seis Sigma é derivado deste foco na análise quantitativa: Sigma, a letra grega minúscula " $\sigma$ ", é utilizada na matemática estatística para representar o desvio padrão de uma população. O termo "Seis Sigma" vem da idéia, desenvolvida pela Motorola, de que se existem 6 desvios padrões entre o resultado médio de um processo e o limite de especificação mais próximo, então esse processo produzirá uma quantidade ínfima de produtos fora dos limites de especificação. Seguindo esse raciocínio, um processo Seis Sigma é aquele que estatisticamente produz apenas 3,4 produtos defeituosos a cada 1 milhão de produtos produzidos.

Não e foco deste trabalho detalhar a fundamentação teórica da metodologia, mas sua aplicabilidade à indústria de serviços de telecomunicações. Para uma discussão mais detalhada sobre o arcabouço estatístico do Seis Sigma, ver [36] (pág. 22) e [37] (pág. 35).

A flexibilidade da metodologia confere múltiplos significados ao Seis Sigma [36]:

Seis Sigma é Benchmark: parâmetro para comparar o nível de qualidade entre diversos processos, operações e produtos;

Seis Sigma é Meta: aproximar-se de zero defeito;

Seis Sigma é Medida: representação do nível de qualidade;

Seis Sigma é Filosofia: de melhoria perpétua do processo e eterna redução de sua variabilidade;

Seis Sigma é Estatística: calculada para cada característica crítica da qualidade; 
Seis Sigma é Estratégia: baseada na inter-relação existente entre projeto, fabricação, qualidade final, confiabilidade, ciclo de controle, inventários, reparos, sucata, defeitos, falhas e entrega de um produto a um cliente;

Seis Sigma é Valor: derivado da multiplicação de 12 vezes um sigma característico;

Seis Sigma é Visão: a de levar a empresa a ser a melhor em seu ramo estendendo a qualidade para além do que é esperado pelos clientes.

Neste trabalho, o Seis Sigma é entendido simplesmente como uma abordagem para melhoria de processos que pode ser utilizada por Provedores de Serviços para garantir que os serviços fornecidos a seus clientes são o mais aderentes possível à sua especificação inicial, com a menor variabilidade possível.

Dentre as diversas ferramentas oferecidas pelo Seis Sigma ([36], [37]) selecionou-se o DMAIC como mais relevante para o contexto definido no parágrafo anterior: a otimização dos processos (notadamente os de entrega) de um Provedor de Serviços de Telecomunicações. O DMAIC será introduzido a seguir, na seção 4.1.5.

\subsubsection{DMAIC}

Como o PDCA, o DMAIC [38] é uma metodologia iterativa que tem como objetivo a melhoria contínua de processos. Também como no caso do PDCA, o nome DMAIC é formado pelas iniciais das etapas da metodologia, que neste caso são cinco (Figura 16):

- Define: Definir as metas de melhoria do processo, em linha com as demandas do cliente e a estratégia da organização

- Esta etapa responde à pergunta: Que problema precisa ser resolvido?

- Measure: Medir o processo atual, coletando os dados relevantes para futuras comparações e análises

- Esta etapa responde às perguntas: Qual é a performance do processo? Quais são suas capacidades máxima e mínima? 
- Analyze: Analisar os dados coletados para verificar correlações e relações de causa-efeito entre fatores. Determinar que relações são estas e fazer o máximo possível para garantir que todos os fatores tenham sido adequadamente considerados

- Esta etapa responde à pergunta: Quando e onde ocorrem problemas ou defeitos?

- Improve: Melhorar ou otimizar o processo, baseando-se nas analyses efetuadas na etapa anterior

- Esta etapa responde às perguntas: Como levar a qualidade deste processo até o padrão Seis Sigma? Quais os Fatores Críticos de Sucesso para tal?

- Control: Controlar o processo para garantir que quaisquer variâncias sejam corrigidas antes de resultarem em defeitos.

- Esta etapa responde à pergunta: Que mecanismos podem ser implementados para manter os ganhos obtidos na etapa anterior?

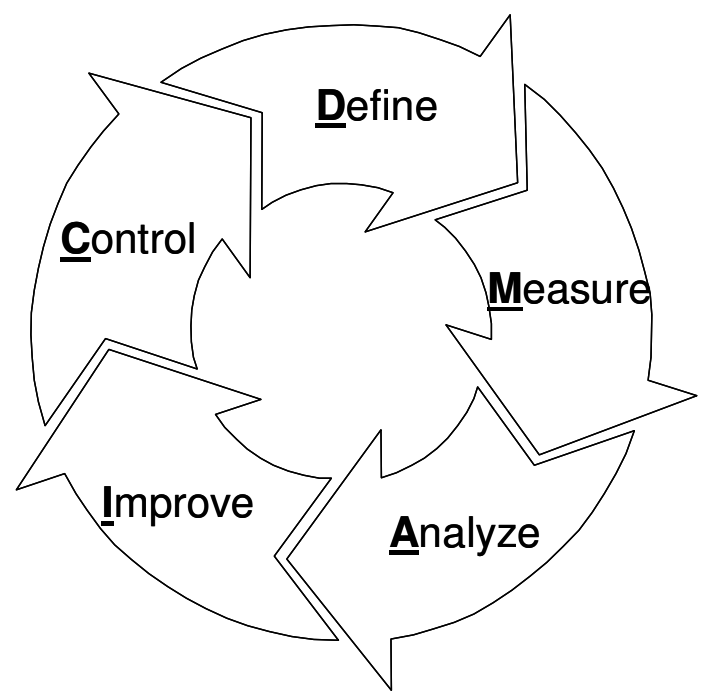

Figura 16 - Ciclo DMAIC de melhoria contínua e controle estatístico de processos

Neste trabalho, a maior diferença do DMAIC para o PDCA é sua ênfase na redução de erros em processos muito repetitivos e / ou de produção em massa, característica herdada do Seis Sigma e seu sofisticado ferramental estatístico 
(vide seção 4.1.4 ). O PDCA, como visto anteriormente, oferece uma perspectiva mais generalista, propondo-se a melhorar qualquer atividade ou processo minimamente estruturado. Assim, para os serviços de telecomunicação de que trata esta Dissertação, o DMAIC se mostra mais apropriado enquanto abordagem de melhoria para os processos de alto volume (Ex.: venda, aprovisionamento ou instalação de um serviço de acesso à Internet com milhares de usuários ou o atendimento e resposta a falhas de uma operadora de telefonia móvel com milhões de usuários).

\subsection{Programa NGOSS (New Generation OSS)}

O programa NGOSS [39] foi desenvolvido pelo TMForum [18] como a tangibilização do seu programa Lean Operator, um conjunto de iniciativas conceituais que buscam trazer para o ambiente de Telecomunicações os conceitos de produção enxuta do Lean Thinking (Figura 11). Nesse sentido, o TMForum definiu 3 níveis de maturidade das práticas de operação de um Provedor de Serviços nos estágios evolutivos da Figura 11. Assim, a visão da entidade é que os processos, pessoas e sistemas dedicados à operação de um Provedor de Serviços se encontram em um desses 3 níveis (descritos na Figura 17). 


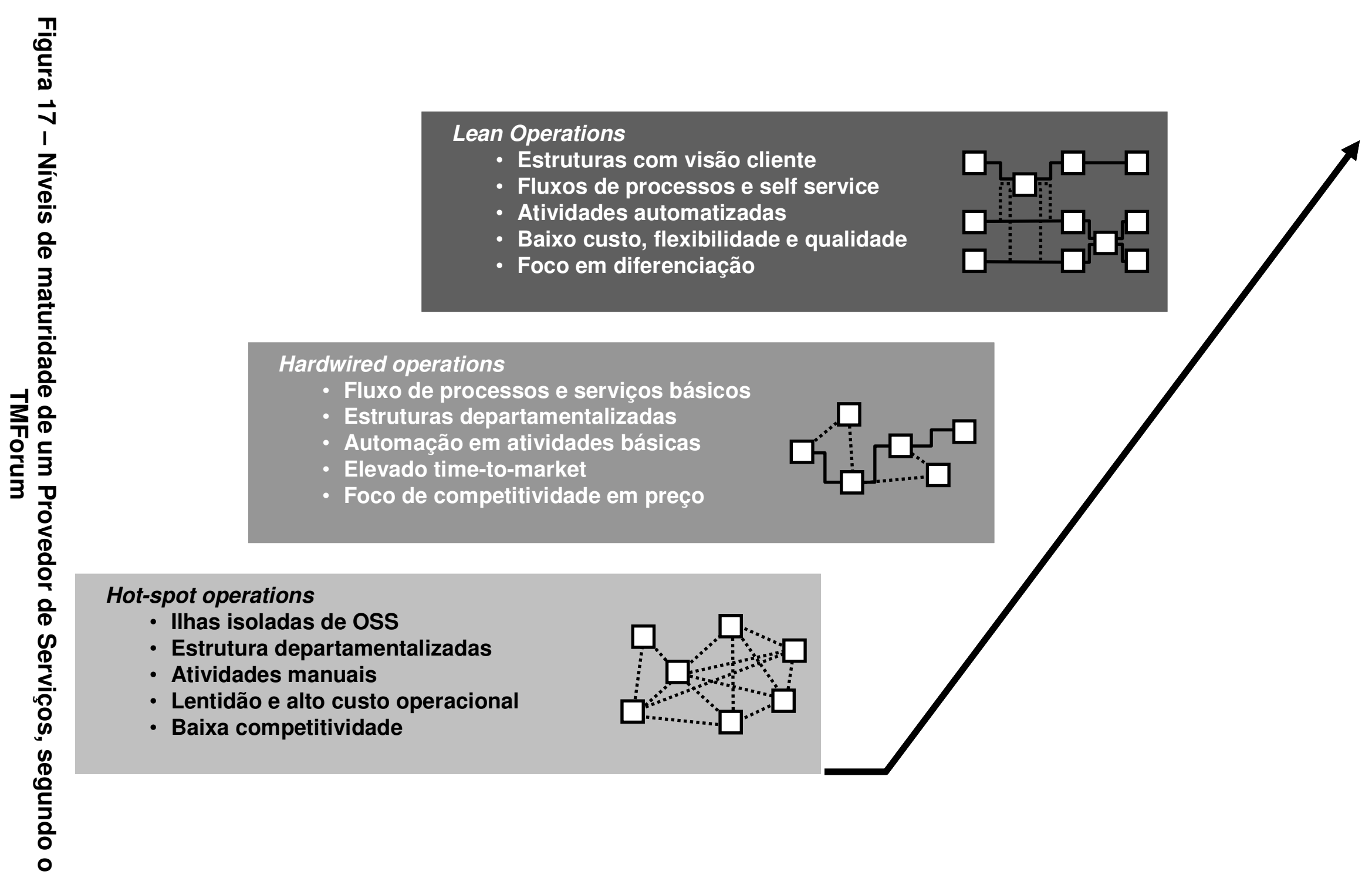


Como seu nome indica, o programa NGOSS se concentra em estruturar 0 Suporte à Operação dos Provedores de Serviços. Essa estruturação é dada na forma de iniciativas de desenvolvimento de melhores práticas que, se adotadas, permitem a um Provedor de Serviços evoluir seu ambiente operacional até o nível de Lean Operation da Figura 17.

\subsubsection{Visão Geral}

O programa NGOSS contempla tanto uma Arquitetura recomendada para os Sistemas de Suporte à Operação quanto a Metodologia para implantá-la (Figura 18).

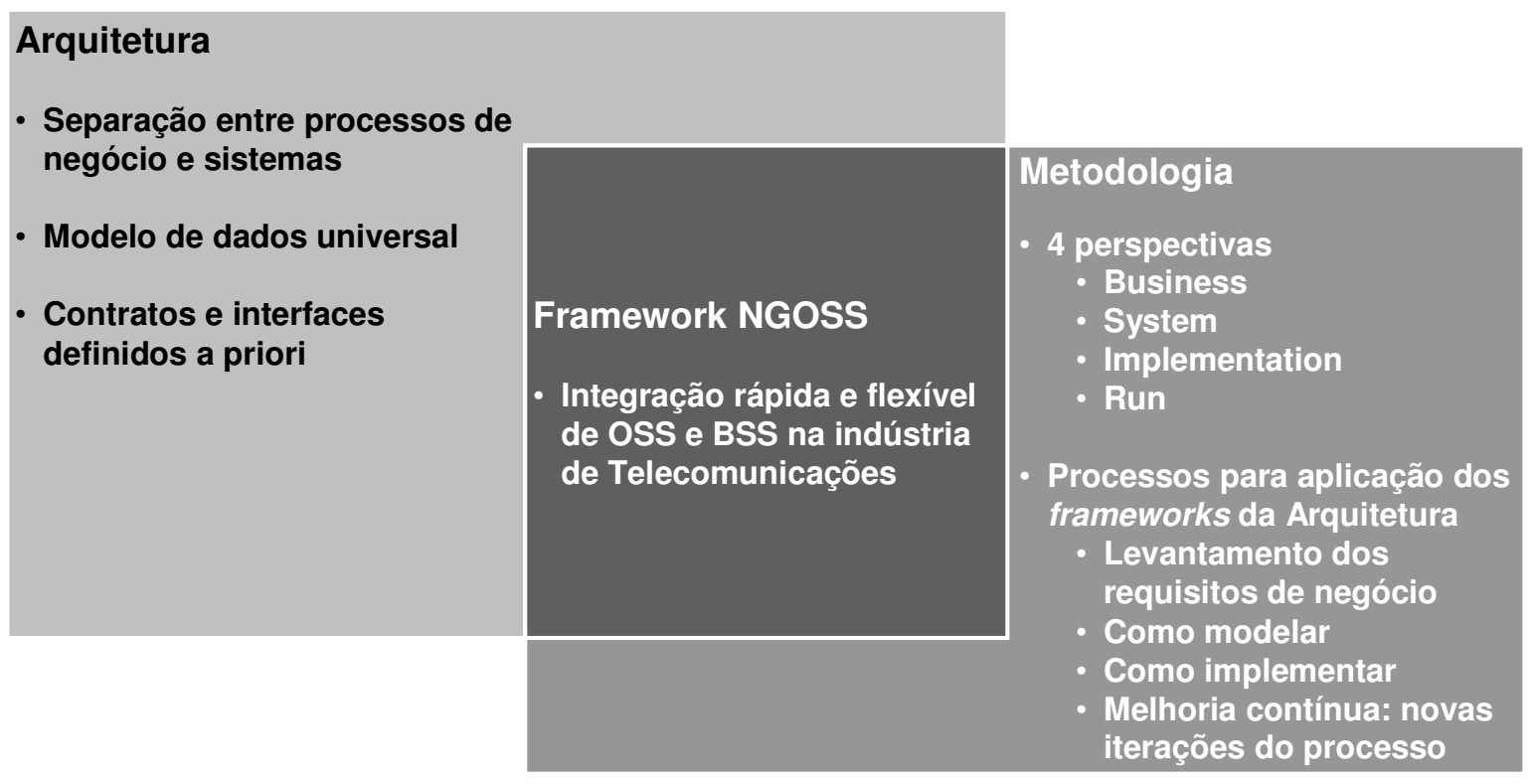

Figura 18 - Abrangência do programa NGOSS

\subsubsection{Arquitetura}

As recomendações de Arquitetura do NGOSS foram divididas em 4 pilares principais:

- Processos, com o objetivo em mapear todos os processos de negócio que suportam o fornecimento de serviços de telecomunicações 
- Aplicações, com o objetivo de mapear todas as diferentes aplicações necessárias a suportar os processos identificados

- Arquitetura tecnológica e de infra-estrutura, iniciativa que visa desenvolver uma visão de alto nível da arquitetura de redes e sistemas que implementa as aplicações mapeadas e, em última instância, entrega ao cliente final os serviços do Provedor de Serviços

- Modelo de Dados, projeto que está desenvolvendo um Modelo de Dados universalmente aplicável a Provedores de Serviços de Telecomunicações

Estas iniciativas, parte do programa NGOSS e, por extensão do programa Lean Operator, encontram-se sumarizadas na Figura 19. 


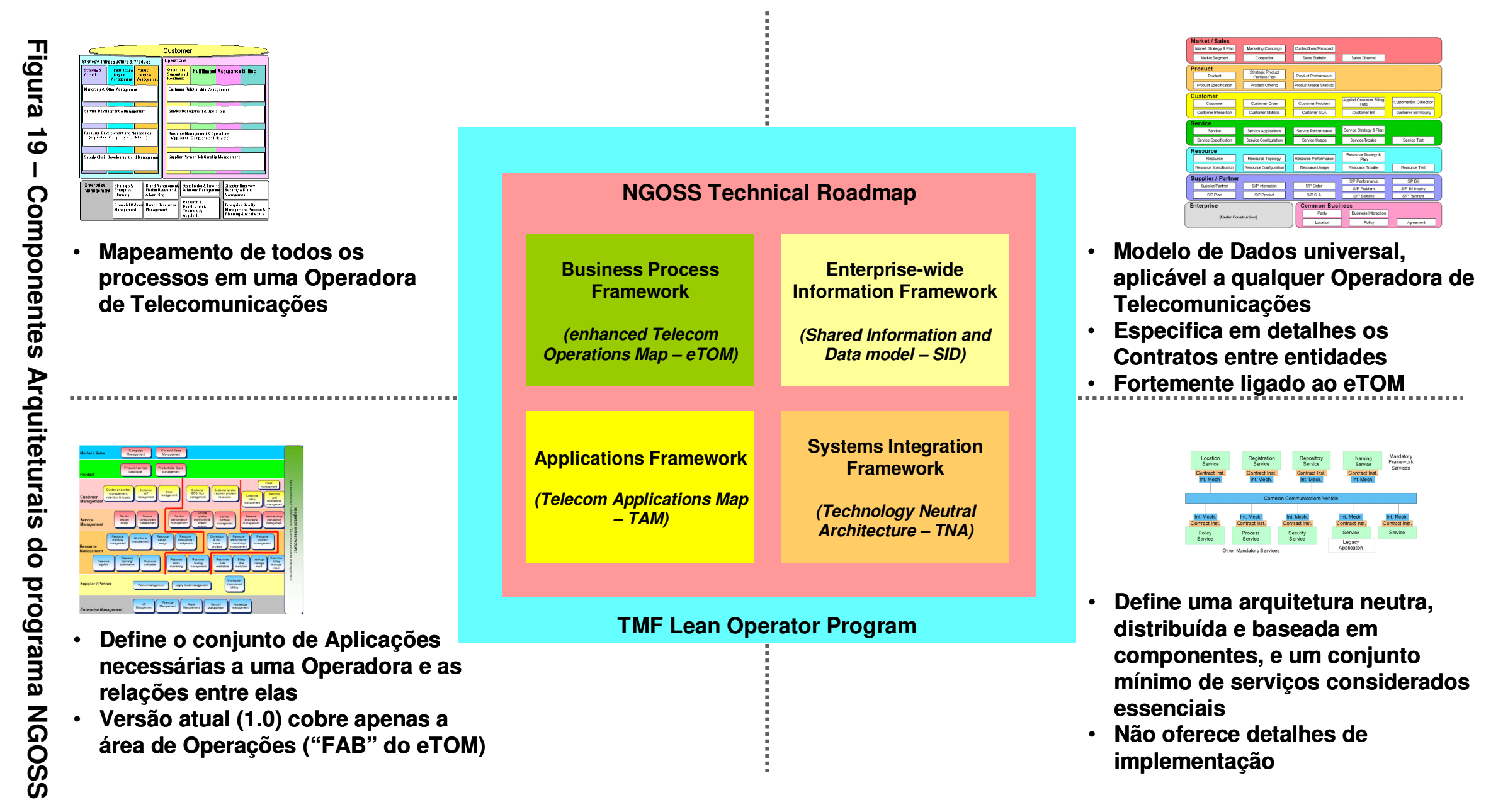




\subsubsection{Metodologia}

A metodologia definida pelo NGOSS está dividida em 2 grandes componentes: - NGOSS Lifecycle, que define os níveis de abstração utilizados na implementação dos conceitos do programa e o SANRR, que trata dos passos específicos a serem seguidos.

Esses 2 componentes absorveram melhores práticas de outros modelos consagrados, em especial:

- Framework Zachman: ênfase na empresa e em seu modelo de negócios

- Arquitetura baseada em modelos: separação dos modelos de negócio e tecnologia

- Reference Model for Open Distributed Programming: separação da metodologia em perspectivas

- Unified Software Development Process / RUP: metodologia de desenvolvimento iterativa e baseada em Casos de Uso

\subsubsection{NGOSS Lifecycle}

O NGOSS Lifecycle (literalmente "Ciclo de Vida NGOSS") oferece um modelo comum para o entendimento e uso dos artefatos desenvolvidos pelo TMForum. Neste sentido, o NGOSS Lifecycle utiliza o modelo de processos eTOM, o SID e a TNA (Technology-Neutral Architecture) - vide Figura 19 - para oferecer uma metodologia que cubra modelagem de processos, design de sistemas, implementação e implantação de soluções.

Um dos princípios fundamentais do NGOSS Lifecycle é o reconhecimento de que diferentes comunidades como Provedores de Serviços, Desenvolvedores de Software, Integradores de Sistemas, Fabricantes de Equipamentos, Usuários e outros necessitam ser capazes de ver uma solução NGOSS a partir do seu próprio ponto de vista. 
Com este intuito, o NGOSS Lifecycle foi divido em quatro dimensões e quatro perspectivas, representadas a seguir na Figura 20.

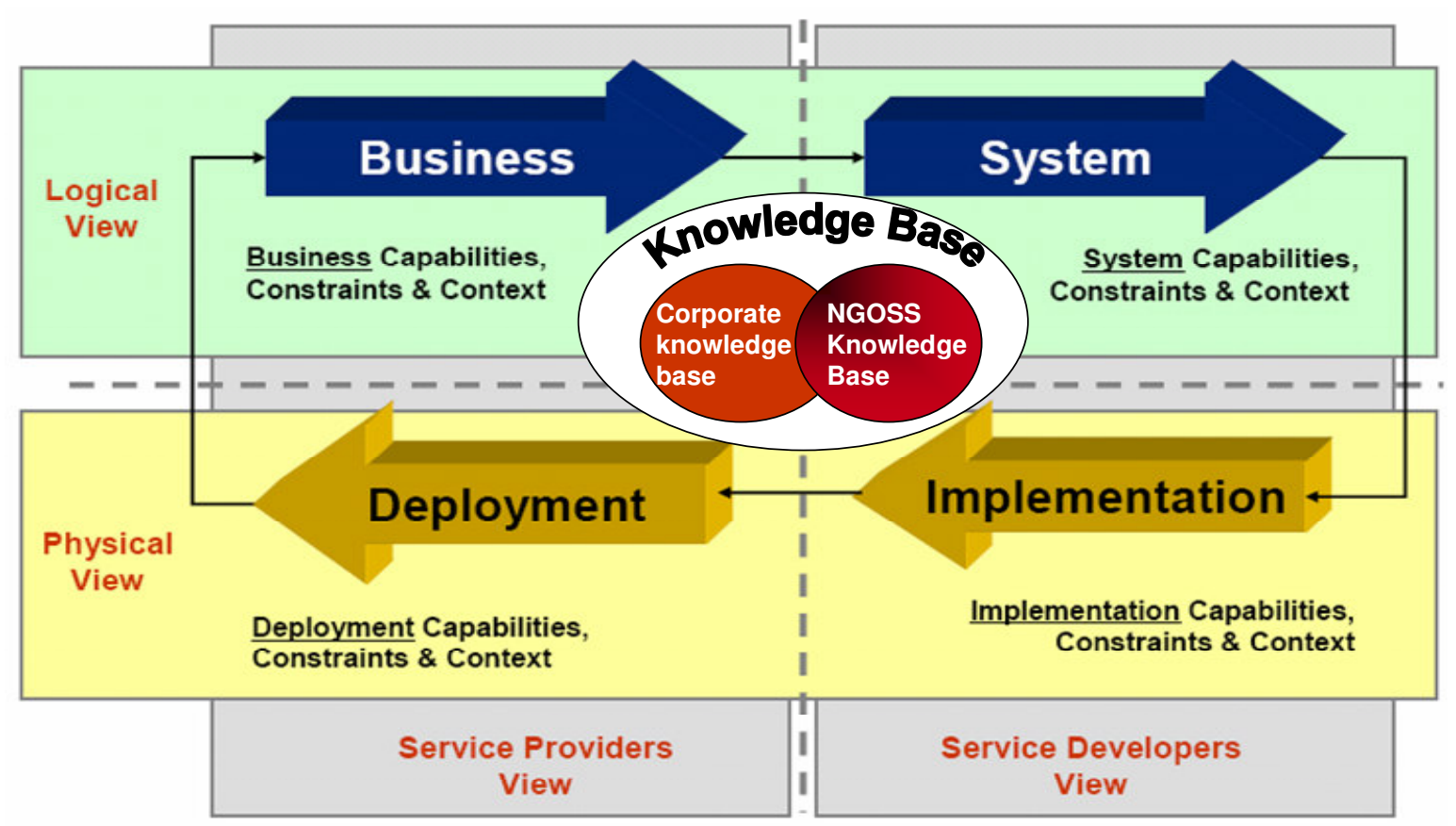

Figura 20 - Perspectivas e Dimensões do NGOSS Lifecycle

As duas categorias de perspectiva são:

- Lógica e física (Logicale Physical, na figura)

- Provedor de Serviços e Desenvolvedor de Serviços (Service Provider e Service Developer, na figura)

E as quatro Dimensões fundamentais são:

- Negócio (Business): foco nos processos de negócio, na informação e na interação entre ambos. O eTOM e o SID, em conjunto, identificam tanto os processos quanto as entidades de negócio que interagem a fim de suportar os objetivos estratégicos

- Sistema (System): focos em objetos, comportamentos e interações computacionais; a dimensão Sistema, também representada no eTOM e no SID, define as funcionalidades de cada sistema na forma de "contratos" que descrevem a troca de informações entre as entidades que compõem uma solução 
- Implementação (Implementation): foco no desenvolvimento e na construção do software, hardware e firmware que implementará a solução sendo projetada. Esta dimensão mapeia uma especificação tecnologicamente neutra em uma arquitetura tecnológica real

- Operação (Deployment): foco na operação e monitoramento da solução pronta com o objetivo de assegurar que ela atenda às expectativas de todas as partes interessadas

Como representado na Figura 20, cada perspectiva é composta por um subconjunto das 4 dimensões.

As perspectivas Lógica e Física permitem a separação dos aspectos e componentes lógicos (visões neutras de Negócios e Sistemas) e físicos (visões específicas de Implementação e Operação), permitindo por conseqüência a separação entre a definição da solução (visão lógica) e sua(s) implementação(ões) e operação(ões) (visão física). Este nível de separação possibilita o desenvolvimento de múltiplas soluções físicas a partir de uma única especificação lógica.

As perspectivas do Provedor e do Desenvolvedor de Serviços interceptam as demais perspectivas e dimensões na medida em que possuem diferentes interesses nelas.

O interesse de um Provedor de Serviços na perspectiva Lógica da dimensão Negócios é a definição da solução a ser ofertada para o seu usuário final. $O$ interesse do Provedor na perspectiva Física da dimensão Operação são as questões da operação cotidiana dos sistemas e aplicações que implementam essa solução.

Similarmente, o interesse de um Desenvolvedor de Serviços na perspectiva Lógica da dimensão Sistema são os requisitos em que o Desenvolvedor irá se basear para construir a solução. Por outro lado, seu interesse na perspectiva Física da dimensão de Implementação são as tecnologias que ele utilizará nessa construção.

A adoção de um modelo de interação baseado no NGOSS Lifecycle por Provedores e Desenvolvedores de Serviço traria uma maior estruturação ao processo de transição de serviços da dimensão Implementação para a 
dimensão Operação, na medida em que formalizaria os papéis e responsabilidades de cada parte.

\subsubsection{SANRR}

A metodologia SANRR (acrônimo para Scope, Analyze, Normalize, Rationalize e Rectify) define uma abordagem para a análise, especificação, projeto e implementação de soluções de suporte à operação de telecomunicações.

O SANRR está dividido em 5 passos iterativos (Figura 21):

- Scope - Definição de Escopo: definir as fronteiras da solução, entendendo e documentando seu objetivo de negócio, o ambiente de mercado e negócios atual e futuro. Esta fase garante que os objetivos e missões da solução são consistentes durante todo o ciclo, da dimensão Negócio à dimensão Operação

- Analyze - Análise: preparar documentação detalhada sobre o ambiente de negócios atual e futuro, incluindo processos, políticas e estratégias de negócio e tecnologia. Esta fase também serve como preparação para a identificação de funcionalidades faltantes ou duplicadas na solução, atividade que virá nas próximas fases

- Normalize - Normalizar: facilitar a interoperacão das diferentes perspectivas Físicas baseando-se numa mesma perspectiva Lógica, assegurando que todos os componentes estejam mapeados em uma linguagem comum (no NGOSS, esta linguagem é o SID) e estendendo-a se necessário

- Rationalize - Racionalizar: identificar novos processos, políticas, funcionalidades e tecnologias que necessitem ser projetadas, desenvolvidas ou implementadas para suportar o novo ambiente de negócios. Funcionalidades faltantes ou duplicadas são identificadas nesta fase. Eventuais ajustes considerados necessários serão alvo da próxima etapa

- Rectify - Retificar: propor e fornecer novos processos, políticas e funcionalidades para cobrir as necessidades identificadas na fase anterior, 
implementando mudanças que tornem a solução aderente ao novo ambiente de negócios

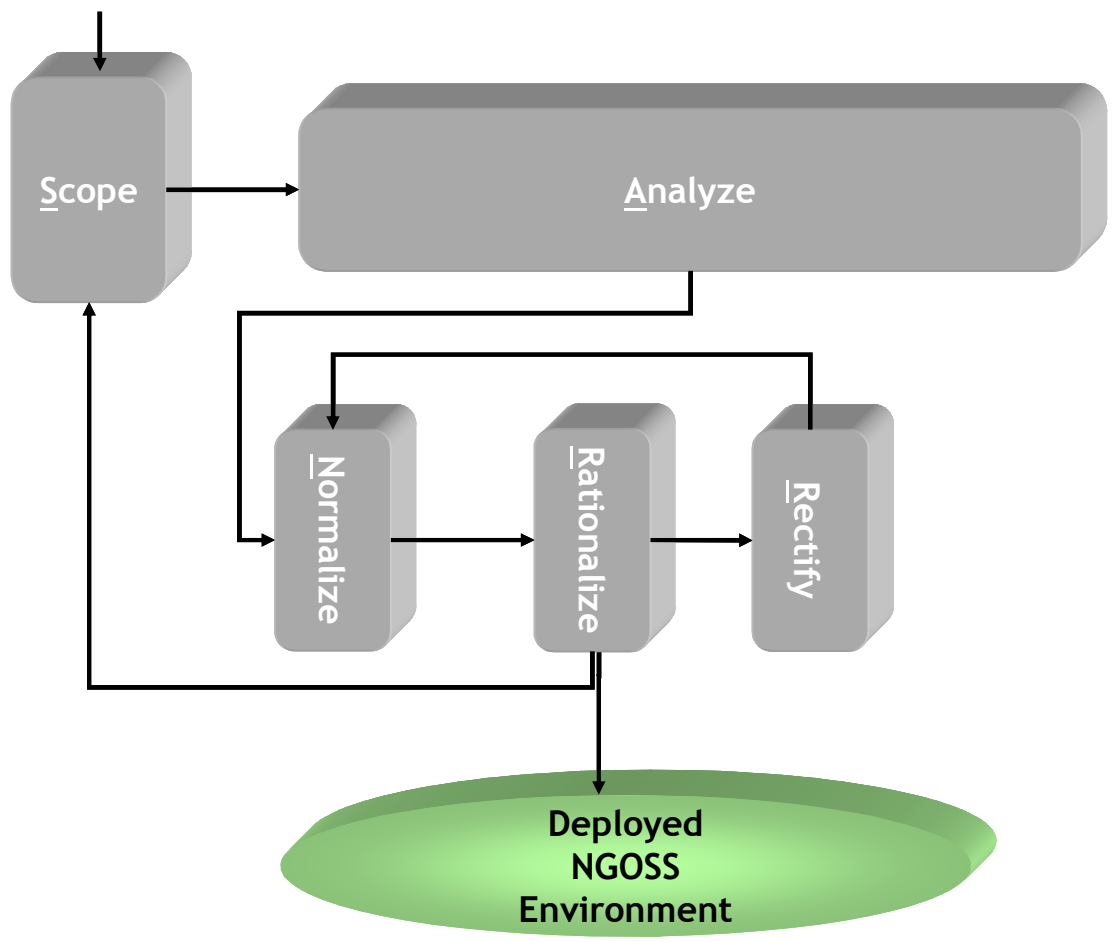

Figura 21 - Metodologia SANRR

Como se depreende da Figura 21, a metodologia SANRR deve muito às idéias do PDCA e do Unified Process, principalmente no que tange ao seu caráter iterativo e de refinamento sucessivo.

\subsection{Metodologia QFD (Quality Function Deployment)}

O QFD é uma técnica para tomada de decisões em grupo durante iniciativas de desenvolvimento orientado ao consumidor. Em essência, o QFD é um método para identificar as características mais importantes de um grupo de consumidores e detectar as correlações entre estas e os parâmetros de projeto influenciáveis pela equipe de desenvolvedores. Por ser bastante flexível e focado no cliente, o QFD se aplica a iniciativas de desenvolvimento de produtos, serviços, marcas ou outros ativos que necessitam ser desenhados para atender às necessidades de clientes - especialmente quando estas necessidades são 
subjetivas ou intangíveis [41]. Exemplos desta flexibilidade de aplicação do QFD vão do desenvolvimento de efeitos especiais em parques de diversão [42] ao plantio de mudas de café [43].

Desenvolvida no Japão na década de 60 pelos professores Shiguero Mizuno e Yoji Akao [1], a metodologia conhecida como QFD é na verdade um conjunto de conceitos e técnicas relativamente independentes [40]. As mais relevantes para este trabalho, e que por isso serão detalhadas a seguir, são:

- Voice Of Customer

- House of Quality

- Visitas Gemba

- Maximum Value Table

Assim, como será visto nas próximas sessões, o QFD pode ser resumido como uma aplicação das técnicas listadas acima: entender as necessidades do mercado ouvindo a voz do consumidor (VOC) e indo até o seu ambiente (Visitas Gemba), quantificá-las e priorizá-las através de técnicas formais (como a Maximum Value Table) e traduzi-las em requisitos objetivos de projeto (através da House of Quality).

\subsubsection{VOC (Voice Of Customer)}

Segundo a ASQ, o termo Voz do Consumidor significa "os requisitos expressos e as expectativas do consumidor em relação a produtos ou serviços" [13].

Neste trabalho, nos referimos ao termo VOC como o processo de captura de requisitos dos clientes, ou seja, uma técnica de pesquisa de mercado capaz de identificar e estruturar as necessidades (muitas vezes subjetivas, intangíveis ou abstratas) dos consumidores.

O foco de um estudo VOC é identificar todos os requisitos dos consumidores, tanto explícitos quanto implícitos (vide seção 2.2 ). Existem muitas ferramentas 
para se atingir este objetivo: focus groups, entrevistas livres, entrevistas contextuais, visitas, sensos etnográficos e que tais (vide

Tabela 5, adaptada de [16] e também [44], [17], [45]).

\section{Tabela 5 - Ferramentas VOC}

\section{Ferramenta}

Brainstorming (Brassard e Ritter -1994)

\section{Objetivo}

Geração rápida de idéias via discussão sem críticas

Diagrama de afinidades (Brassard e

Ritter, 1994; Mizuno, 1988; Nayatami et al Mostrar conexões naturais entre idéias. 1994)

Diagrama de árvore (Brassard e Ritter, 1994; Mizuno, 1988; Nayatami et al 1994)

Refinar os agrupamentos do diagrama de afinidades em termos de sobreposição identificação de idéias esquecidas.

Processo de hierarquia analítica - AHP Comparação de pares afins para medir a importância (Saaty, 1990; Zultner, 1993) e estabelecer uma escala de relação de prioridades.

Tabela de segmentação de consumidores (Daetz et al 1995; Mazur e Zultner, 1996) Identificar dados de uso e demográficos sobre segmentos de consumidores e encontrar os segmentos mais importantes.

Identificar os consumidores mais suscetíveis a auxiliar

Matriz de segmentação de consumidores (Zultner, 1992; Mazur, 1995) o projeto de desenvolvimento de produto (consumidores que serão alvo do estudo VOC).

Check list (McQuarrie, 1993; Mazur, Assegurar que as visitas aos consumidores sejam 1995) bem conduzidas.

Diagramas de fluxo, Diagramas de árvore, Tabela de processos para o consumidor (Nelson, 1992)

Desenhar os processos e assuntos de interesse para o consumidor.

\begin{tabular}{ll}
\hline $\begin{array}{l}\text { Diagrama de transição de estado (Gane e } \\
\text { Sarsson, 1977; Mazur, 1995) }\end{array}$ & $\begin{array}{l}\text { Capturar a lógica do consumidor durante o uso de um } \\
\text { produto ou serviço. }\end{array}$ \\
\hline Diagrama de fluxo de dados - DFD & Mostrar o processo decisório e os dados que o \\
(Gane e Sarsson, 1977; Mazur, 1995) & consumidor utiliza ao avaliar um produto \\
\hline Tabela contextual do consumidor - CCT & CCT: registrar o contexto de uso do produto ou \\
e Tabela de tradução literal - VTT (Ohfuji & serviço. Pode ser combinada com a VTT para revelar \\
\hline
\end{tabular}




\begin{tabular}{ll}
\hline $\begin{array}{l}\text { et al 1990; Marsh et al 1991; Mazur, } \\
\text { 1995; Mazur e Zultner, 1996) }\end{array}$ & $\begin{array}{l}\text { palavras e observações ocultas sobre as } \\
\text { necessidades dos consumidores. }\end{array}$ \\
\hline $\begin{array}{l}\text { Tabela da voz do consumidor - CVT } \\
\text { (Ohfuji et al 1990; Marsh et al 1991; } \\
\text { Mazur, 1995; Mazur e Zultner, 1996) }\end{array}$ & $\begin{array}{l}\text { Capturar e estruturar os benefícios que os } \\
\text { consumidores vêem em um produto. }\end{array}$ \\
\hline & Diagrama de afinidade: identificar e formalizar as \\
estruturas subjetivas que formam o conceito de \\
Diagrama de afinidade da qualidade & qualidade do ponto de vista do consumidor. \\
requerida e diagrama de árvore. & Diagrama de árvore: corrigir a estrutura identificada e \\
& procurar por mais dados ocultos. \\
\hline Tabela da qualidade planejada (Mazur, & Decidir qual será a qualidade-alvo do produto em \\
desenvolvimento. & Esta tabela é o quadro à direita da Casa da \\
& Qualidade (Figura 22).
\end{tabular}

A aplicação de todas essas ferramentas segue aproximadamente o mesmo processo [17]:

- Definir e priorizar os segmentos de mercado a serem estudados, de acordo com os objetivos estratégicos da organização;

- Visitar os consumidores in loco, ou seja, no gemba (conceito definido e explorado na seção 4.3.3 ),

- Mapear seu processo de uso do produto;

- Coletar sua opinião / percepção / visão sobre o produto, utilizando os termos do consumidor,

- Distribuir as percepções coletadas em dimensões pertinentes ao design e desenvolvimento do produto, traduzindo-as em benefícios que o cliente irá auferir do produto;

- Fazer com que o consumidor estruture suas necessidades a partir do seu próprio ponto de vista (que pode ser diferente do da organização);

- Buscar identificar necessidades latentes, implícitas ou de outra forma ainda não identificadas; 
- Pedir ao consumidor que priorize suas necessidades e identifique a maneira como ele mede sua satisfação;

- Se necessário, identificar as alternativas ao produto mais favorecidas pelo consumidor.

Porém, independente das ferramentas utilizadas, o resultado de um bom estudo VOC tem de conter no mínimo:

- Um entendimento detalhado (e estruturado) das necessidades do consumidor;

- Um dicionário de termos que defina uma linguagem comum com a qual a equipe de desenvolvimento do produto irá trabalhar;

- Dados suficientes para suportar as escolhas que a equipe de desenvolvimento terá de fazer ao longo do projeto do produto.

\subsubsection{House of Quality}

Ferramenta central do QFD, a House of Quality (Casa da Qualidade) é uma matriz de planejamento de produtos (arranjada no formato de uma casa, daí o nome) que desempenha a função primordial do QFD: converter as necessidades dos clientes em requisitos de projeto tangíveis e implementáveis [40].

A estrutura conceitual da Casa da Qualidade está representada na Figura 22, retirada de [1]; ao examiná-la, fica evidente a principal função da matriz: correlacionar as necessidades dos consumidores e as especificações técnicas (esta correlação forma a maior parte da "casa", na Figura 22). 


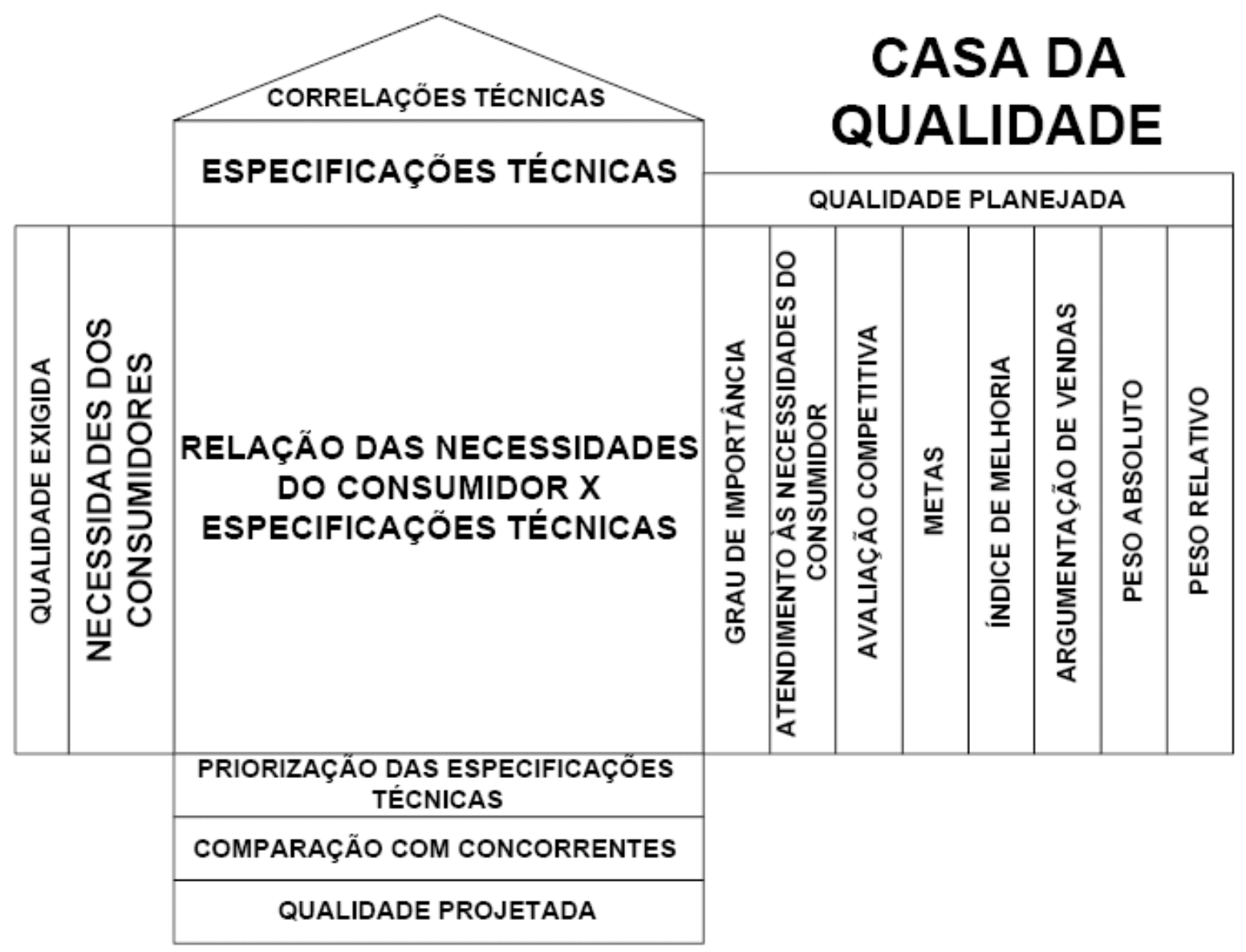

Figura 22 - Casa da Qualidade

Os passos genéricos para construir uma Casa da Qualidade são [41]:

- Primeiro passo: a equipe de desenvolvimento identifica os atributos do produto que são críticos para o consumidor, utilizando para isso o estudo VOC realizado anteriormente (vide seção 4.3.1). Esses atributos formam as linhas da matriz central da Casa da Qualidade ("Necessidades do Consumidor", na Figura 22), e podem ser descritos utilizando as palavras do próprio consumidor (abordagem utilizada no estudo VOC) ou de maneira simplificada (macro categorias de requisitos identificados pela equipe). Identificados os atributos, a equipe extrai dos dados do estudo VOC a importância de cada atributo para o consumidor e preenche com valores porcentuais o campo "Grau de Importância" da Figura 22;

- Segundo passo: a equipe de desenvolvimento identifica os parâmetros de design que mais influenciam a performance do produto e os utiliza para formar as colunas da matriz (campo "Especificações Técnicas" na Figura 
22). Estes parâmetros devem descrever o produto com a maior precisão possível, ser mensuráveis objetivamente e estar ligados aos atributos mais valorizados pelo consumidor (passo anterior);

- Terceiro passo: a equipe de desenvolvimento preenche o corpo principal da matriz. Aqui, cada célula representa uma potencial relação entre um atributo valorizado pelo consumidor e um parâmetro de projeto. A simbologia utilizada nesta parte da matriz varia conforme a riqueza da informação disponível sobre o relacionamento; no melhor caso, cada célula é preenchida com uma fórmula que mede objetivamente a relação entre as duas variáveis, no pior, a célula é preenchida apenas com uma indicação qualitativa ("a correlação entre as duas variáveis existe e é positiva"). $\mathrm{O}$ preenchimento desta matriz é crucial para o sucesso do exercício, por isso deve ser feito lançando-se mão de toda a informação disponível (resultados do estudo VOC, melhores práticas do mercado, experiência dos engenheiros da equipe etc.);

- Quarto passo: aqui, são preenchidos os campos à direita da matriz principal na Figura 22. A equipe define aqui quais as suas forças e fraquezas atuais, as metas para o seu produto e realiza uma análise competitiva do seu produto (caso o exercício consista em melhorar um produto existente) ou de sua imagem (caso se trate do desenvolvimento de um novo produto), preenchendo o campo "Avaliação Competitiva" da Figura 22. Aqui são utilizados os atributos valorizados pelo consumidor (linhas da matriz) para medir a posição relativa do produto ou organização em relação a seus competidores, como percebido pelo cliente;

- Quinto passo: por fim, é preenchido o "telhado" da Casa da Qualidade através de uma análise de inter-relacionamento entre os parâmetros de projeto. Esta análise mostra as diferentes situações que irão requerer soluções de compromisso por parte da equipe (um exemplo típico é o compromisso Preço x Qualidade) e pode revelar relações antes insuspeitas sobre a performance do produto. 
Ao final do processo, o resultado obtido é uma visão completa das necessidades do consumidor, o peso relativo de cada uma delas na composição da percepção que consumidor tem do produto e a relação entre cada necessidade e as características técnicas e funcionais do produto.

Em exemplo de Casa da Qualidade preenchida com todos os requisitos de um cliente sobre uma organização e todas as competências dessa organização encontra-se na Figura 23. 


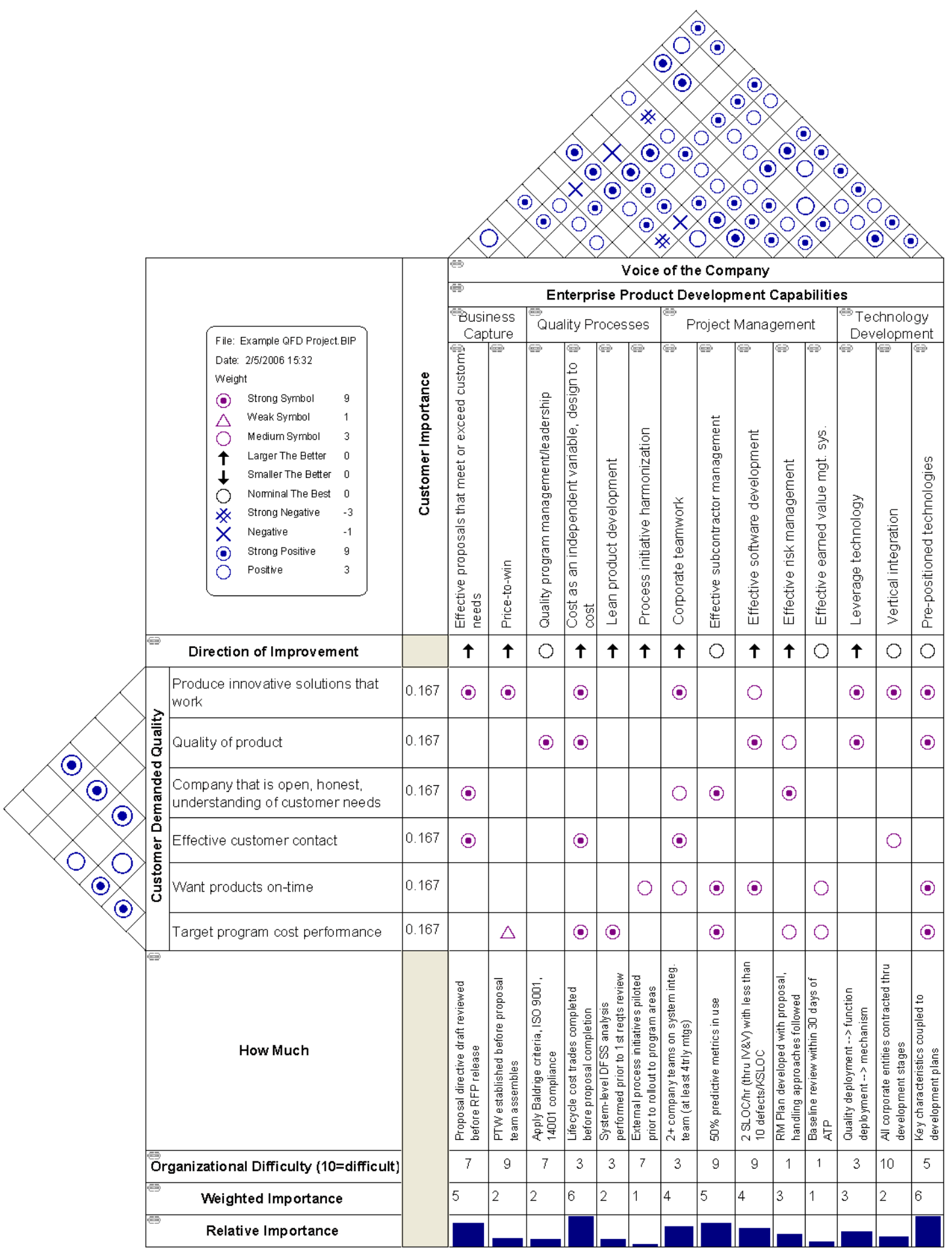

Figura 23 - Exemplo de Casa da Qualidade preenchida

\subsubsection{Visitas Gemba}


Gemba é uma palavra Japonesa que significa "o lugar onde a verdade pode ser encontrada" [13].

Em sua acepção original, Gemba referia-se ao chão de fábrica - como tantos outros conceitos da Engenharia da Qualidade, o Gemba também foi identificado no segmento industrial.

O entendimento moderno é que Gemba é verdadeiro o local em que o Valor é criado para o consumidor [45]. Ao aplicar este conceito ao mundo de serviços, Mazur definiu o Gemba como o ambiente ou situação de trabalho do consumidor ou mesmo seu estilo de vida [45]. Para entender realmente as necessidades do consumidor, o engenheiro deve testemunhar o uso do produto pelo consumidor em seu Gemba.

Diferente de técnicas como focus groups ou pesquisas, Visitas Gemba não possuem roteiros nem são limitadas pelo que a equipe de desenvolvimento deseja saber. As principais características de uma Visita Gemba são [16]:

- O objetivo primário é observar e ocasionalmente perguntar; raramente guiar ou dirigir;

- A visita ocorre não só no lugar, mas no contexto em que o produto ou serviço é usado, permitindo a observação direta de dificuldades enfrentadas pelo consumidor, usos inesperados do produto e funcionalidades ou características que nunca são utilizados;

- Por vezes o consumidor é solicitado a descreve o que ele está fazendo enquanto usa o produto - esta prática permite compreender melhor o seu processo de pensamento, o que em geral revela diferenças entre o modelo mental do consumidor e o modelo dos Desenvolvedores ou Provedores do serviço;

- Quando no seu contexto habitual, o consumidor em geral expressa desejos ou necessidades que seriam deixadas de lado em outras ocasiões (como entrevistas ou pesquisas).

Uma Visita Gemba tipicamente segue os seguintes passos [45]: 
- Identificar o perfil do consumidor e o contexto em que este utiliza o produto (este passo está ligado ao conceito de Gemba, explorado a seguir);

- Coletar a representação visual do contexto de uso do produto;

- Capturar a visão do consumidor sobre o produto (opinião, problema, oportunidade de melhoria etc.) nas palavras do próprio consumidor;

- Opcionalmente, reescrever a visão do consumidor na forma de benefícios para ele - este passo é especialmente interessante durante exercícios de desenvolvimento de um novo produto para sanar um problema percebido pelo consumidor;

- Identificar as características e funcionalidades do produto que estão ligadas à percepção do consumidor (esta é a etapa em que os dados coletados se tornam estruturados);

- Opcionalmente, identificar que pontos de referência são utilizados pelo usuário em decisões de compra, troca ou comparação entre produtos.

\subsubsection{Maximum Value Table}

Identificadas as necessidades dos consumidores (através das ferramentas VOC e das Visitas Gemba - seções 4.3.1 e 4.3.2, respectivamente) e mapeada a sua importância em relação aos parâmetros básicos de projeto (via Casa da Qualidade, vide 4.3.3 ) é necessário definir que características serão privilegiadas no desenvolvimento do produto final, dadas todos os compromissos e condições de contorno identificados e que ações devem ser tomadas prioritariamente pela equipe de desenvolvimento.

Com essa finalidade utiliza-se a Maximum Value Table, ou Tabela para Máximo Valor, cujo nome vem do objetivo de projetar um produto ou serviço que ofereça o máximo valor para o cliente - e entendendo valor da mesma maneira que ele.

O conceito da Maximum Value Table é, a partir dos benefícios identificados via VOC e visitas Gemba e dos atributos priorizados na Casa da Qualidade, encontrar a combinação de atributos que maximize o valor do produto para 0 
consumidor e esteja dentro das restrições impostas pelo Desenvolvedor ou Provedor de Serviços (restrições políticas, de recursos, econômicas, ambientais etc.). A Figura 24, extraída de [17], apresenta uma Maximum Value Table hipotética.

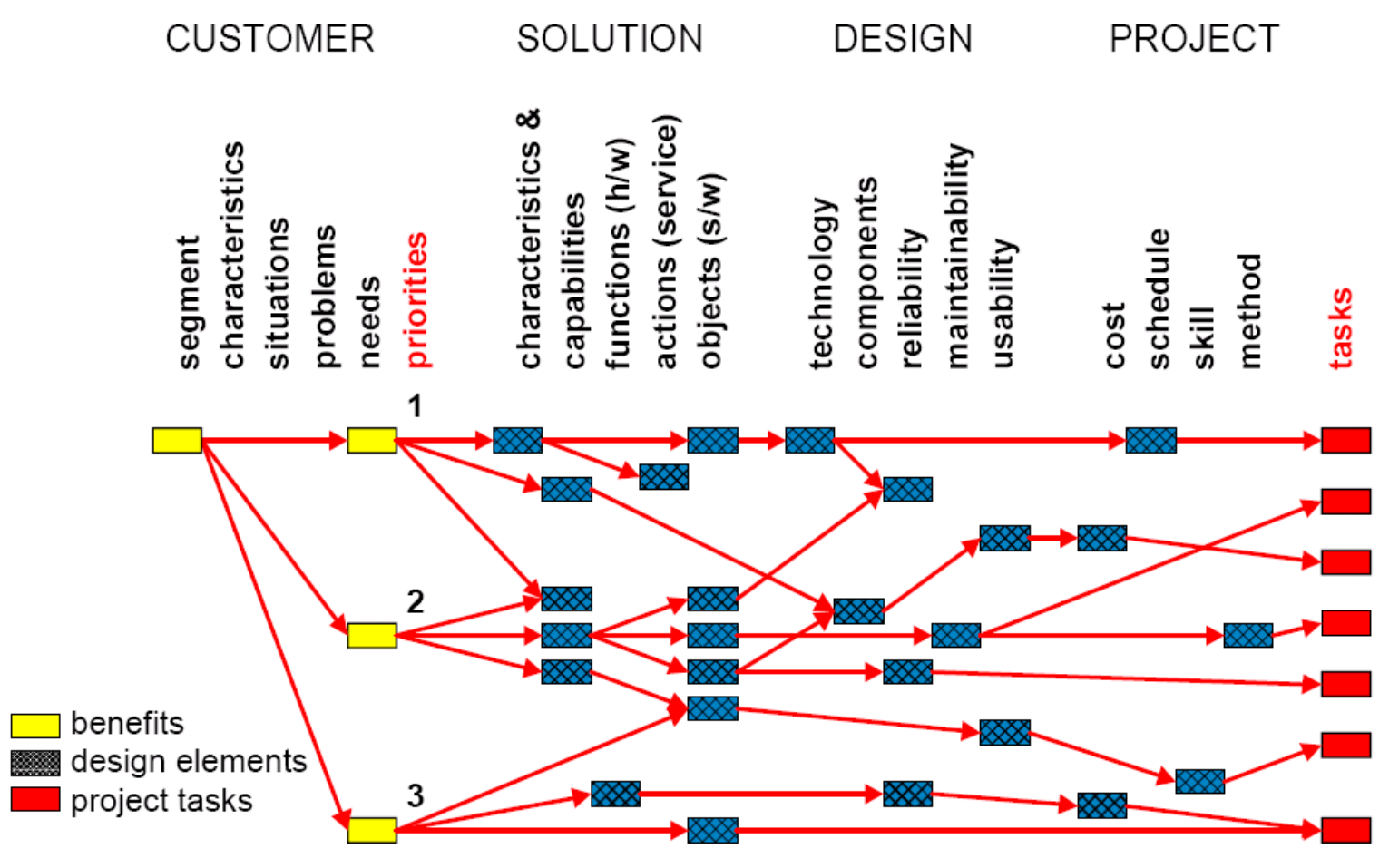

Figura 24 - Maximum Value Table

\subsection{Práticas de Gestão da FNQ (Fundação Nacional da Qualidade)}

A FNQ (Fundação Nacional da Qualidade), uma organização nãogovernamental sem fins lucrativos fundada por 39 organizações há 15 anos, é hoje o principal centro brasileiro de estudo sobre excelência em gestão.

Seu objetivo é contribuir para o aumento da competitividade das organizações e do Brasil, promovendo a qualidade da gestão empresarial. Para tanto, a FNQ criou um Modelo de Gestão baseado nas melhores práticas mundiais de administração para a qualidade. A promoção do Modelo de Gestão da FNQ é realizada por meio de ciclos anuais de concessão do Prêmio Nacional da 
Qualidade, outorgado à empresa cujas práticas de gestão mais se aproximam do Modelo.

O conceito de Gestão defendido pela FNQ é fortemente baseado nas idéias de melhoria contínua contidas em outras metodologias pertencentes à disciplina da Gestão da Qualidade Total (como o Kaizen e o ciclo PDCA, já apresentados). Especificamente, a FNQ defende que a gestão de uma empresa pode ser decomposta em ciclos PDCA concêntricos (Figura 25, adaptada de [47]). Assim, a empresa necessita melhorar continuamente suas práticas e padrões de trabalho (ciclo PDCA mais externo) e, no dia a dia das suas atividades, deve adotar uma postura de aderência a padrões de qualidade (ciclo PDCA interno) a mesma postura preconizada pela filosofia Kaizen de gestão.

Para este trabalho, a importância do Modelo de Excelência da Gestão da FNQ está justamente na promoção do alinhamento de toda a empresa a um conjunto muito específico e concreto de objetivos estratégicos definidos a priori.

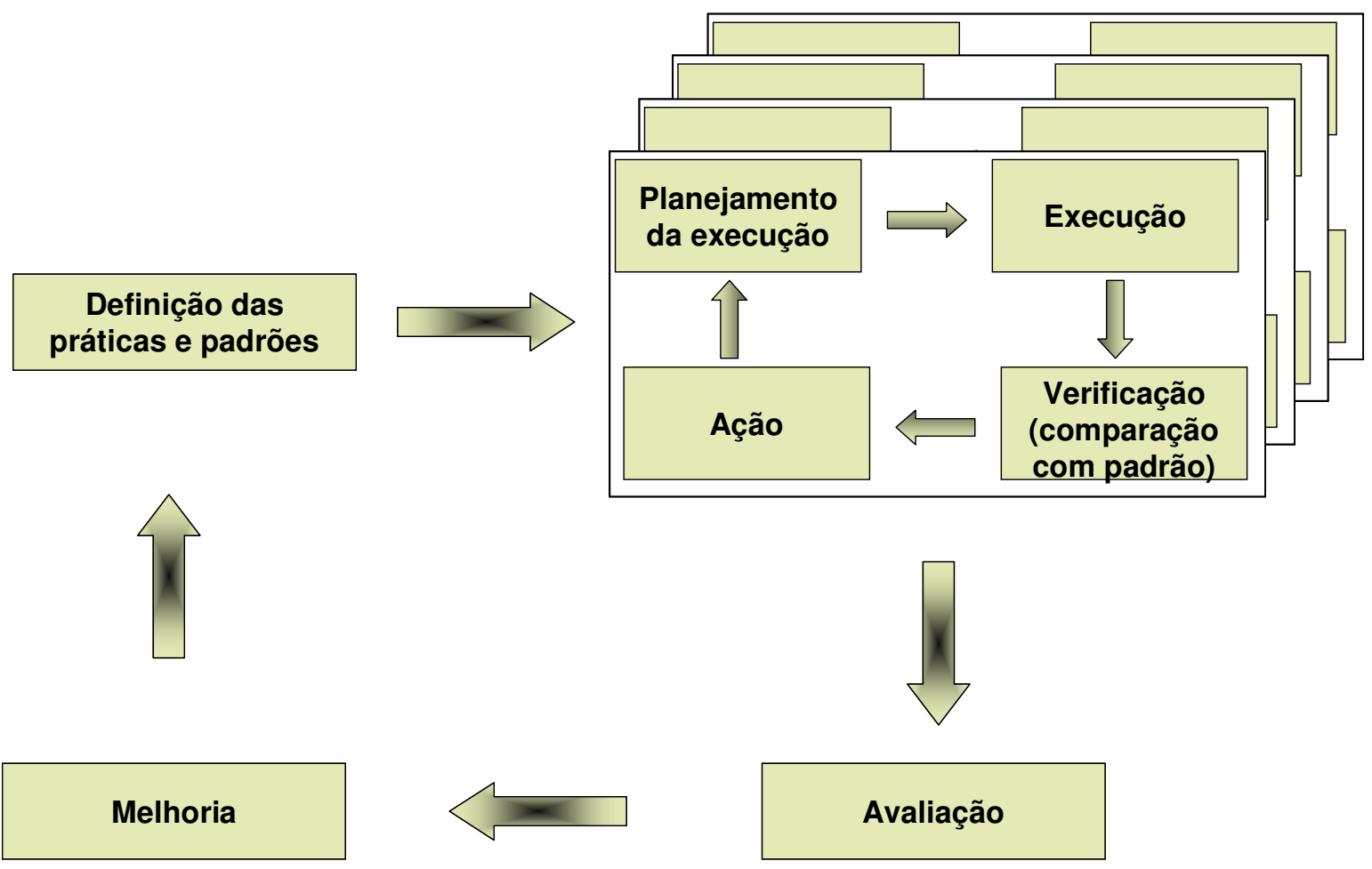

Figura 25 - Diagrama da Gestão (FNQ) 
O Modelo de Excelência da Gestão proposto pela FNQ se apóia em 8 Critérios de Excelência, por sua vez construídos sobre uma base de conceitos considerados essenciais à obtenção da excelência do desempenho. Estes conceitos são chamados Conceitos Fundamentais da Excelência em Gestão, sendo descritos pela FNQ nos seguintes termos [46]:

- Pensamento Sistêmico: Entendimento das relações de interdependência entre os diversos componentes de uma organização, bem como entre a organização e o ambiente externo.

- Aprendizado Organizacional: Busca e alcance de um novo patamar de conhecimento para a organização por meio da percepção, reflexão, avaliação e compartilhamento de experiências.

- Cultura de Inovação: Promoção de um ambiente favorável à criatividade, experimentação e implementação de novas idéias que possam gerar um diferencial competitivo para a organização.

- Liderança e Constância de Propósitos: Atuação de forma aberta, democrática, inspiradora e motivadora das pessoas, visando ao desenvolvimento da cultura da excelência, à promoção de relações de qualidade e à proteção dos interesses das partes interessadas.

- Orientação por Processos e Informações: Compreensão e segmentação do conjunto das atividades e processos da organização que agreguem valor para as partes interessadas, sendo que a tomada de decisões e execução de ações deve ter como base a medição e análise do desempenho, levandose em consideração as informações disponíveis, além de incluir os riscos identificados.

- Visão de Futuro: Compreensão dos fatores que afetam a organização, seu ecossistema e o ambiente externo no curto e no longo prazo, visando à sua perenização.

- Geração de Valor: Alcance de resultados consistentes, assegurando a perenidade da organização pelo aumento de valor tangível e intangível de forma sustentada para todas as partes interessadas. 
- Valorização das Pessoas: Estabelecimento de relações com as pessoas, criando condições para que elas se realizem profissionalmente e humanamente, maximizando seu desempenho por meio do comprometimento, desenvolvimento de competências e espaço para empreender.

- Conhecimento sobre o Cliente e o Mercado: Conhecimento e entendimento do cliente e do mercado, visando à criação de valor de forma sustentada para o cliente e, conseqüentemente, gerando maior competitividade nos mercados.

- Desenvolvimento de Parcerias: Desenvolvimento de atividades em conjunto com outras organizações, a partir da plena utilização das competências essenciais de cada uma, objetivando benefícios para ambas as partes.

- Responsabilidade Social: Atuação que se define pela relação ética e transparente da organização com todos os públicos com os quais se relaciona, estando voltada para o desenvolvimento sustentável da sociedade, preservando recursos ambientais e culturais para gerações futuras; respeitando a diversidade e promovendo a redução das desigualdades sociais como parte integrante da estratégia da organização.

Sobre estes 12 Conceitos Fundamentais a FNQ construiu seus 8 Critérios da Excelência [47], em geral representados de forma gráfica no Modelo de Excelência da Gestão (Figura 26). 


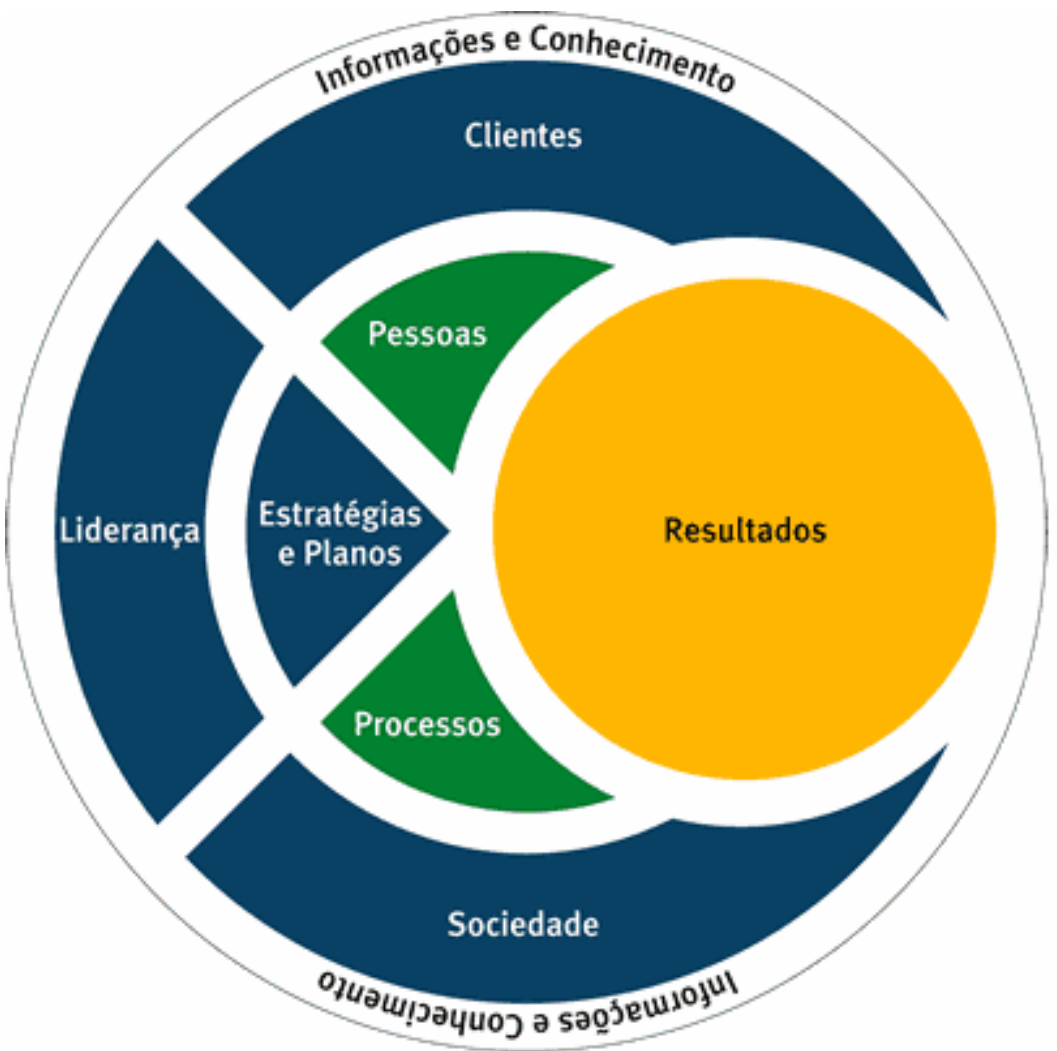

Figura 26 - Critérios de Excelência da FNQ

Os 8 Critérios da Excelência são:

- Liderança: Este critério trata do sistema de liderança da organização e do comprometimento pessoal dos membros da direção no estabelecimento, disseminação e atualização de valores e princípios organizacionais que promovam a cultura da excelência, considerando as necessidades de todas as partes interessadas. Também versa sobre como é implementada a governança, como é analisado o desempenho da organização e como são implementadas as práticas voltadas para assegurar a consolidação do aprendizado organizacional.

- Estratégias e Planos: Este critério examina, em detalhe, o processo de formulação das estratégias, enfatizando a análise do setor de atuação, do macro-ambiente e do modelo de negócio da organização. Também examina o processo de implementação das estratégias, incluindo a definição de indicadores, o desdobramento das metas e planos para as diversas áreas da organização e o acompanhamento dos ambientes internos e externos. 
- Clientes: Este critério determina como a organização identifica, analisa e compreende as necessidades e expectativas dos clientes e dos mercados; divulga seus produtos, marcas e ações de melhoria; e estreita seu relacionamento com os clientes. Além disso, aqui estão as práticas pelas quais a organização mede e intensifica a satisfação e a fidelidade dos clientes em relação a seus produtos e marcas, bem como avalia a insatisfação.

- Sociedade: Este critério define como a organização contribui para o desenvolvimento econômico, social e ambiental de forma sustentável - por meio da minimização dos impactos negativos potenciais de seus produtos e operações na sociedade - e como interage com a sociedade de forma ética e transparente.

- Informações e Conhecimento: Este critério examina a gestão e a utilização das informações da organização e das informações comparativas pertinentes, bem como a gestão dos ativos intangíveis.

- Pessoas: Este critério examina como são proporcionadas as condições necessárias para o desenvolvimento e utilização plena do potencial das pessoas que compõem a força de trabalho, em consonância com as estratégias organizacionais. Também examina os esforços para criar e manter um ambiente de trabalho e um clima organizacional que conduzam à excelência do desempenho, à plena participação e ao crescimento das pessoas.

- Processos: este critério rege como a organização gerencia os seus processos; identifica os processos de agregação de valor; e identifica, gerencia, analisa e melhora os processos principais do negócio e os processos de apoio. Também versa sobre como a organização gerencia o processo de relacionamento com os fornecedores e conduz a gestão dos processos econômico-financeiros, visando à sustentabilidade econômica do negócio.

- Resultados: Este critério examina os resultados da organização, abrangendo os aspectos econômico-financeiros e os relativos aos clientes e mercados, 
sociedade, pessoas, processos principais do negócio e de apoio, bem como os relativos ao relacionamento com fornecedores.

Como já mencionado, os 8 Critérios de Excelência se baseiam nos 12 Conceitos Fundamentais estabelecidos pela FNQ (vide código de cores da Figura 27).

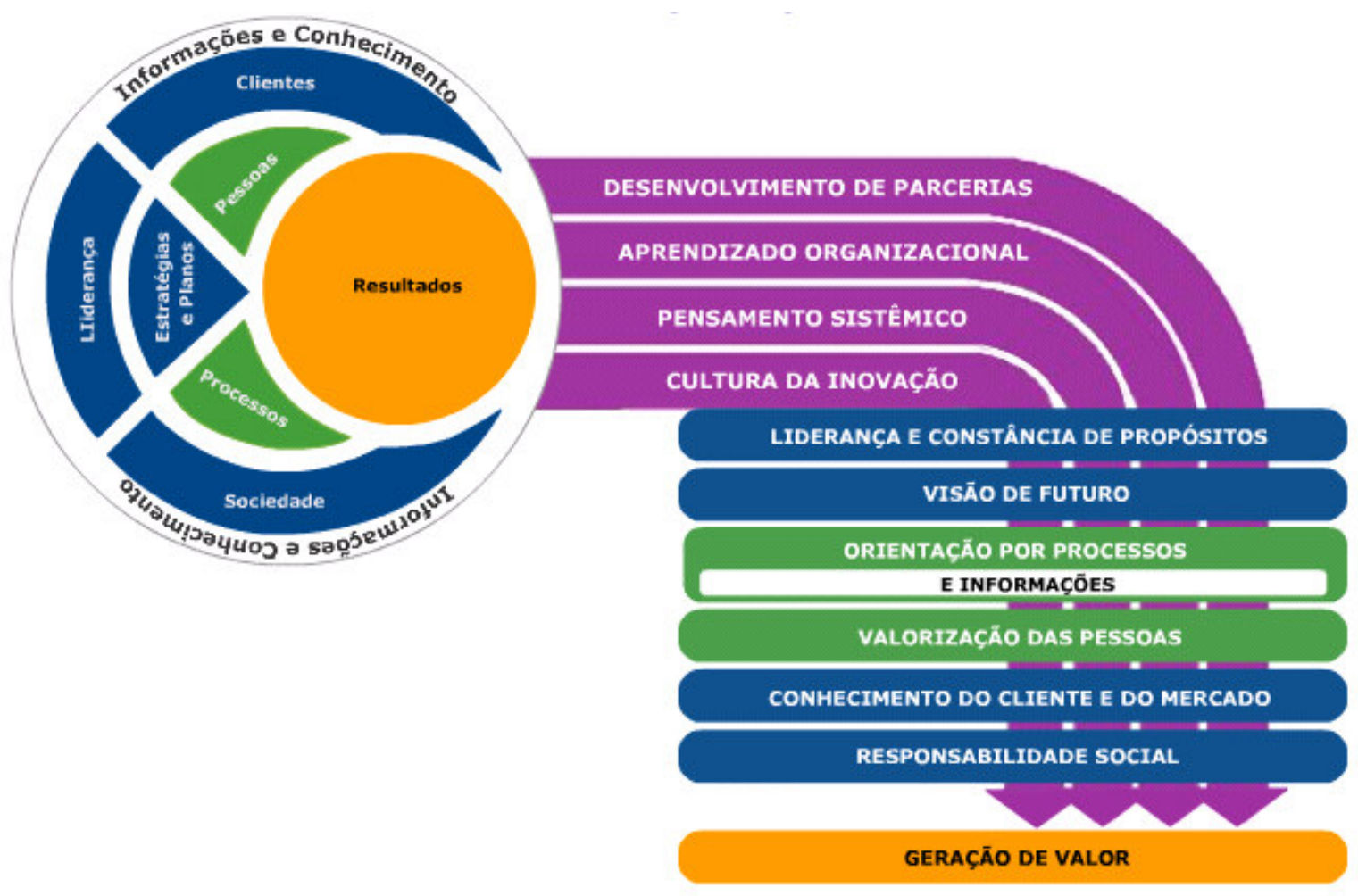

Figura 27 - Fundamentos x Critérios de Excelência da FNQ

O Modelo de Excelência da Gestão, em função de sua flexibilidade e simplicidade de linguagem e, principalmente, por ser baseado nos 8 Critérios de Excelência apresentados e não prescrever ferramentas e práticas de gestão específicas, pode ser útil para a avaliação, o diagnóstico e o desenvolvimento do sistema de gestão de qualquer tipo de organização.

\subsubsection{Melhores práticas do RUP (Rational Unified Process)}

O RUP - Rational Unified Process, ou Processo Unificado Rational, é uma metodologia desenvolvida pela empresa Rational (hoje IBM) para cobrir todo o 
ciclo de desenvolvimento de software, do levantamento inicial de requisitos aos testes e à entrega final. O RUP formaliza a idéia de que toda a equipe de Engenharia de Software, do Arquiteto de Sistemas mais conceitual ao Programador mais humilde, deve trabalhar tendo em mente os requisitos de negócio do seu cliente.

Sua relevância para este trabalho repousa no fato de que muitas das ferramentas introduzidas ou popularizadas pelo RUP se tornaram melhores práticas ou recomendações em outras atividades de Engenharia - incluindo a Engenharia ou Design de Serviços, disciplinas das quais este trabalho está muito próximo. Este é o caso, por exemplo, da adaptação da linguagem de modelagem UML (Unified Modeling Language), popularizada pelo RUP, para uso no desenvolvimento e descrição de processos de negócio numa técnica conhecida como Business Process Modeling (o uso de UML neste caso deu origem à BPML - Business Process Modeling Language) [48].

Kruchten, um dos "pais" do RUP, apresenta em [49] alguns dos problemas que o motivaram a desenvolver a metodologia:

- Entendimento impreciso dos requisitos do usuário final;

- Falta de habilidade para lidar com requisitos mutáveis;

- Construção de módulos que não se combinam em um todo maior;

- Software difícil de manter ou estender;

- Descoberta tardia de falhas graves de projeto;

- Baixa qualidade no produto entregue;

- Baixa performance do produto entregue;

- Pouca ou nenhuma rastreabilidade: equipes desorganizadas impossibilitando a reconstituição de quem fez o quê, quando, onde e porquê;

- Um ciclo de "construção-lançamento" descuidado e pouco confiável.

Estes motivadores são muito semelhantes à situação do mercado brasileiro de telecomunicações [19] - e daí a adequação do RUP ao problema aqui tratado. Além disso, o fato do RUP ser um modelo de processos aberto a modificações 
pelos seus usuários o torna ideal para adaptação em contextos como o desenvolvimento de serviços de telecomunicações.

\subsubsection{Visão Geral}

O RUP foi desenvolvido em torno de um conjunto de "Princípios Chave para Desenvolvimento Orientado a Negócios”. São eles [50]:

- Adaptar o Processo: este princípio ressalta a adaptabilidade do RUP, dizendo explicitamente que é "crítico dimensionar o processo de desenvolvimento para as necessidades do projeto". A idéia é definir o formalismo, a precisão da documentação, a rigidez do controle e outros fatores presentes no projeto de acordo com o seu contexto (conceito que engloba uma variedade de fatores, incluindo o tamanho e a distribuição de equipes, a quantidade de restrições externamente impostas e a fase na qual o projeto se encontra). As recomendações específicas do RUP para este princípio são:

"1. Dimensionar corretamente o processo para as necessidades do projeto incluindo:

- o tamanho e a distribuição da equipe do projeto,

- a complexidade do aplicativo,

- a necessidade para conformidade.

2. Adaptar a cerimônia do processo para fase de ciclo de vida

3. Aprimorar o processo continuamente

4. Equilibrar planos e estimativas com o nível de incertezas"

- Prioridades do Investidor na Competição do Saldo: Este princípio formaliza a importância da solução de compromisso, isto é, a necessidade de lidar com os negócios e necessidades conflitantes investidores do projeto, bem como equilibrar a quantidade de desenvolvimento customizado e a reutilização de recursos na satisfação dessas necessidades. As recomendações específicas do RUP para este princípio são: 
"1. Definir, compreender e priorizar os negócios e as necessidades do usuário

2. Priorizar os projetos e os requisitos e unir as necessidades com as capacidades do software

3. Compreender quais recursos podemos alavancar

4. Equilibrar a reutilização dos recursos com as necessidades do usuário"

- Trabalhar em conjunto com equipes: este princípio ressalta tanto a necessidade de desenvolver uma equipe de trabalho coesa quanto a importância de fomentar uma comunicação ideal ampla no projeto. No RUP, os fatores críticos de sucesso para isso são a organização adequada da equipe e, principalmente, a criação de ambientes de colaboração; na verdade, o tema "ambiente colaborativo" está intimamente ligado à essência do RUP e permeia todas as suas etapas. As recomendações específicas do RUP para este princípio são:

"1. Motivar pessoas a realizarem seu melhor

2. Criar equipes auto-gerenciadas

3. Encorajar colaboração funcional (ex. entre analistas, desenvolvedores, testadores)

4. Proporcionar ambientes de colaboração efetiva

5. Gerenciar artefatos em desenvolvimento e tarefas para melhorar a colaboração e a percepção de qualidade do progresso com ambientes integrados

6. Integrar negócios, software e equipes de operação"

- Demonstrar o Valor Iterativamente: esse princípio está ligado a um dos pilares de toda a metodologia - a idéia de que o desenvolvimento de software é muito melhor quando segue um processo repetitivo. Um processo repetitivo torna possível acomodar facilmente as alterações, obter feedback mais rapidamente e reduzir os riscos do projeto, ao minimizar a incerteza através de constantes realinhamentos de expectativas. As recomendações específicas do RUP para este princípio são:

"1. Ativar o feedback fornecendo um valor incremental do usuário em cada iteração

2. Adaptar seus planos utilizando um processo repetitivo 


\section{Adotar e gerenciar alterações}

4. Atacar inicialmente os principais riscos técnicos, comerciais e programáticos"

- Elevar o Nível de Abstração: este princípio busca reduzir a complexidade do projeto adotando uma abordagem top-down - inicia-se a modelagem com uma visão de alto nível e refina-se este modelo até o nível de detalhe necessário. Um efeito colateral desta prática é a redução da quantidade de documentação necessária ao projeto, obtida através de reutilização de componentes, uso de ferramentas de modelagem de alto nível e estabilização da arquitetura inicial. As recomendações específicas do RUP para este princípio são:

"1. Reutilizar ativos existentes

2. Utilizar ferramentas de nível mais alto e linguagens para reduzir a quantidade de documentação produzida

3. Focalizar primeiro a arquitetura

4. Arquitetar para obter controles da elasticidade, qualidade, instabilidade e complexidade."

- Focalizar Continuamente na Qualidade: Esse princípio enfatiza que, para obter qualidade é preciso acompanhar atividades por todo o ciclo de vida do processo. Um processo repetitivo só é adaptado para obter qualidade quando oferece muitas oportunidades de medida e correção. As recomendações específicas do RUP para este princípio são:

"1. Assegurar direito à propriedade, para a equipe, sobre a qualidade do produto

2. Testar antecipadamente e continuamente na etapa com integração de capacidades demonstráveis

3. Construir incrementalmente a automação do teste"

Sobre estes 6 princípios chave construiu-se um processo completo de desenvolvimento de sofware que pode ser aplicado a outras áreas da Engenharia. Este processo descreve um projeto como composto de 4 grandes fases:

- Iniciação 
- Elaboração

- Construção

- Transição

Durante estas 4 etapas seqüenciais, devem ser gerenciadas iterativamente 9 disciplinas:

- Modelagem de negócios

- Requisitos

- Análise e Design

- Implementação

- Teste

- Implantação

- Gerenciamento de Configuração e Mudanças

- Gerenciamento de Projetos

- Ambiente

A intensidade de trabalho em cada uma destas disciplinas varia de acordo com a fase em que o projeto se encontra: por exemplo, a atividade de Modelagem de Negócios é muito mais intensa no início do projeto do que a atividade de Implantação, que por sua vez é muito mais ativa nas fases finais do projeto. Este entendimento é representado na Figura 28, retirada de [50]. 


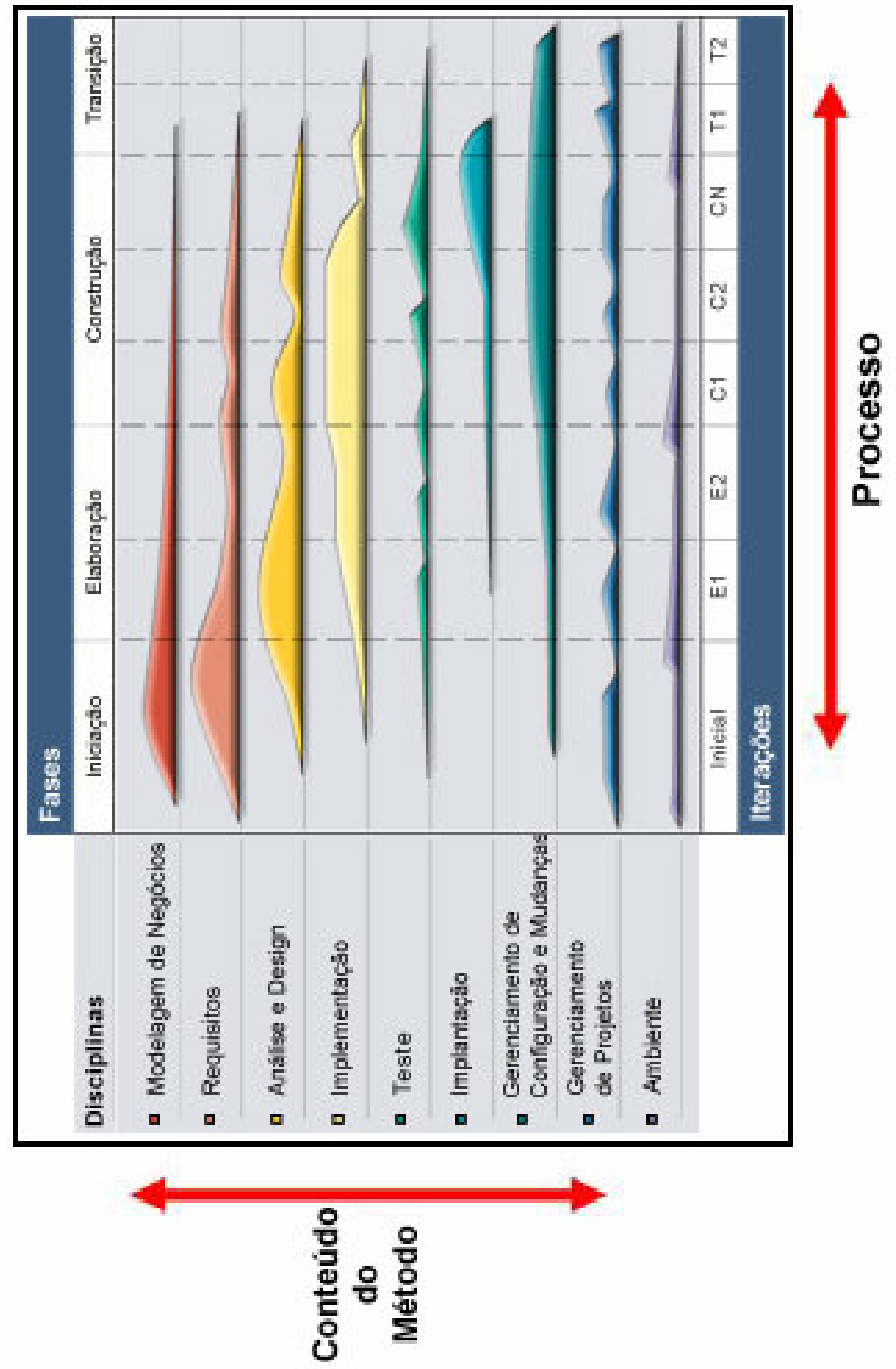

Figura 28 - Disciplinas e Fases do RUP 


\subsubsection{Práticas interessantes para o desenvolvimento de Serviços de Telecomunicações}

Para uso em serviços de Telecomunicações, identificam-se duas práticas do RUP especialmente interessantes: a iteratividade e a Gestão de Implantação.

\subsection{Iteratividade}

Todo o modelo RUP foi concebido a partir de uma idéia central: a iteratividade [49]. Conceitualmente, trata-se de substituir a visão tradicional de Desenvolvimento de Sistemas (seqüencial, ou "em cascata" - Figura 29) por um processo iterativo (Figura 30), alinhado com os preceitos de Melhoria Contínua presentes nas demais metodologias estudadas neste trabalho.

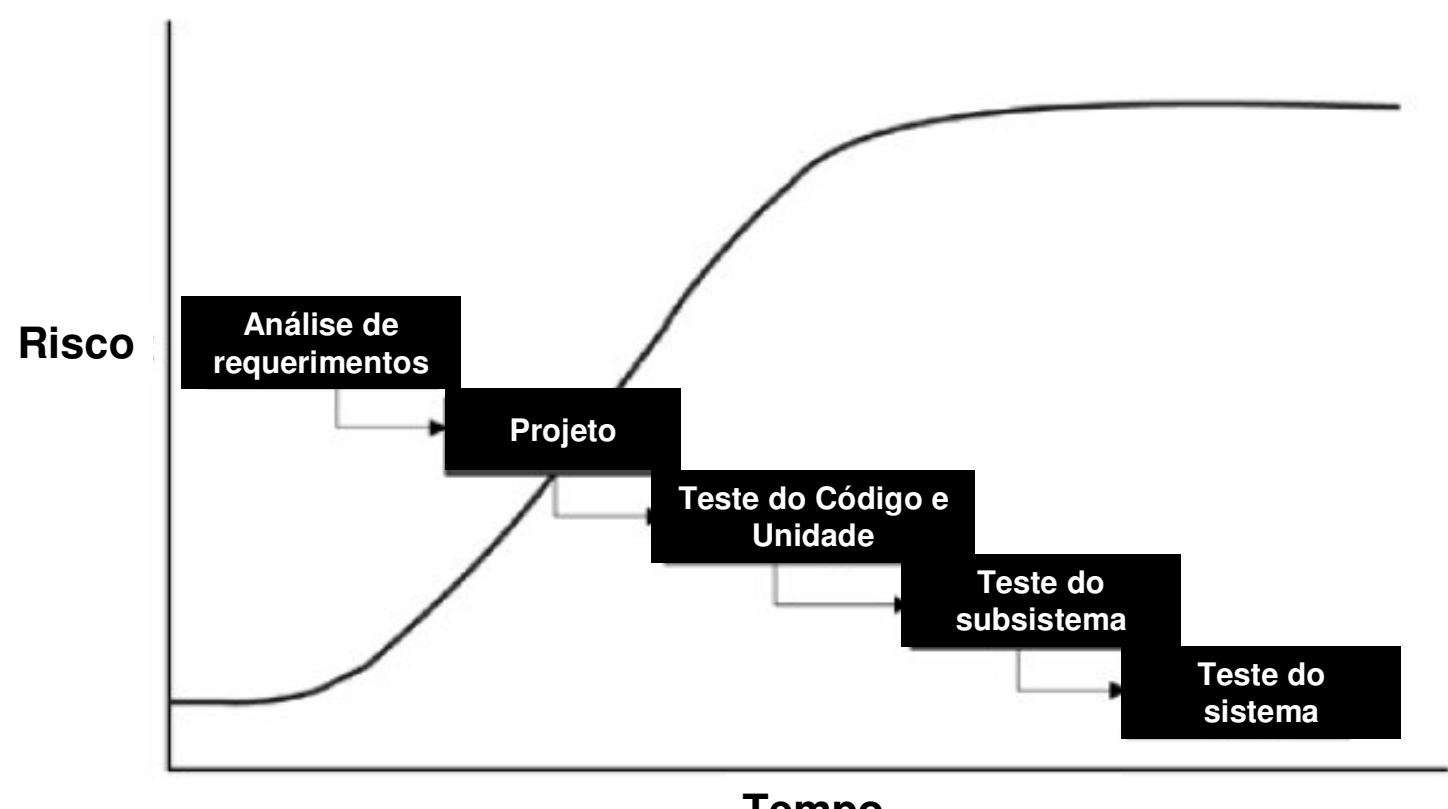

Tempo

Figura 29 - Processo de Desenvolvimento "em cascata" 


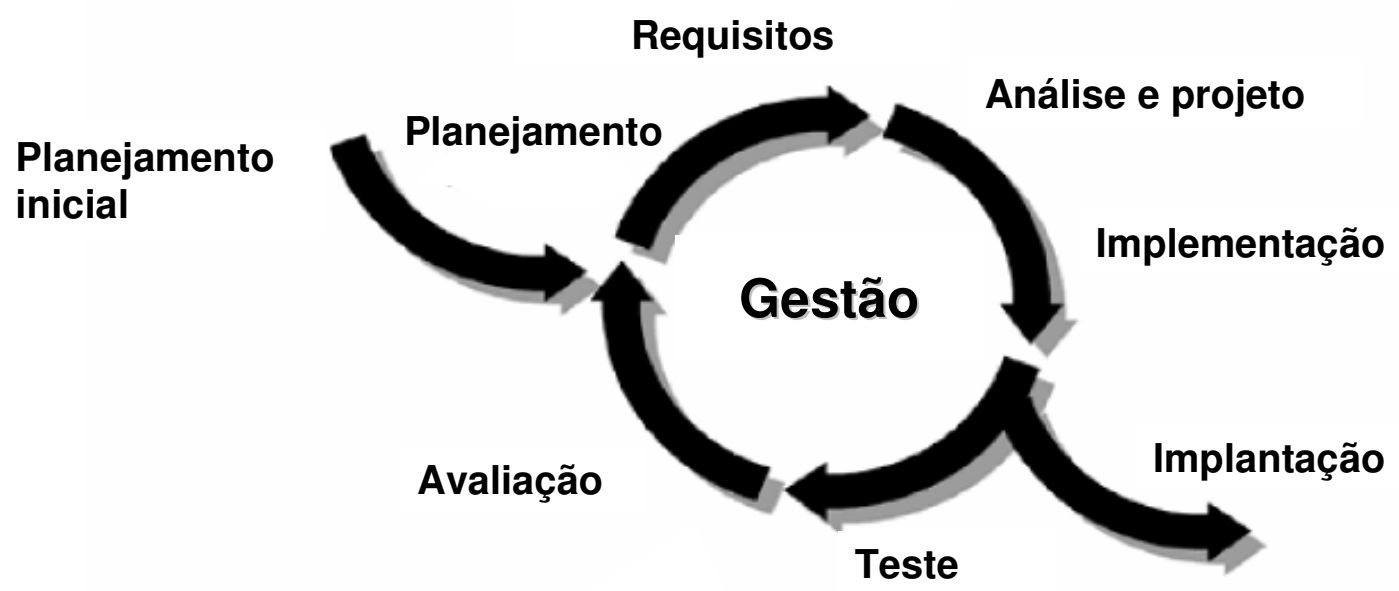

Figura 30 - Processo de Desenvolvimento iterativo

O valor que os stakeholders identificados tiram deste modelo iterativo é a oportunidade de refinamento contínuo do entendimento das necessidades do consumidor - e obter este entendimento é o objetivo da metodologia que está sendo construída aqui.

\subsection{Gestão de Implantação}

Uma das necessidades identificadas diz respeito à transição do serviço do ambiente de Desenvolvimento (responsabilidade do Desenvolvedor de Serviços) para o ambiente de Produção (responsabilidade do Provedor de Serviços). Na experiência do autor, esta transição costuma ser bastante traumática por ser baseada em processos totalmente desestruturados (ou inexistentes).

O RUP possui uma disciplina inteira dedicada à Implantação (Figura 28), da qual faz parte essa transição. A adoção do processo de Gestão de Implantação do RUP, representado na Figura 31, seria um grande avanço no relacionamento Desenvolvedor - Provedor de Serviços de telecomunicações. 


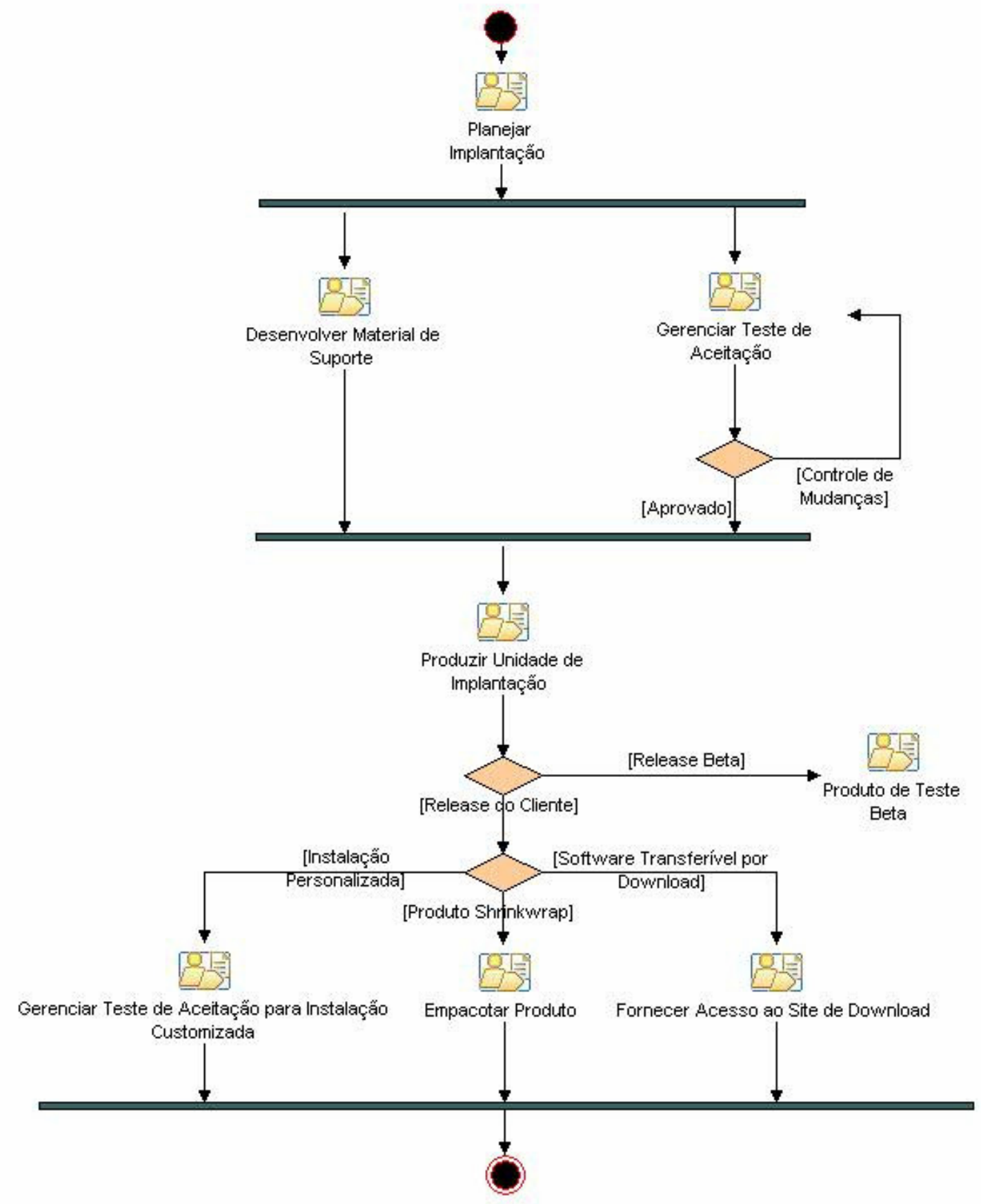

Figura 31 - Processo RUP de Gestão da Implantação 


\subsection{Outras ferramentas}

A seguir encontra-se uma breve discussão a respeito de outras ferramentas que, embora identificadas na pesquisa e relacionadas ao tema deste trabalho, não foram consideradas relevantes, interessantes ou adequadas para serem incluídas no mapeamento.

\subsubsection{ISO 9000}

A norma ISO 9000 [12] (Sistemas de gestão da qualidade - Fundamentos e vocabulário) foi responsável pela disseminação da cultura e das práticas de gestão da qualidade no Brasil.

Seu caráter eminentemente normativo e seu foco na auditoria e certificação de organizações a tornam pouco interessante para este trabalho. Ademais, os princípios defendidos pela ISO 9000 encontram-se amplamente representados pelas disciplinas de TQM e Lean Thinking (seção 4.1 ).

\subsubsection{ITIL}

Desenvolvido inicialmente pelo governo Britânico e hoje mantido pelo ITSMF (IT Service Management Forum [51]), o ITIL (IT Infrastructure Library) é um conjunto de melhores práticas para o gerenciamento da prestação de serviços em Tecnologia da Informação, composto por um conjunto de processos (Figura 32) que incorporam melhores práticas e pela especificação das relações, ou fluxos, entre esses processos.

A missão do ITIL é guiar a concepção e melhoria de processos e fluxos de processos de gerenciamento da prestação de serviços em Tecnologia da Informação, trazendo diversos benefícios para as organizações que o adotam:

- Melhoria dos serviços devido ao uso de melhores práticas comprovadas 
- Melhoria na satisfação dos clientes mediante o uso de uma abordagem mais profissional para a prestação de serviços

- Melhoria na produtividade

- Melhor uso das competências de capacidades da equipe

- Melhorias na contratação de serviços externos, mediante a utilização da norma BS15000 como requisito para o prestador de serviço (por sua maturidade, o ITIL deu origem à norma técnica BS15000). 


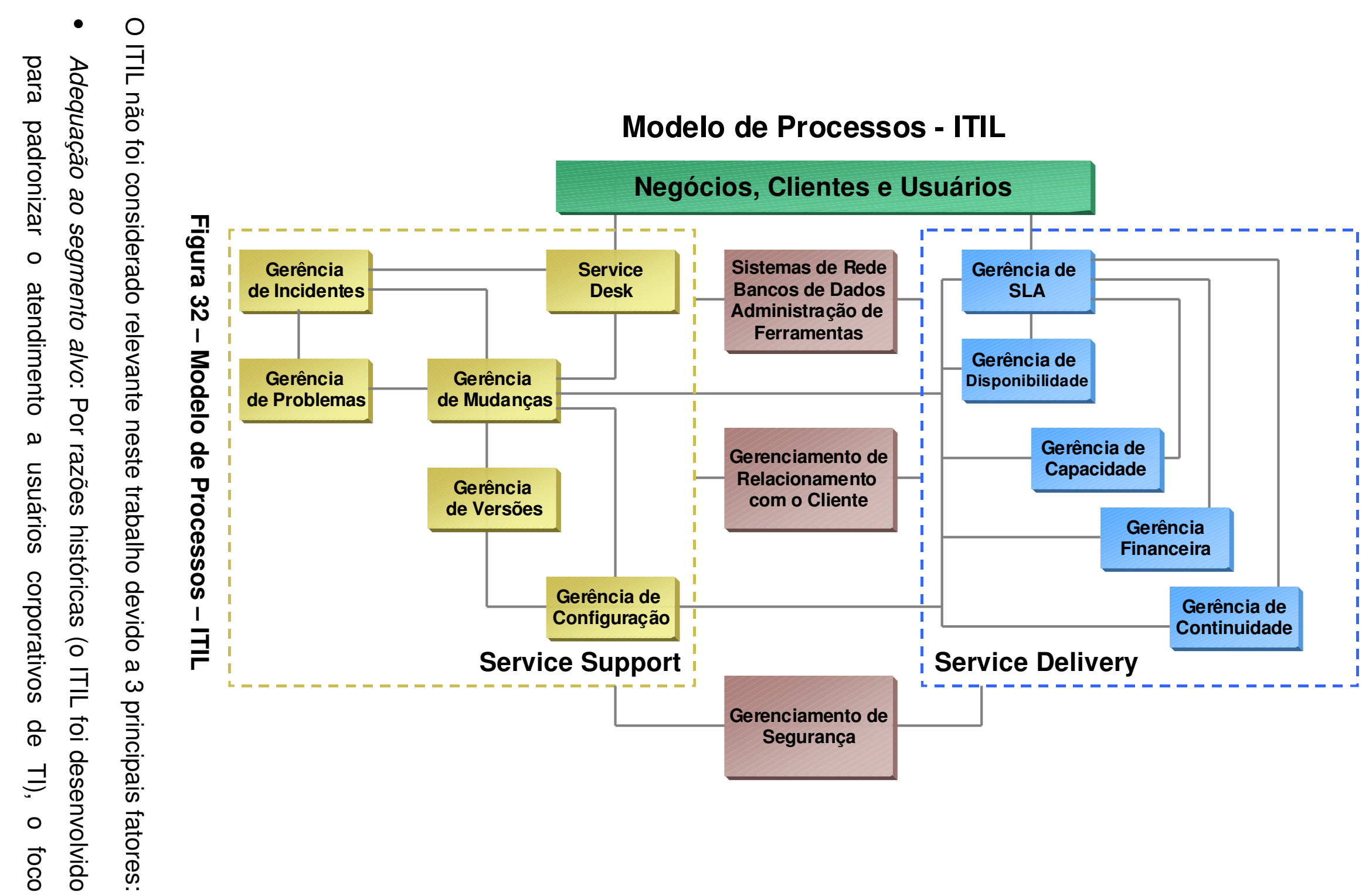


principal das melhores práticas é no gerenciamento de serviços de TI e não na prestação de serviços de Telecom;

- Sobreposição com eTOM: Os processos de Operações do eTOM (enumerados na Figura 42 da seção 5.1.2.3.3.1, mais adiante) possuem uma sobreposição considerável com o ITIL - recentemente, o TMForum incorporou ao eTOM [11] um anexo que traz um mapeamento desta sobreposição. Apesar desta possibilidade de uso conjunto, entendeu-se que o eTOM é suficiente para a necessidade deste trabalho por um modelo de processos;

- Enfoque: Este trabalho se preocupa em incorporar a perspectiva do consumidor aos processos do Desenvolvedor e do Prestador de serviços, enquanto o ITIL foi desenvolvido sob a ótica do gestor dos processos de TI de uma organização.

\subsubsection{COBIT}

O COBIT (Control Objectives for Information and related Technology) é um conjunto de melhores práticas criado pela ISACA (Information Systems Audit and Control Association) [52] e pelo ITGI (IT Governance Institute) [53] em 1992. O COBIT fornece a gestores, auditores e usuários de TI um conjunto de métricas, indicadores e processos para auxiliá-los a maximizar o desempenho de seus processos de gestão de TI e desenvolver uma prática de controle e governança de TI alinhada com padrões e legislações mundiais.

O COBIT divide a Governança de TI em 5 grandes áreas [54]:

- Strategy Alignment busca garantir a coerência entre o planejamento estratégico de TI e do negócio, manter e validar a proposição de valor de TI e alinhar as operações de TI com as operações do negócio principal.

- Value delivery cuida de executar a proposição de valor durante todo o ciclo de entrega, garantindo que $\mathrm{TI}$ (pessoas, processos e tecnologia) realmente entregue os benefícios prometidos. 
- Resource management busca otimizar os investimentos e a gestão dos recursos críticos de TI: processos, pessoas, aplicações, infra-estrutura e informação. Assuntos chave nesta área são a gestão do conhecimento e a otimização da infra-estrutura tecnológica.

- Risk management requer a conscientização dos altos executivos da organização a respeito do risco, um entendimento claro da tolerância ao risco da organização, transparência sobre os riscos reais que a organização corre e a disseminação da responsabilidade pela gestão do risco em toda a organização.

- Performance measurement monitora a implementação das estratégias, o andamento dos projetos, a utilização de recursos, o desempenho de processos e a entrega de serviços. A ferramenta mais utilizada por esta área é o balance scorecard, que concentra os indicadores mais relevantes sobre um determinado processo.

Para controlar essas 5 áreas e obter uma visão integrada de toda a Governança de TI, o COBIT propõe um conjunto de 34 objetivos, divididos em 4 grandes áreas:

- Planejamento e Organização

- Aquisição e implementação

- Entrega e suporte

- Monitoramento

Para uma introdução aos 34 objetivos, ver [55].

O foco do COBIT em definir indicadores para os processos de gestão de TI é certamente interessante e importante para o desempenho de uma organização, mas foge ao escopo deste trabalho. Além disso, o COBIT foi desenvolvido para que os executivos da organização tenham uma visão integrada do desempenho de seus processos - o cliente final aparece apenas como um "usuário" em um dos objetivos da área de Entrega e suporte [55]. 
Assim, optou-se por deixar o COBIT de fora do mapeamento de ferramentas apresentado no capítulo 6. No entanto, adicionar ao COBIT uma dimensão focada no consumidor com um conjunto de objetivos focados em atender aos seus requisitos seria um interessante trabalho futuro.

\subsubsection{PMBoK}

Desenvolvido pelo Project Management Institute (PMI) [56], o PMBoK (Project Management Body of Knowledge) é um conjunto de melhores práticas na disciplina de Gerenciamento de Projetos. Sua perspectiva é a do Gerente de Projetos (de fato, foi o PMI que popularizou a figura do Gerente de Projetos através dos seus textos e do deu programa de certificação), ou seja, as práticas contidas no PMBoK são aplicadas pelos responsáveis pelo sucesso de um projeto.

O PMBoK foi dividido em 9 áreas de conhecimento (Figura 33):

- Gerenciamento de Custos - inclui as atividades:

- Planejamento de recursos

- Estimativa de custos

- Elaboração, acompanhamento e controle do orçamento

- Elaboração, acompanhamento e controle do fluxo de caixa

- Análises de Earned Value, Cost Project Index e Cost Variance

- Gerenciamento de Escopo - inclui as atividades:

- Planejamento do escopo

- Definição do escopo

○ Verificação do escopo implantado

○ Gestão dos desvios de escopo

- Controle do escopo dos fornecimentos

- Gerenciamento de Prazo - inclui as atividades: 
- Elaboração dos cronogramas

- Análise da programação de terceiros

- Identificação e acompanhamento dos prazos e eventos críticos

- Elaboração e acompanhamento da curva de progresso

- Análise de desvios, tendências, Earned Value, Schedule Project Index e Schedule Variance

- Gerenciamento de Qualidade - inclui as atividades:

- Elaboração do plano da qualidade

- Acompanhamento e controle da qualidade

- Diagnóstico, proposição e acompanhamento de medidas preventivas e corretivas

- Gerenciamento de Recursos Humanos - inclui as atividades:

- Dimensionamento dos recursos humanos

○ Mobilização

- Desenvolvimento e capacitação

- Gerenciamento de Comunicações - inclui as atividades:

- Estruturação e gestão dos processos de coleta, tratamento e síntese de informações

- Gestão de base de dados

- Condução dos processos de divulgação de informações

- Gerenciamento de Risco - inclui as atividades:

- Identificação dos eventos de risco

- Quantificação dos eventos de risco

○ Elaboração de planos de contingências

- Acompanhamento e controle da evolução dos fatores de risco

- Gerenciamento de Suprimento - inclui as atividades:

- Planejamento de compras 
- Seleção de fornecedores

- Administração de contratos

- Diligenciamento das informações relativas ao suprimento

- Encerramento de contratos

- Gerenciamento de Integração - inclui as atividades:

- Elaboração do plano do projeto

- Articulação dos processos gerenciais

- Implementação e controle do plano do projeto

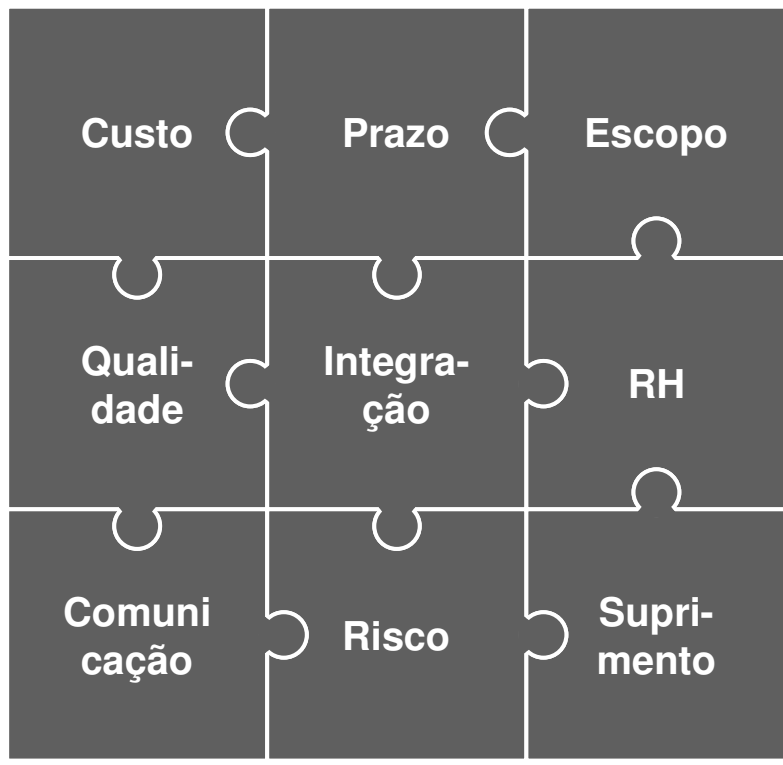

Figura 33 - Áreas de conhecimento do PMBoK

O PMBoK apresenta melhores práticas que trazem benefícios para qualquer entidade que as aplique - empresas, organizações não governamentais, até mesmo pessoas físicas. No entanto, neste trabalho considerou-se que o Gerenciamento de Projetos já faz parte das atribuições tanto de Desenvolvedores quanto de Provedores de Serviço, ou seja, entende-se que gerenciar bem os seus recursos e atividades é uma obrigação básica de ambos. Por esta razão deixou-se o PMBoK de fora do mapeamento do capítulo 6 , privilegiando-se as ferramentas que enfocam o atendimento dos requisitos do consumidor. 


\subsection{Sumário}

As seções anteriores apresentaram as 5 disciplinas selecionadas como mais relevantes, bem como as ferramentas que podem atender às necessidades identificadas no Capítulo 3. Em resumo, as ferramentas selecionadas foram (Tabela 6):

Tabela 6 - Ferramentas selecionadas

\begin{tabular}{|c|c|}
\hline Disciplina & Ferramentas selecionadas \\
\hline $\begin{array}{l}\text { Lean Thinking e Total Quality } \\
\text { Management }\end{array}$ & $\begin{array}{l}\text { - Kansei Engineering } \\
\text { - Kaizen } \\
\text { - } \text { PDCA } \\
\text { - Seis Sigma } \\
\text { - } \text { DMAIC }\end{array}$ \\
\hline $\begin{array}{l}\text { Progama NGOSS (New Generation } \\
\text { OSS) }\end{array}$ & $\begin{array}{l}\text { - NGOSS Implementation Model } \\
\text { - SANRR }\end{array}$ \\
\hline $\begin{array}{l}\text { Metodologia QFD (Quality Function } \\
\text { Design) }\end{array}$ & $\begin{array}{l}\text { - } \text { VOC (Voice Of Customer) } \\
\text { - House of Quality } \\
\text { - Visitas Gemba } \\
\text { - Maximum Value Table }\end{array}$ \\
\hline $\begin{array}{l}\text { Práticas de Gestão da FNQ } \\
\text { (Fundação Nacional da Qualidade) }\end{array}$ & - Diagrama da Gestão \\
\hline $\begin{array}{l}\text { Melhores práticas do RUP (Rational } \\
\text { Unified Process) }\end{array}$ & - Todo o Processo Unificado \\
\hline
\end{tabular}


O resultado do cruzamento das ferramentas listadas com as necessidades das partes interessadas encontra-se na Tabela 7, construída seguindo o mesmo código de cores utilizado na Figura 10. As técnicas identificadas encontram-se descritas em maiores detalhes logo a seguir.

Tabela 7 - Ferramentas identificadas para cada relacionamento entre as partes interessadas

\begin{tabular}{|c|c|c|}
\hline Parte & Necessidades & Ferramentas identificadas \\
\hline \multirow{3}{*}{ 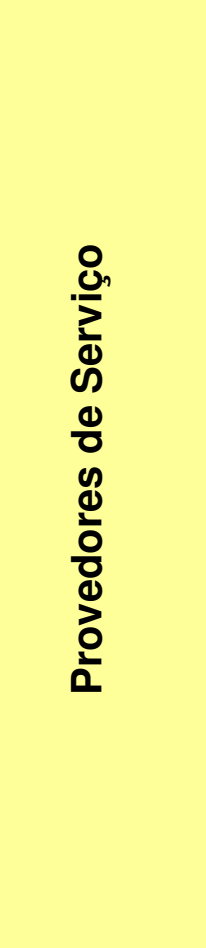 } & $\begin{array}{l}\text { Ferramentas de captura de } \\
\text { feedback }\end{array}$ & $\begin{array}{l}\text { - Kansei (TQM) } \\
\text { - } \operatorname{VOC~(Voice~Of~Customer)~} \\
\text { - House of Quality (QFD) }\end{array}$ \\
\hline & $\begin{array}{l}\text { Ferramentas de garantia de } \\
\text { ótima entrega }\end{array}$ & - Seis Sigma \\
\hline & $\begin{array}{l}\text { Ferramentas de otimização } \\
\text { de processos }\end{array}$ & $\begin{array}{l}\text { - } \text { DMAIC (Seis Sigma) } \\
\text { - } \text { PDCA } \\
\text { - } \text { Diagrama da Gestão (FNQ) } \\
\text { - } \text { SANRR (NGOSS) } \\
\text { - } \text { Kaizen (TQM) }\end{array}$ \\
\hline \multirow{2}{*}{ 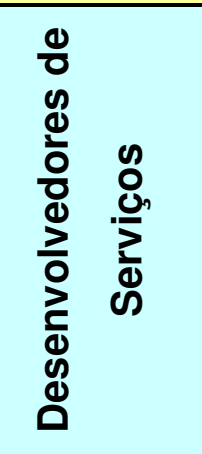 } & $\begin{array}{l}\text { Ferramentas de captura das } \\
\text { necessidades do } \\
\text { Consumidor }\end{array}$ & $\begin{array}{l}\text { - Visitas Gemba } \\
\text { - VOC (Voice Of Customer) }\end{array}$ \\
\hline & $\begin{array}{l}\text { Ferramentas de conversão } \\
\text { de Necessidades para } \\
\text { Requisitos }\end{array}$ & $\begin{array}{l}\text { - } \text { Maximum Value Table (QFD) } \\
\text { - House of Quality (QFD) }\end{array}$ \\
\hline 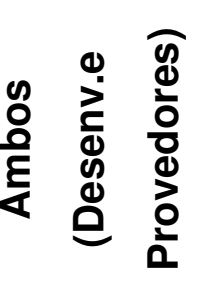 & $\begin{array}{l}\text { Ferramentas de transição de } \\
\text { ambiente de } \\
\text { Desenvolvimento para } \\
\text { ambiente de Produção }\end{array}$ & $\begin{array}{l}\text { - RUP (Rational Unified } \\
\text { Process) } \\
\text { - NGOSS Implementation } \\
\text { Model }\end{array}$ \\
\hline
\end{tabular}




\section{MODELO DE PROCESSOS E A CADEIA DE PRESTAÇÃO DE SERVIÇOS DE TELECOMUNICAÇÕES}

O objetivo deste capítulo é apresentar o framework de trabalho selecionado como a base para o mapeamento das ferramentas identificadas no Capítulo 4. Esta seleção se mostrará de grande importância para o resultado do trabalho, pois esse framework é o substrato onde será construído o mapa final de ferramentas.

\subsection{Modelos de Processos}

$\mathrm{Na}$ busca por modelos que representem os processos de negócio e operação de todas as partes interessadas em um serviço de telecomunicações, invariavelmente o pesquisador irá chegar ao trabalho do TeleManagement Forum (TMForum).

Considerada a mais madura e abrangente, a visão do TMForum sobre o que é a prestação de serviços de telecomunicações permeia a literatura (e também este trabalho).

Assim, este capítulo se foca em apresentar, analisar e adaptar o material desenvolvido pelo TMForum às necessidades do presente trabalho.

\subsubsection{O TeleManagement Forum}

Com quase 20 anos de existência, o TeleManagement Forum [18] oferece liderança centralizada, visão estratégica e soluções práticas para evoluir a gestão e operação de serviços de informação e comunicação (Figura 34). 
O TMForum foi fundado em 1988 como o OSI/Network Management Forum, com o objetivo de acelerar a compatibilidade e interoperabilidade dos produtos de gerenciamento de redes sendo lançados. Entre seus membros fundadores encontram-se os provedores de serviços AT\&T e British Telecom e os fornecedores Northern Telecom (hoje Nortel) e Hewlett-Packard.

Em 1989 o Forum aprovou sua primeira especificação, o OSI/NM Forum Protocol Specification; em 1990, a entidade já tinha crescido bastante - 85 membros de 13 países. Hoje o TMForum conta com mais de 500 membros, entre provedores de serviços, desenvolvedores de software, fabricantes de hardware e usuários finais, incluindo aí empresas e entidades brasileiras. 


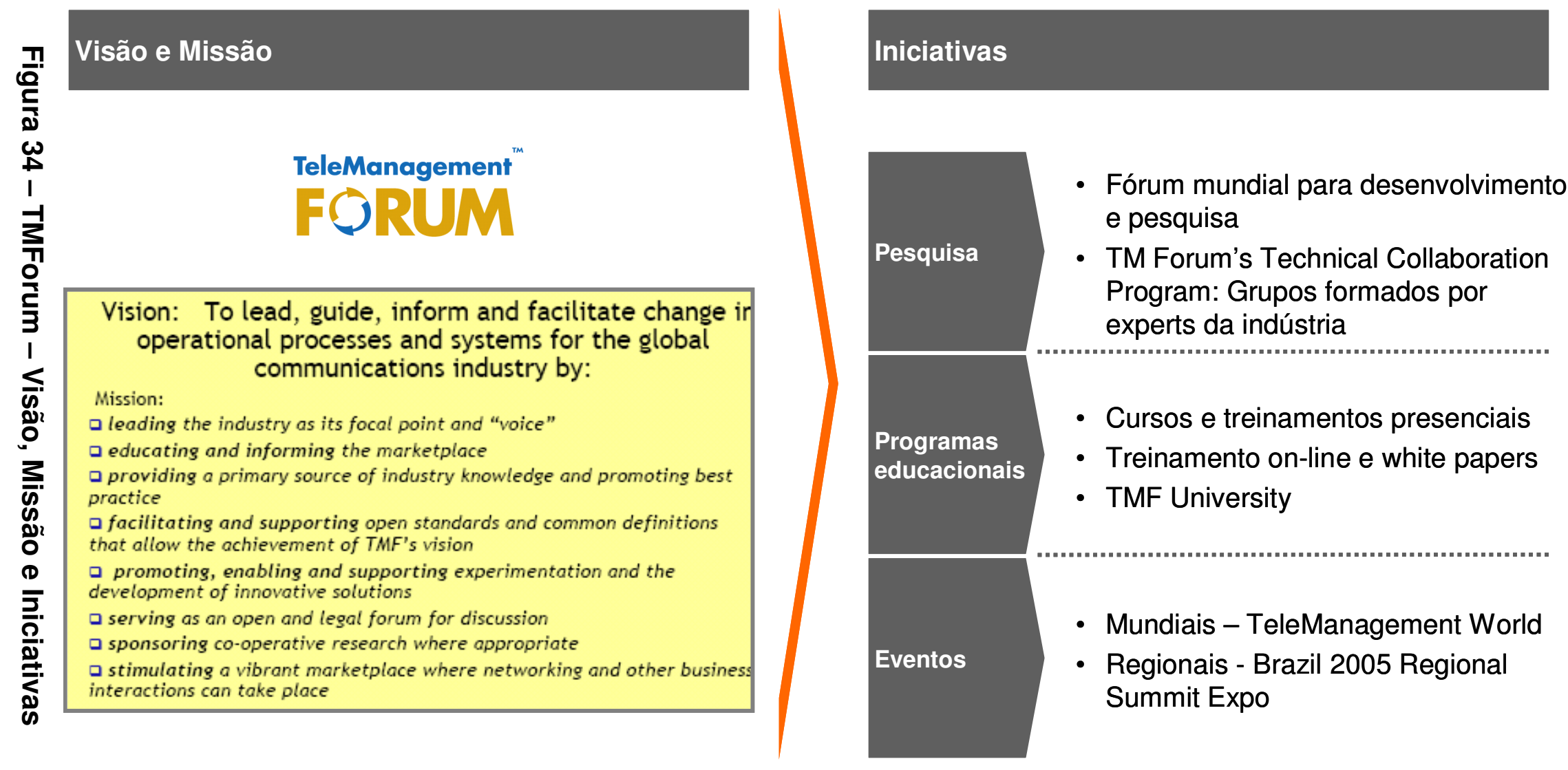




\subsubsection{Evolução dos modelos de processos em Telecomunicações}

A Figura 35 sumariza os modelos que serão apresentados nas seções a seguir. Estes 3 modelos, apresentados num grau crescente de complexidade e abrangência, representam a evolução da visão do que significa gerenciar serviços de telecomunicações, tendo sido inicialmente desenvolvidos para uso pelos Provedores de Serviço. Com sua evolução, passaram a ter como públicoalvo todas as partes interessadas, incluindo os Desenvolvedores de Serviço e os Consumidores.
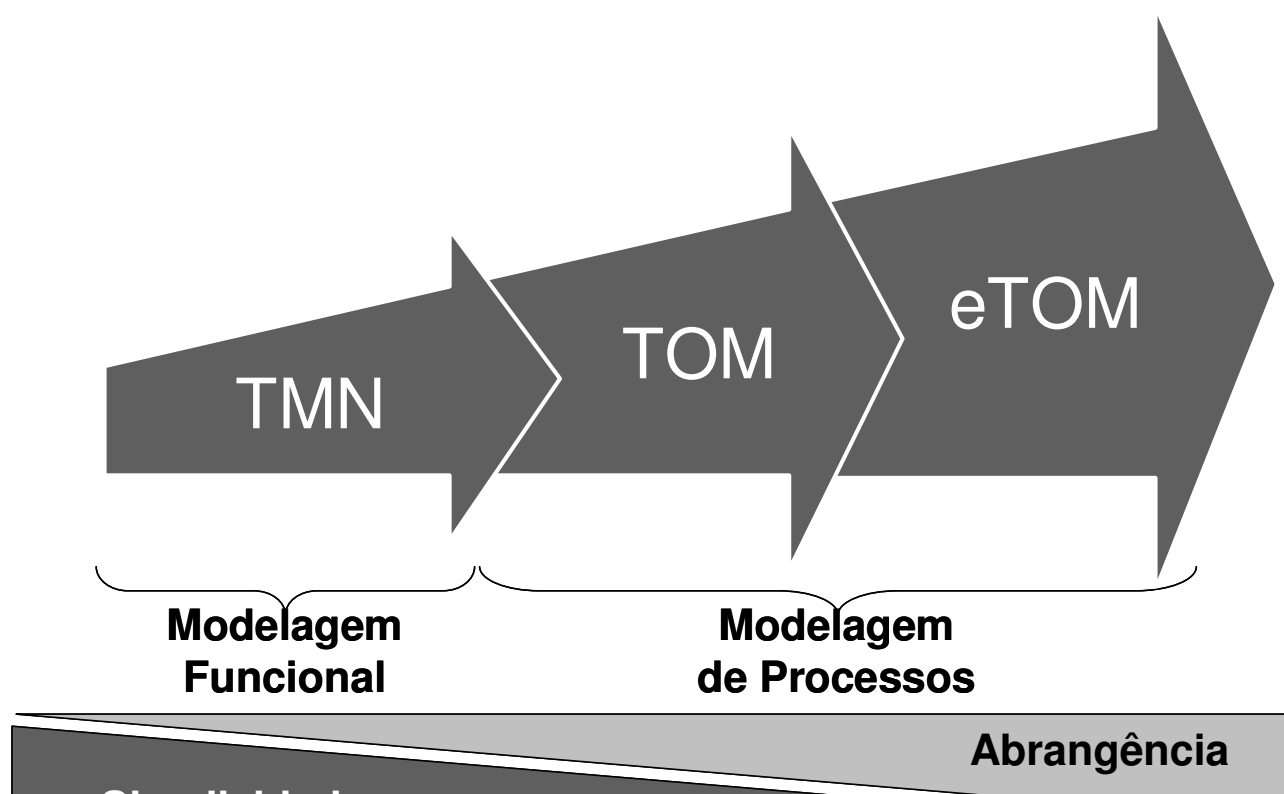

Simplicidade

Figura 35 - Evolução dos modelos de processos de gestão de serviços de telecomunicações

\subsubsection{A Pirâmide TMN}

O primeiro modelo apresentado é a Pirâmide TMN (Figura 36), modelo em camadas desenvolvido pelo ITU-T como parte do seu conjunto de normas de gerenciamento de redes [8][57][58] e considerado como "o modelo OSI da gestão de telecomunicações". Similarmente ao modelo OSI (para uma introdução ao OSI, ver [59]), cada camada da Pirâmide depende apenas da 
camada imediatamente inferior e oferece "primitivas" ou "serviços" apenas à camada imediatamente superior.

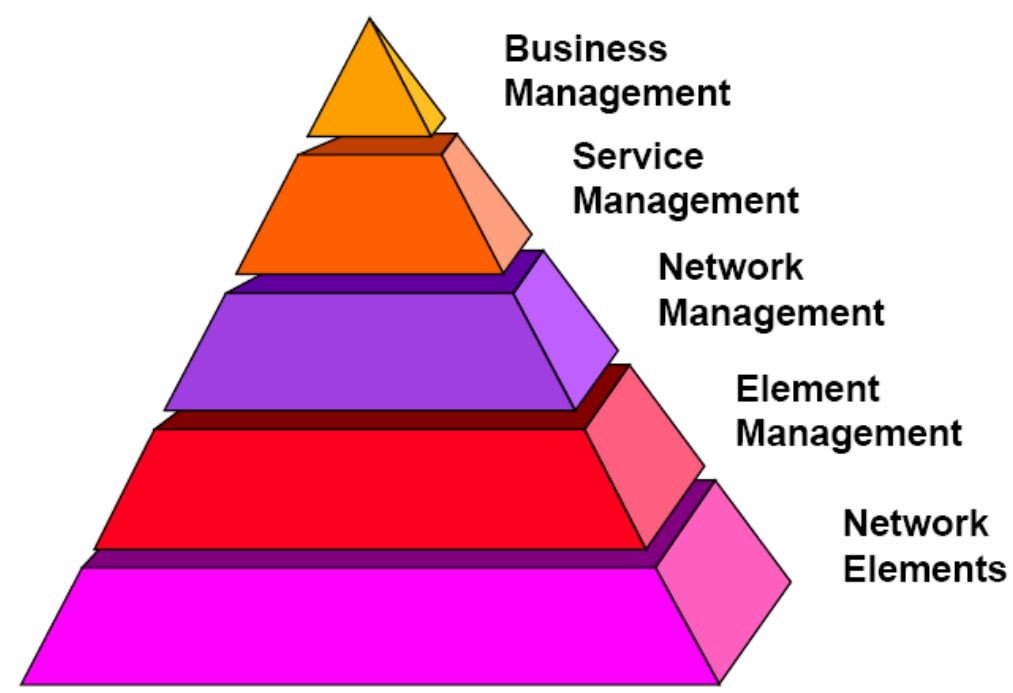

Figura 36 - Pirâmide TMN

A Pirâmide TMN ainda não pode ser considerada um "modelo de processos"; trata-se, antes, de uma tentativa de dividir um serviço de telecomunicações em camadas estanques que possam ser tratadas de maneira independente, mas mantendo consistentes as interfaces entre camadas.

As 5 camadas definidas pela Pirâmide TMN (percorridas de baixo para cima na Figura 36) são:

- Network Elements - Elementos de Rede

- Rede física da operadora, sendo constituída por cada equipamento que dela faz parte (roteadores, switches, multiplexadore, servidores etc.). O TMN se refere aos elementos de rede como recursos

- Element Management-Gerência de Elementos

- Representa o conjunto de funcionalidades necessárias para operar um único equipamento

- Ferramentas: inclui as soluções proprietárias que acompanham cada equipamento, bem como soluções baseadas em padrões abertos que permitem gerenciar equipamentos individualmente (caso das soluções baseadas no protocolo SNMP) 
- Processos: atividades de configuração básica de cada equipamento: ativação e desativação de portas, configuração de rotas e circuitos virtuais e configuração de endereçamento etc.

- Network Management - Gerência de Rede

- Função: controlar o conjunto de elementos que tomam parte em uma conexão fim-a-fim

- Ferramentas: extensão das utilizadas na Gerência de Elementos, oferecendo uma visão da rede completa. Presente nesta camada encontra-se o Inventário de Redes

- Processos: medição da performance da rede, a configuração fim-a-fim de rotas e circuitos virtuais, a definição e otimização das políticas de endereçamento e roteamento etc.

- Service Management-Gerência de Serviços

- Atividades necessárias ao controle dos serviços oferecidos

- controle de qualidade e níveis de serviço, correlação entre os serviços e a rede que os suporta fazem parte desta camada.

- Ferramentas: fortemente associadas à camada imediatamente superior

- Business Management - Gerência de Negócio

- Todas as atividades que dizem respeito à gestão dos clientes

- Processos e ferramentas estão intimamente ligados

- Processos de gestão dos clientes implementados nos sistemas de CRM

- Processos de Tarifação e Cobrança implementados nas ferramentas de Mediation, Rating e Billing 


\subsubsection{TOM - Telecom Operations Map}

A partir do trabalho do ITU-T foi desenvolvido o TOM (Telecom Operations Map, ou Mapa Operacional de Telecom), com o objetivo de transformar a visão em camadas da pirâmide TMN (seção 5.1.2.1 ) num efetivo modelo de processos.

O processo de construção do TOM é, em essência, bastante simples: criou-se uma matriz bidimensional em que o eixo vertical é formado pelas camadas da pirâmide TMN e o eixo horizontal é uma visão seqüencial das etapas necessárias à disponibilização do serviço ou infra-estrutura da camada sendo descrita. Essa é a mesma técnica utilizada para descrever a Abrangência deste trabalho

Figura 2).

Assim, a melhor maneira de utilizar o TOM é compreendendo sua estrutura matricial (Figura 37). A seguir serão descritos cada um dos processos que compreendem o TOM, representados por "caixas" brancas na Figura 37.

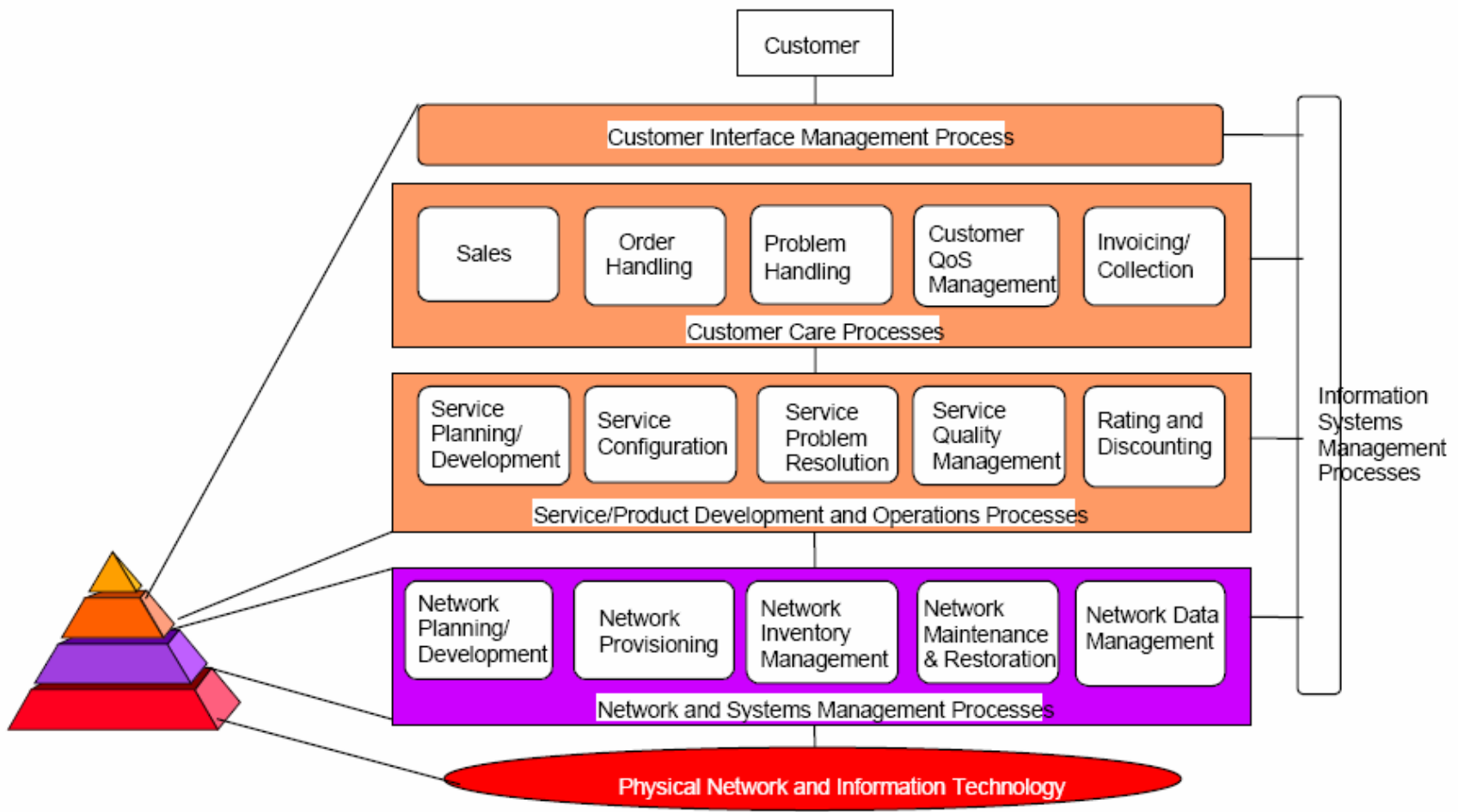

Figura 37 - TOM - Telecom Operations Map 


\subsection{Network and Systems Management Processes - Processos de Gerência de Redes e Sistemas}

O TOM inicia sua modelagem já na camada de Gerência de Rede, que agrega também as funções da Gerência de Elementos da Pirâmide TMN. Percorrendo esta camada da esquerda para a direita, temos os processos necessários à disponibilização da infra-estrutura de rede que suporta um serviço de telecomunicações. Estes processos são:

- Network Planning \& Development: inclui atividades como Planejamento da Capacidade (geração e análise de dados estatísticos sobre o volume de tráfego na rede, visando projetar a demanda futura de capacidade e planejar as expansões de acordo)

- Network Provisioning: todas as atividades relativas a instalação e configuração de equipamentos de rede (cobertas na Gerência de Configuração do Modelo FCAPS)

- Network Inventory Management: criação e manutenção do Inventário de Redes. Um dos grandes objetivos deste processo é manter o cadastro atualizado; em redes de grande porte, muitas vezes isso é um objetivo extremamente desafiador

- Network Maintenance \& Restoration: todas as atividades cobertas na Gerência de Falhas do Modelo FCAPS, adicionadas de uma atividade de Planejamento para Recuperação de Desastres

- Network Data Management: geração, armazenamento e análise de dados da rede, incluindo (mas não se limitando a) os dados de utilização previstos pela área de Medição e Tarifação do Modelo FCAPS 


\subsection{Service /Product Development and Operation Processes - Processos de Desenvolvimento e Operação de Serviços}

Na Camada de Gerência de Serviço, surgem os processos que, por estarem em um nível de abstração maior, não "enxergam" a rede:

- Service Planning \& Development: atividade essencialmente de Marketing (e não Operacional), inclui todos os passos necessários à criação de novos serviços (estudos de demanda, pesquisas primárias com os clientes, estudos de posicionamento e branding etc.)

- Service Configuration: todas as atividades necessárias ao aprovisionamento de um serviço para um cliente

- Service Problem Resolution: atividades correspondentes à Gerência de Falhas do Modelo FCAPS, aplicadas a problemas de serviço, e não de rede

- Service Quality Management: atividades que visam garantir que o serviço atenda às especificações mínimas contratadas pelo cliente. Processo de fundamental importância, em especial com a crescente sofisticação dos Acordos de Nível de Serviço exigidos pelos clientes

- Rating \& Discounting: processo de tarifação, responsável por definir o valor a ser pago pelo usuário. Especificamente, entende-se o processo de rating como a atribuição de um valor de tarifa para um dado instante de utilização do serviço (exemplo: atribuir a Tarifa Reduzida a todos os minutos utilizados pelo usuário no horário noturno)

\subsection{Customer Care Processes - Processos de Atendimento ao Cliente}

Na Gerência de Negócios, os processos estão muito próximos do cliente, e bastante dissociados da rede: 
- Sales: Processo genérico de venda de serviços, iniciado com o primeiro contato com o cliente e terminando com a geração de um pedido

- Order Handling: todas as atividades de processamento de Pedido, incluindo sistemas de acompanhamento do pedido por todo o fluxo da operadora

- Problem Handling: processos de Suporte ao cliente, que processam os problemas reportados pelo cliente (vindos dos Processos de Interface - vide descrição a seguir). Este processo recebe informações de todos os processos de Resolução de Problemas das camadas inferiores

- Customer QoS Management: Similar ao processo de Service Quality Management já mencionado, este processo visa garantir o cumprimento dos Acordos de Nível de Serviço, mas aqui com uma ênfase maior no negócio do cliente. Este processo tem uma visão do cliente como um todo, e não de um serviço específico

- Invoicing \& Collection: Processos de emissão de faturas e cobrança, incluindo o tratamento de clientes inadimplentes e a resolução dos problemas relativos a cobrança, conforme reportados pelo processo de Problem Handling.

\subsubsection{3 eTOM - enhanced Telecom Operations Map}

Evolução do TOM, o eTOM é hoje considerado o melhor modelo de processos disponível para o mercado de Telecomunicações. Sua maturidade, abrangência e nível de adoção por empresas do mundo todo fizeram com que em 2004 o modelo se tornasse um padrão do ITU-T.

Embora a discussão que se segue seja genérica e aplicável a qualquer versão do eTOM, as figuras e comentários (principalmente os relacionados aos níveis de maior detalhamento) se referem ao eTOM versão 6.1 [11]. 


\subsection{Componentes fundamentais}

O primeiro passo para compreender o Modelo de Processos eTOM é entender seus 3 componentes fundamentais: o conjunto de partes interessadas reconhecidas, o conjunto de macro-agrupamentos de processos (Figura 38) e as definições dos conceitos de Produto, Serviço e Recurso (Figura 39).

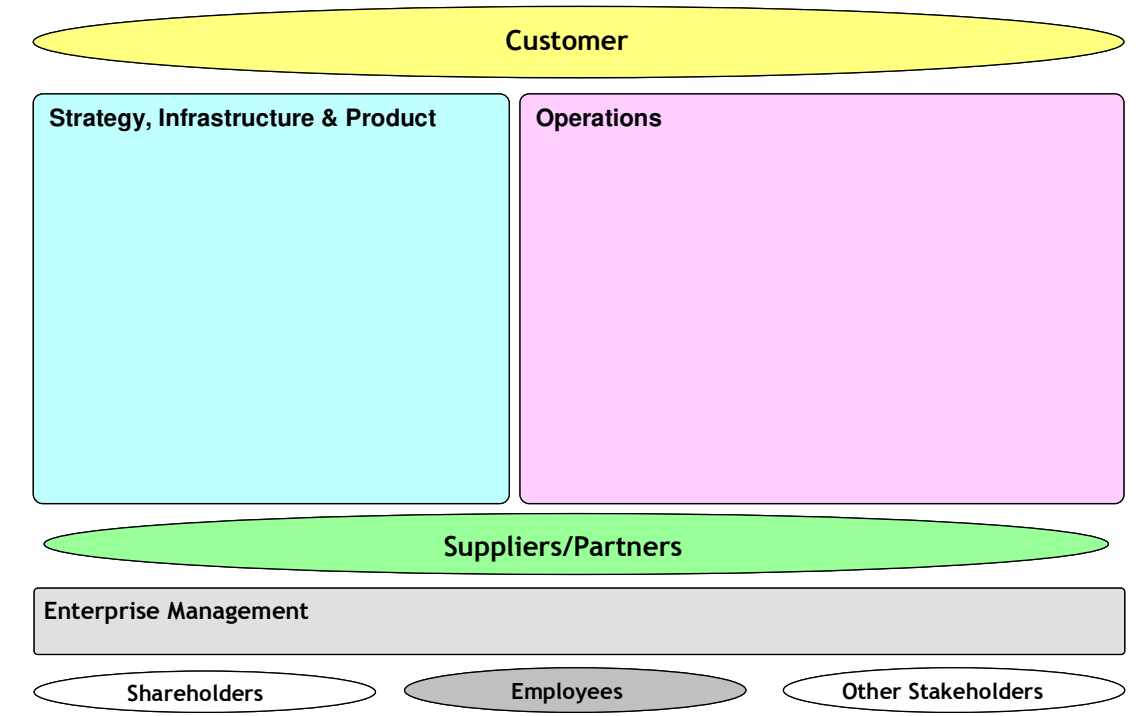

Figura 38 - Conceitos do eTOM: Partes interessadas e Macro-agrupamentos de Processos

\subsection{Partes interessadas}

Com o objetivo de cobrir todo o mercado de Telecomunicações, o eTOM reconhece quatro grandes stakeholders ou partes interessadas (elipses na Figura 38), todos definidos do ponto de vista da empresa sendo representada pelos processos do eTOM:

- Customer (Cliente): entendido como o foco do negócio, o Cliente é a entidade (pessoa física e / ou jurídica) que compra os produtos vendidos pela empresa

- Suppliers(Fornecedores): entidades que oferecem recursos, comprados e utilizados pela empresa direta ou indiretamente para suportar o seu negócio 
- Partners (Parceiros): entidades com quem a empresa coopera em uma área de negócio compartilhada

- Shareholders (Acionistas): entidades que investiram na empresa e que portanto possuem ações / cotas de seu capital

- Employees (Funcionários): aqueles que trabalham para empresa na perseguição dos seus objetivos

- Other Stakeholders (Outras partes interessadas): entidades que possuem algum comprometimento com a empresa diferente da participação no capital (não possuem ações da empresa)

\subsection{Macro-agrupamentos de processos}

Para representar uma empresa com a abrangência necessária aos seus objetivos, o eTOM divide os processos empresariais em 3 grandes grupos (retângulos na Figura 38):

- Strategy, Infrastructure and Products (Estratégia, Infra-estrutura e Produtos): este agrupamento inclui os processos de planejamento e gestão de ciclos de vida (associados a atividades de desenvolvimento e entrega). Aqui estão os processos que desenvolvem as estratégias da empresa, criam, implementam e acompanham os produtos que ela vende e planejam, projetam e implementam a infra-estrutura que os suporta. Estes processos capacitam a empresa a executar os processos do agrupamento de Operações, descrito a seguir

- Operations (Operações): inclui toda a gestão operacional da empresa. Esta área é o núcleo de um Provedor de Serviços e, por conseqüência, do próprio eTOM (este agrupamento representa o TOM original). Aqui estão modelados todos os processos que suportam a operação dos Serviços e Recursos que compõem os Produtos a serem entregues aos Clientes (mais sobre Serviços, Recursos e Produtos na próxima seção) 
- Enterprise Management (Gestão Empresarial): inclui todos os processos corporativos, administrativos ou que constituem alguma forma de suporte à operação do negócio principal da empresa. Estes incluem os processos básicos necessários à gestão de qualquer grande empresa (gestão financeira, gestão de Recursos Humanos etc.)

O TMForum sempre adotou uma abordagem top-down para a construção dos seus modelos de processos e o eTOM não é exceção: os macro-agrupamentos identificados na Figura 38 serão progressivamente detalhados nos diversos "níveis"que compõem o modelo (explorados nas próximas seções).

\subsection{Produtos, Serviços e Recursos}

O eTOM distingue explicitamente os Produtos que uma empresa oferece ao mercado dos Serviços que os compõem e dos Recursos utilizados para implementá-los. Na visão modelada pelo eTOM, Produtos são a visão externa que o mercado possui da oferta de uma empresa, enquanto Serviços e Recursos fazem parte da visão interna que a própria empresa tem da sua oferta (Figura 39).

A seguir encontram-se as definições para cada um destes conceitos, de acordo com o eTOM [11].

- Produto: é o que uma entidade (fornecedor) oferece ou provê a outra entidade (cliente). No eTOM, o Produto é a visão externa que o mercado possui da oferta de um Provedor de Serviços. Um Produto pode incluir serviços, materiais processados, software, hardware ou qualquer combinação destes elementos. Um Produto pode ser tangível (Ex.: bens de consumo) ou intangível (Ex.: conceitos) ou uma combinação de ambos. No entanto, um Produto sempre inclui um componente de Serviço

- Serviço: no entendimento utilizado no eTOM, um Serviço é desenvolvido pelo Provedor de Serviço para ser comercializado como parte dos seus Produtos. Um mesmo Serviço pode ser incluído em múltiplos produtos (empacotado de maneira diferente, com preços diferentes etc.) 
- Recurso: no eTOM Recursos são componentes físicos e não-físicos usados para construir Serviços. Recursos vêm dos domínios das Aplicações, Computação e Redes e incluem, por exempo, elementos de rede, software, infra-estrutura computacional (servidores, discos etc.) ou outros componentes tecnológicos

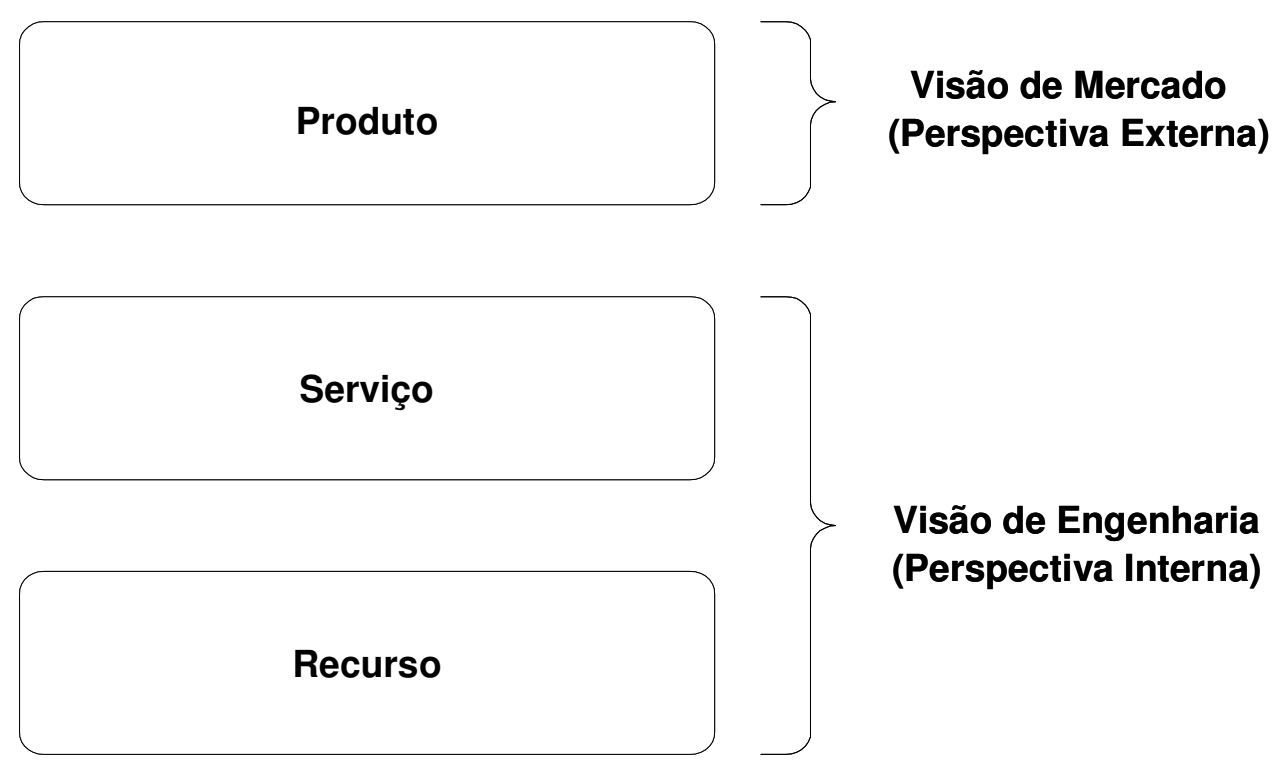

Figura 39 - Conceitos do eTOM: Produto, Serviço, Recurso

\subsection{Nível 0}

A união dos conceitos fundamentais ilustrados na Figura 38 e na Figura 39 resulta na mais abstrata e mais conceitual visão possível do eTOM: a visão de alto nível denominada Visão de Nível 0 (Figura 40). 


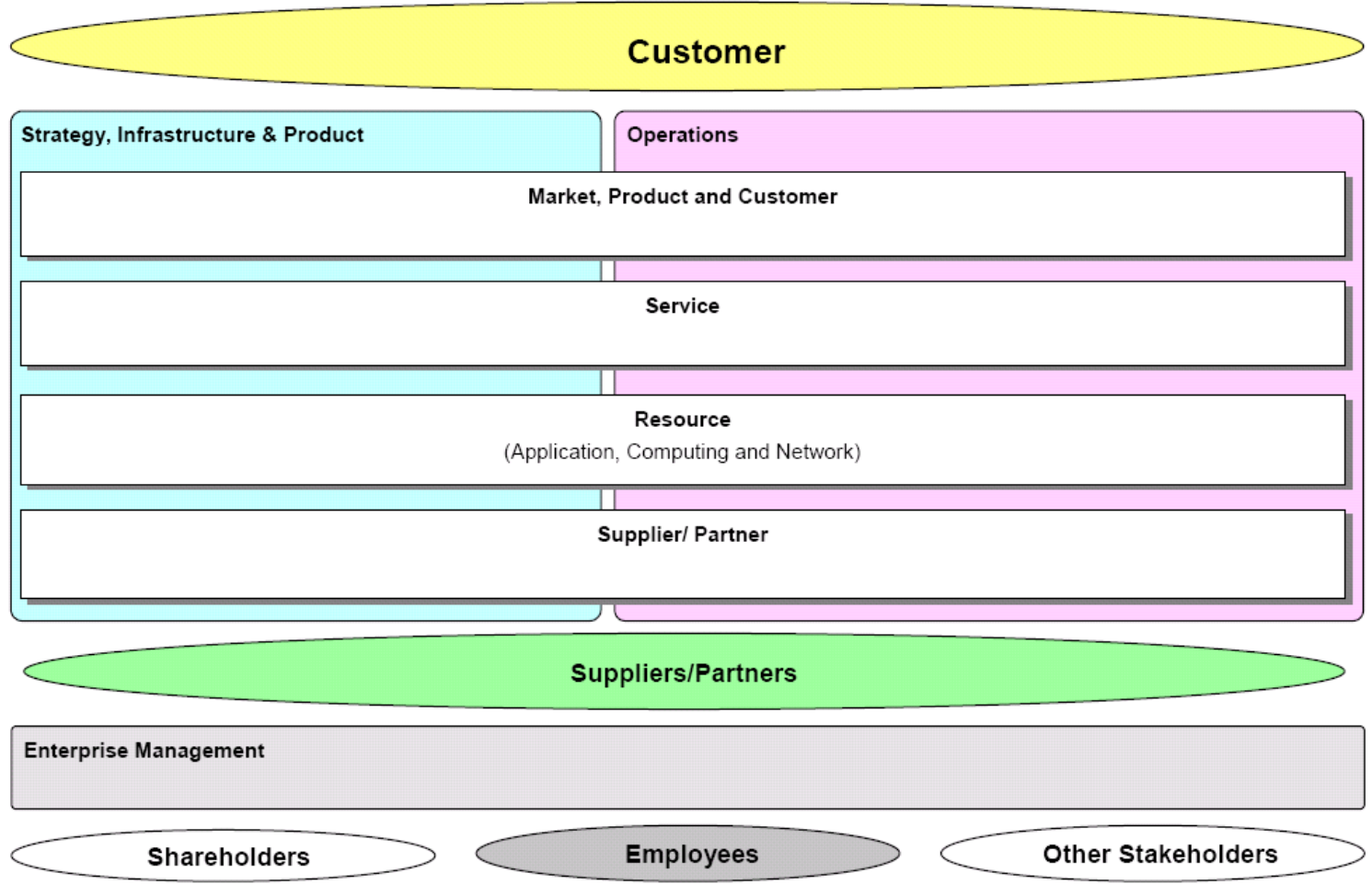

Figura 40 - eTOM - Visão de Nível 0

Nesta visão já se torna clara a principal diferença entre o eTOM e o TOM (seção 5.1.2.2 ): o TOM busca apenas modelar os processos operacionais de um Provedor de Serviços, enquanto o eTOM busca representá-lo como uma empresa, modelando todos os seus processos. Pode-se dizer que o TOM representa apenas o conjunto de processos de Operações na Figura 40, enquanto o eTOM se preocupa em modelar também os processos de desenvolvimento de estratégia, planejamento e gestão do ciclo de vida de produtos e infraestrutura do Provedor. Embora o foco do TMForum seja nos processos que impactam diretamente o dia-a-dia da operação de serviços de informação e comunicação, também são apresentados os processos genéricos de administração de uma empresa (agrupamento inferior da Figura 40).

Outra diferença é o reconhecimento da existência de Fornecedores e Parceiros, que passava despercebida na modelagem do TOM (Figura 37). 


\subsection{Nível 1}

$\mathrm{Na}$ abordagem de detalhamento progressivo utilizada pelo TMForum, os processos identificados em cada Nível do modelo são refinados e detalhados (“decompostos", na terminologia do TMForum) no próximo Nível.

Assim, os processos reconhecidos no Nível 0 do eTOM (Figura 40) serão decompostos em novos agrupamentos que irão compor o Nível 1 do modelo.

\subsection{Estratégia, Infra-estrutura e Produtos}

O agrupamento Estratégia, Infraestrutura e Produto é decomposto em 3 partes, correspondendo respectivamente ao desenvolvimento e à gestão da Estratégia, da Infraestrutura e dos Produtos da empresa (Figura 41). Pelas iniciais dos processos decompostos, este agrupamento é conhecido como "SIP".

\section{Customer}

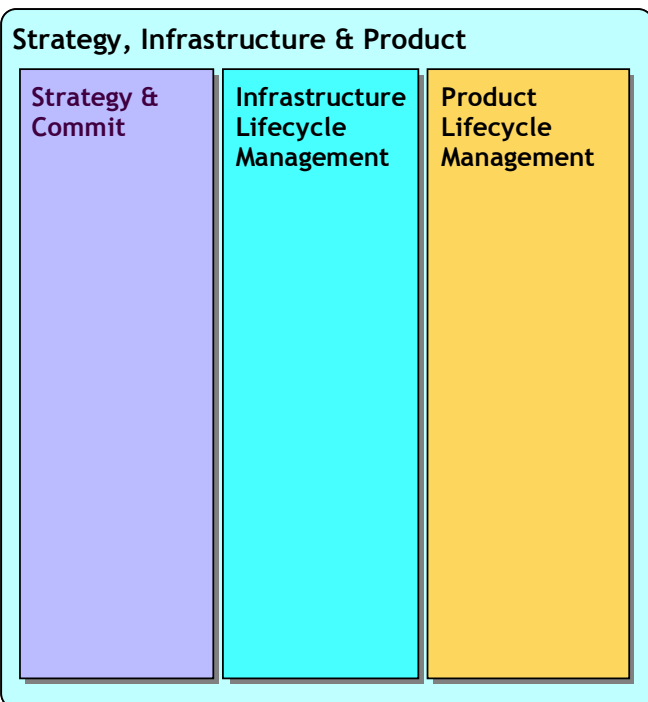

Figura 41 - Decomposição do processos de Nível 0 de Estratégia, Infraestrutura e Produto

- Strategy \& Commit (Estratégia e Execução): o primeiro agrupamento vertical de processos da Figura 41 é responsável por gerar as estratégias que direcionam os processos de gestão de Infra-estrutura e Produtos. Este 
agrupamento também é responsável pela Execução destas estratégias em toda a empresa, ou seja, por garantir o comprometimento e o alinhamento de toda a empresa em torno dos objetivos de negócio definidos. Isso envolve todos os níveis da empresa, desde a camada de mercado até a de serviços e a de recursos. Os processos nesta vertical se focam em atividades analíticas (medir e acompanhar o sucesso e efetividade das estratégias propostas)

- Infrastructure Lifecycle Management (Gestão do Ciclo de Vida de Infraestrutura): este agrupamento vertical é responsável por definir, planejar e implementar toda a infra-estrutura necessária, tecnológica (de aplicação, de rede ou e computacional) ou não (centros de operação, instalações prediais, energia, climatização etc.). Os processos desta vertical identificam novos requisitos e projetam, desenvolvem, implantam e melhoram toda a infraestrutura necessária para suportar os Serviços oferecidos pela empresa

- Product Lifecycle Management (Gestão do Ciclo de Vida de Produto): este agrupamento vertical é responsável por definir, planejar e implementar todo o portfolio de Produtos da empresa, controlando a qualidade e as margens de lucratividade de cada produto e a satisfação dos clientes. Os processos nesta vertical são responsáveis por entender todo o mercado, desde o ambiente competitivo aos requisitos dos clientes

\subsection{0perações}

O agrupamento Operações é decomposto em 4 partes, uma das quais suporta as outras 3 e por isso é representada como levemente separada das demais (Figura 42). Pelas iniciais dos processos estritamente de operação, este agrupamento é conhecido como "FAB".

O fluxo operacional representado pelos processos $F A B$, abrangendo a entrega do serviço, a garantia de sua qualidade e o seu faturamento é a pedra fundamental do eTOM desde a sua primeira versão. Este entendimento da prestação de serviços de comunicação e informação foi tão bem sucedido e se 
tornou tão arraigado na indústria que hoje é considerado um sinônimo do eTOM e também a maior contribuição do TMForum para a formalização dos processos operacionais em telecomunicações.

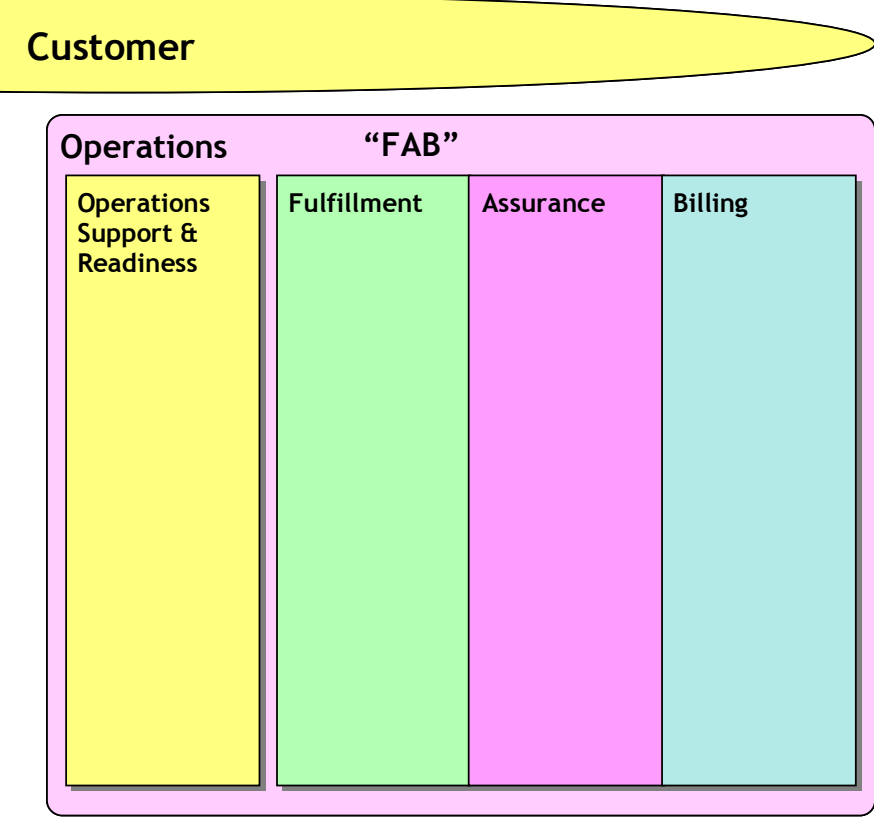

Figura 42 - Decomposição do processos de Nível 0 de Operações

- Operations Support \& Readiness (Suporte à Operação): este agrupamento vertical é responsável por fornecer suporte administrativo, gerencial e logístico aos processos "FAB" (descritos a seguir). Os processos contidos aqui se focam em atividades menos relacionadas a clientes e mais em garantir a execução eficiente e correta dos processos $F A B$.

- Fulfillment (Entrega): este agrupamento vertical é responsável por fornecer aos clientes os Produtos solicitados por eles rápida e corretamente. Seus processos traduzem as necessidades do cliente em uma solução que possa ser entregue utilizando o portfolio de Produtos da empresa. Também é sua atribuição informar o cliente do status da sua ordem de compra, garantir o cumprimento dos prazos relevantes e a satisfação do cliente.

- Assurance (Garantia de Qualidade): este agrupamento vertical é responsável por executar atividades de manutenção pró-ativa e reativa, garantindo a disponibilidade e a aderência dos serviços aos níveis de qualidade contratados pelos usuários, bem como o cumprimento de eventuais Acordos de Nível de Serviço (SLAs). Para tal, estes processos 
incluem o monitoramento contínuo do status e da performance de serviços e recursos, a recepção de reclamações de clientes e a garantia de reparos rápidos e corretos.

- Billing (Faturamento / Cobrança): este agrupamento vertical é responsável por coletar registros de utilização de serviços, processá-los, produzir faturas corretas, processar os pagamentos dos clientes e tratar todo o tipo de problema, dúvida ou questão relacionada à cobrança pelos Produtos fornecidos. Produtos tarifados em regime pré-pago também são tratados por processos desta vertical.

\subsection{Gestão Empresarial}

Este agrupamento inclui os processos que gerenciam atividades pertinentes a toda a empresa, ou seja, processos que:

- São necessários para suportar toda a empresa (gestão financeira, legal, de custos etc.)

- São responsáveis por definir políticas corporativas, estratégias e diretrizes para todo o negócio (incluindo até diretrizes para o desenvolvimento de estratégias no agrupamento "SIP")

- Ocorrem em toda a empresa (Ex.: gerenciamento de projetos, avaliação de desempenho etc.)

A decomposição do Nível 0 de Gestão Empresarial resulta em 7 processos (Figura 43):

- Strategic \& Enterprise Planning (Planejamento Estratégico)

- Enterprise Risk Management (Gestão de Risco)

- Enterprise Effectiveness Management (Gestão de Perfomance)

- Knowledge \& Research Management (Gestão do Conhecimento e Pesquisa)

- Financial \& Asset Management (Gestão Financeira e de Ativos) 
- Stakeholder \& External Relations Management (Relações com Investidores e Relações Externas)

- Human Resources Management (Gestão de Recursos Humanos)

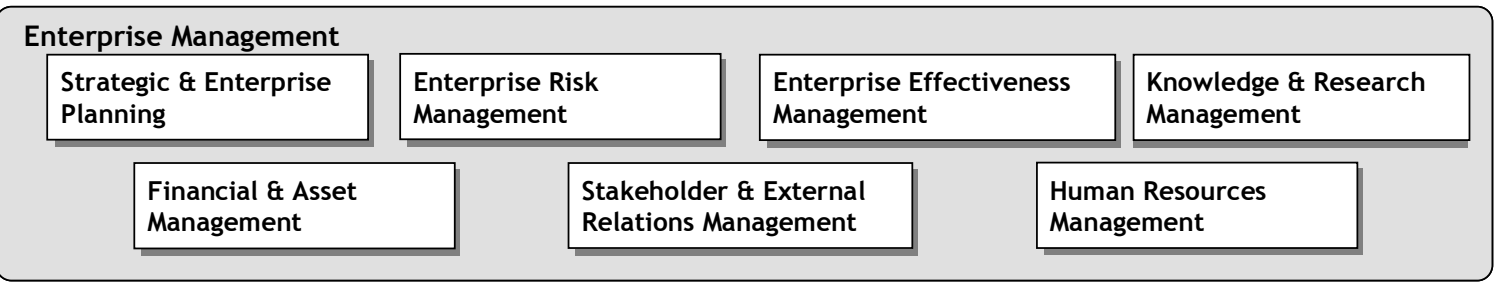

Figura 43 - Decomposição do processo de Nível 0 de Gestão Empresarial

Gestão Empresarial não é o foco deste trabalho, por isso os processos deste agrupamento não serão detalhados. Para uma descrição de cada um deles, consultar [11].

A decomposição no Nível 0 do eTOM (Figura 40) nos processos ilustrados na Figura 41, na Figura 42 e na Figura 43 resulta na visão de Nível 1 (Figura 44). Nesta figura também está representada a natureza matricial do eTOM, indicando-se os agrupamentos horizontais como uma evolução das camadas da pirâmide TMN (Figura 36) e os verticais como o Ciclo de Vida de serviços composto pelos agrupamentos da Figura 41 e da Figura 42. 


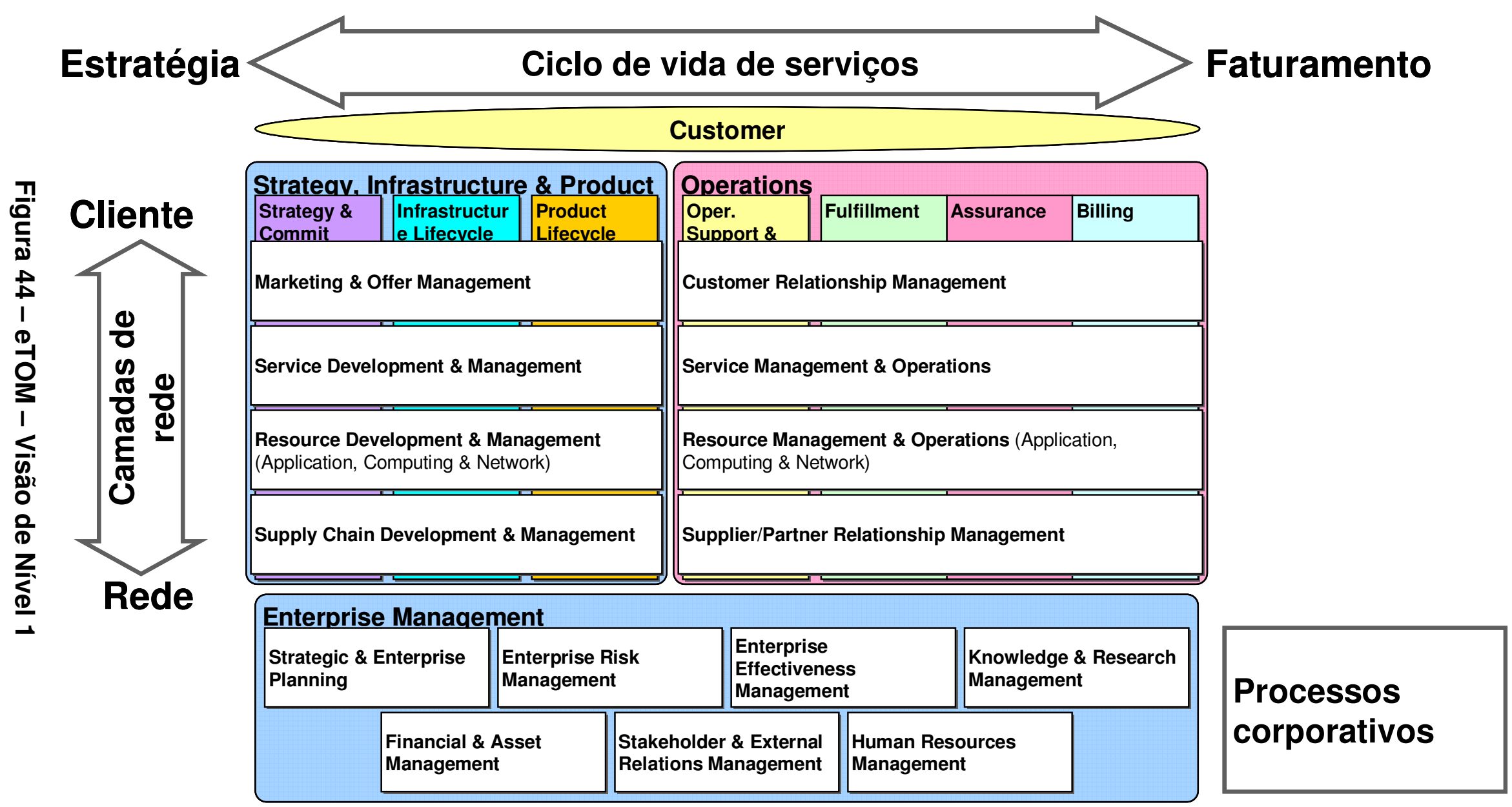


5.1.2.3.4 Nível 2

Embora o TMForum ofereça os processos do eTOM decompostos até o Nível 4 e algumas entidades já tenham proposto detalhamentos ainda maiores (em alguns casos até o Nível 6), neste trabalho o Nível mais profundo a ser apresentado é o Nível 2 (Figura 45). 


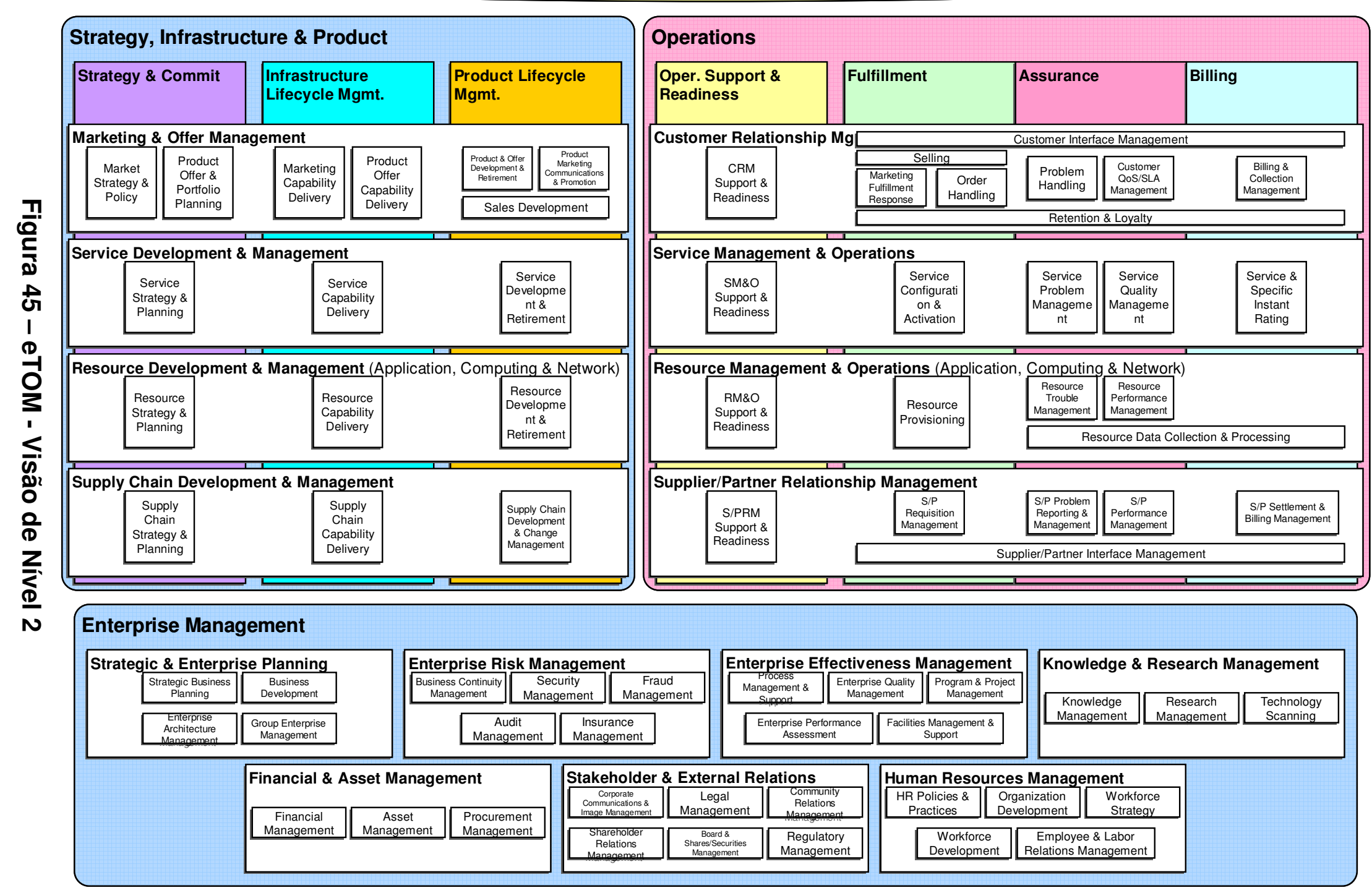


Este Nível decompõe a visão de Nível 1 em 72 processos. Para uma descrição detalhada de cada um deles, consultar a documentação básica do eTOM [11].

\subsection{A Cadeia de Prestação de Serviços de Telecomunicações}

Neste trabalho, a Cadeia de Prestação de Serviços em Telecomunicações utilizada será a intersecção entre o ciclo de vida de serviços presente nas "verticais" do eTOM e a "horizontal" de Serviços (Service Development and Management) - Figura 46.

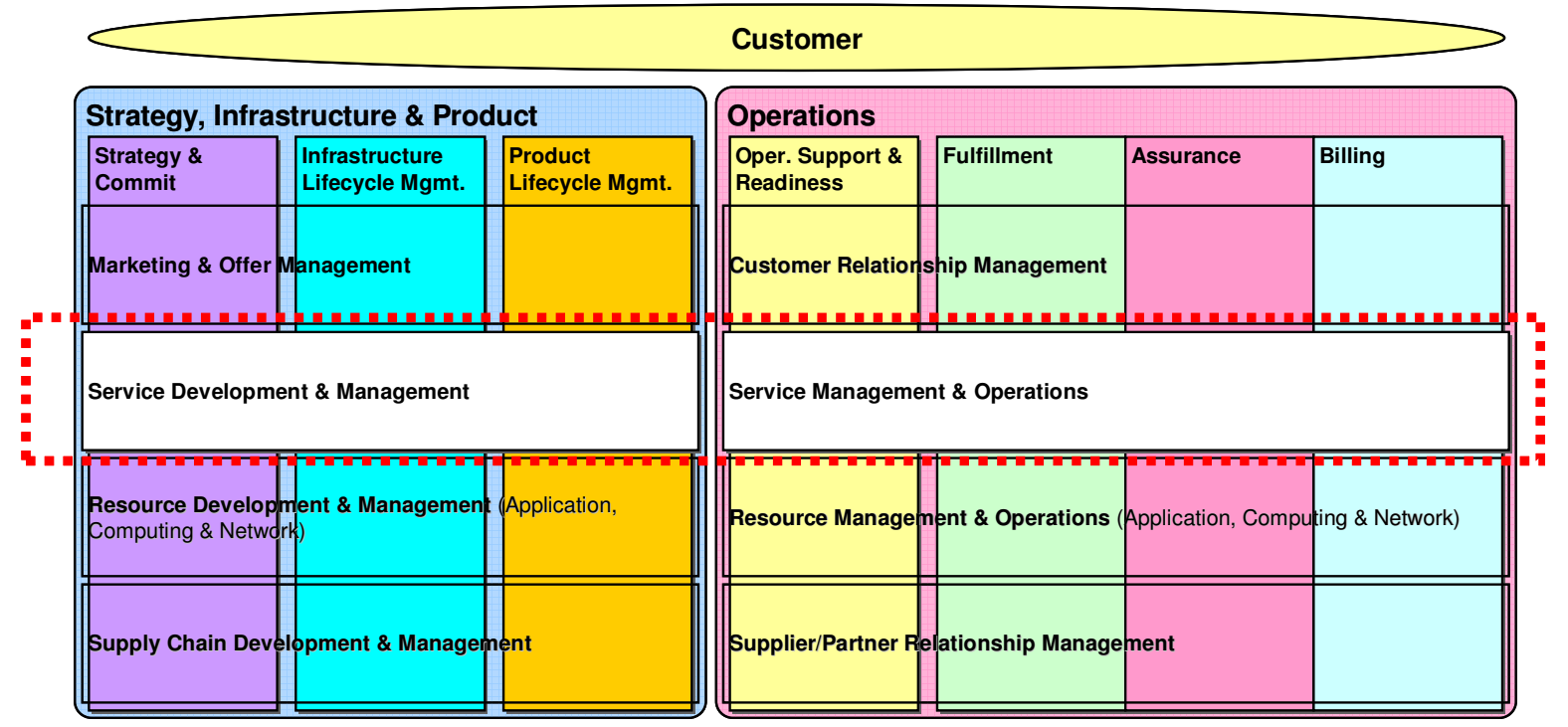

Figura 46 - Entendimento da Cadeia de Prestação de Serviços dentro do eTOM

Isolando as fases do ciclo de vida de Serviços e traduzindo seus nomes em tradução livre, chegamos à Cadeia de Prestação de Serviços da Figura 47. 


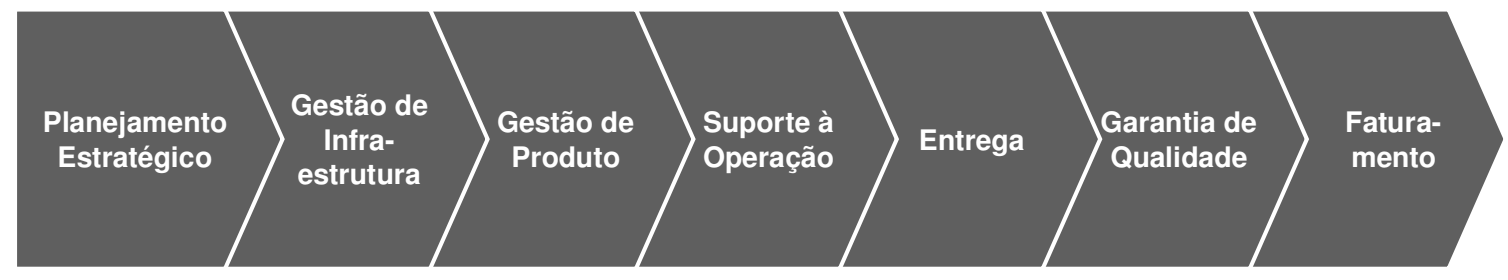

Figura 47 - Cadeia de Prestação de Serviços

Dado o entendimento das funções das partes interessadas descrito na seção 3.1.2, é possível mapear o escopo de atuação de cada uma delas na cadeia da Figura 47 - esse mapeamento encontra-se na Figura 48. 


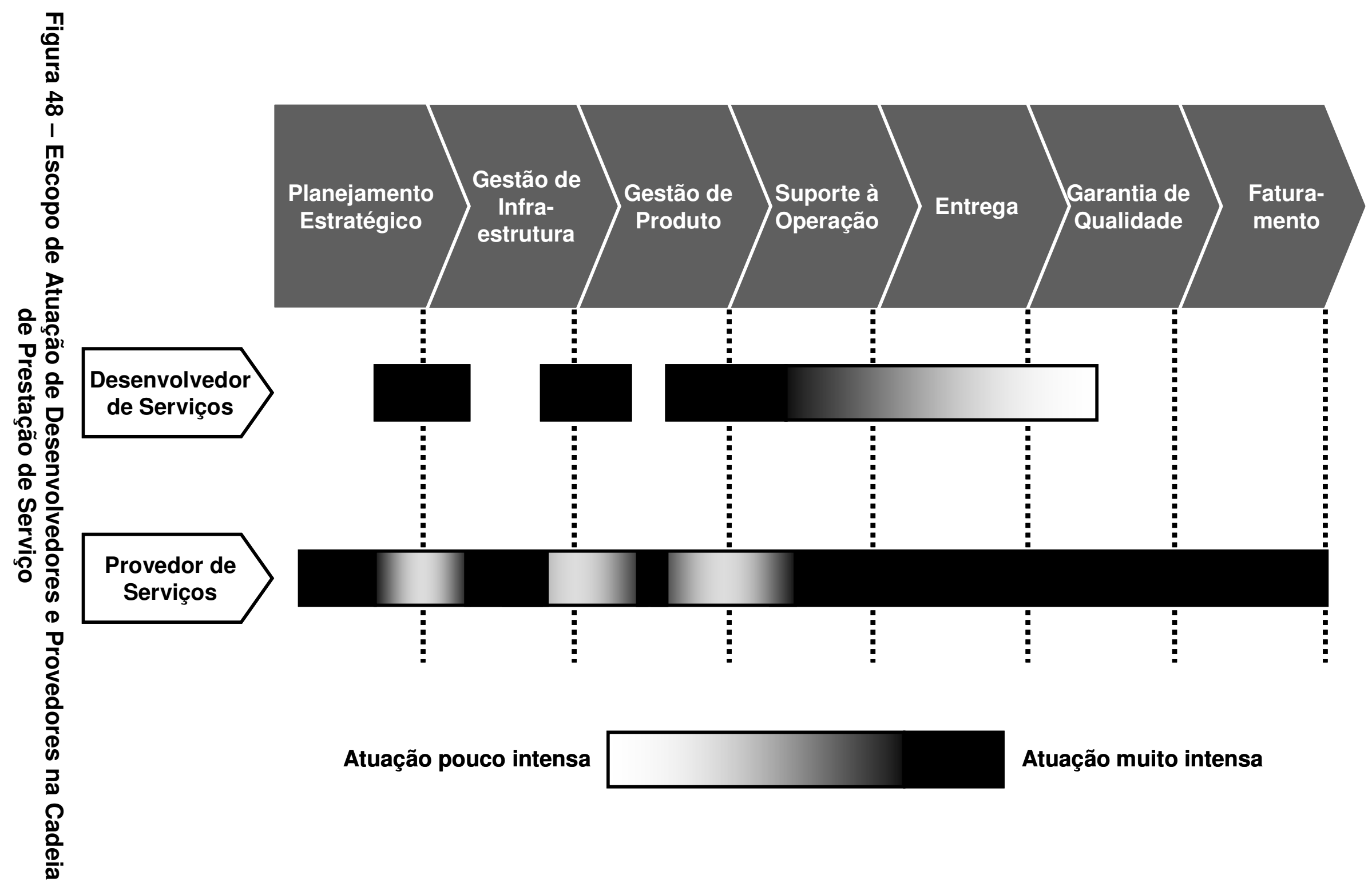


Note-se que, quando vistos sob a ótica da Cadeia de Prestação de Serviços, os papéis dos Desenvolvedores e dos Provedores de Serviço se sobrepõem. Isso é esperado, já que esta Cadeia não visa representar as relações de fornecimento entre Desenvolvedor e Provedor (com esse fim foi proposto o modelo da Figura 9) e sim ilustrar o Ciclo de Vida de um Serviço, da sua concepção estratégica à sua entrega ao usuário final.

Assim, vemos na Figura 48 que o Desenvolvedor de Serviços atua ativamente durante a concepção inicial do serviço (elo de Planejamento Estratégico) e em sua implementação tecnológica (Gestão de Infra-estrutura) e de mercado (Gestão de Produto). Na medida em que o serviço passa a ser operado pelo Provedor de Serviços, a atuação do Desenvolvedor se reduz gradualmente.

O Provedor de Serviços, por sua vez, atua durante toda a Cadeia de Prestação de Serviços - afinal, é ele que detém o relacionamento com o Consumidor. No entanto, sua atuação é mais limitada nas áreas em que o serviço está sendo desenvolvido e implementado pelo Desenvolvedor. 


\section{MAPEAMENTO DE FERRAMENTAS NA CADEIA DE PRESTAÇÃO DE SERVIÇOS}

Neste capítulo, as ferramentas identificadas no Capítulo 4 são classificadas e categorizadas de acordo com sua aplicabilidade a cada uma das Partes Interessadas, a cada elo da Cadeia de Prestação de Serviços e a cada Processo pertencente ao Ciclo de Vida de um serviço de telecomunicações.

Essa categorização será feita em ordem crescente de detalhamento, posicionando-se as ferramentas identificadas nos diversos modelos de referência apresentados nos capítulos 3 e 5.

\subsection{Mapeamento no modelo de Relacionamento entre Stakeholders}

O objetivo desta seção é unir as ferramentas descritas no Capítulo 4 ao modelo de Relacionamento entre Stakeholders proposto na seção 3.1.2 (Figura 9) em um mapa único.

O mapeamento das ferramentas identificadas no modelo de referência adotado encontra-se na Figura 49 - nota: este modelo foi apresentado inicialmente em [19] e posteriormente refinado durante a construção desta dissertação (basicamente, reconheceu-se a importância do conceito de Kansei para o Desenvolvedor de Serviços). 

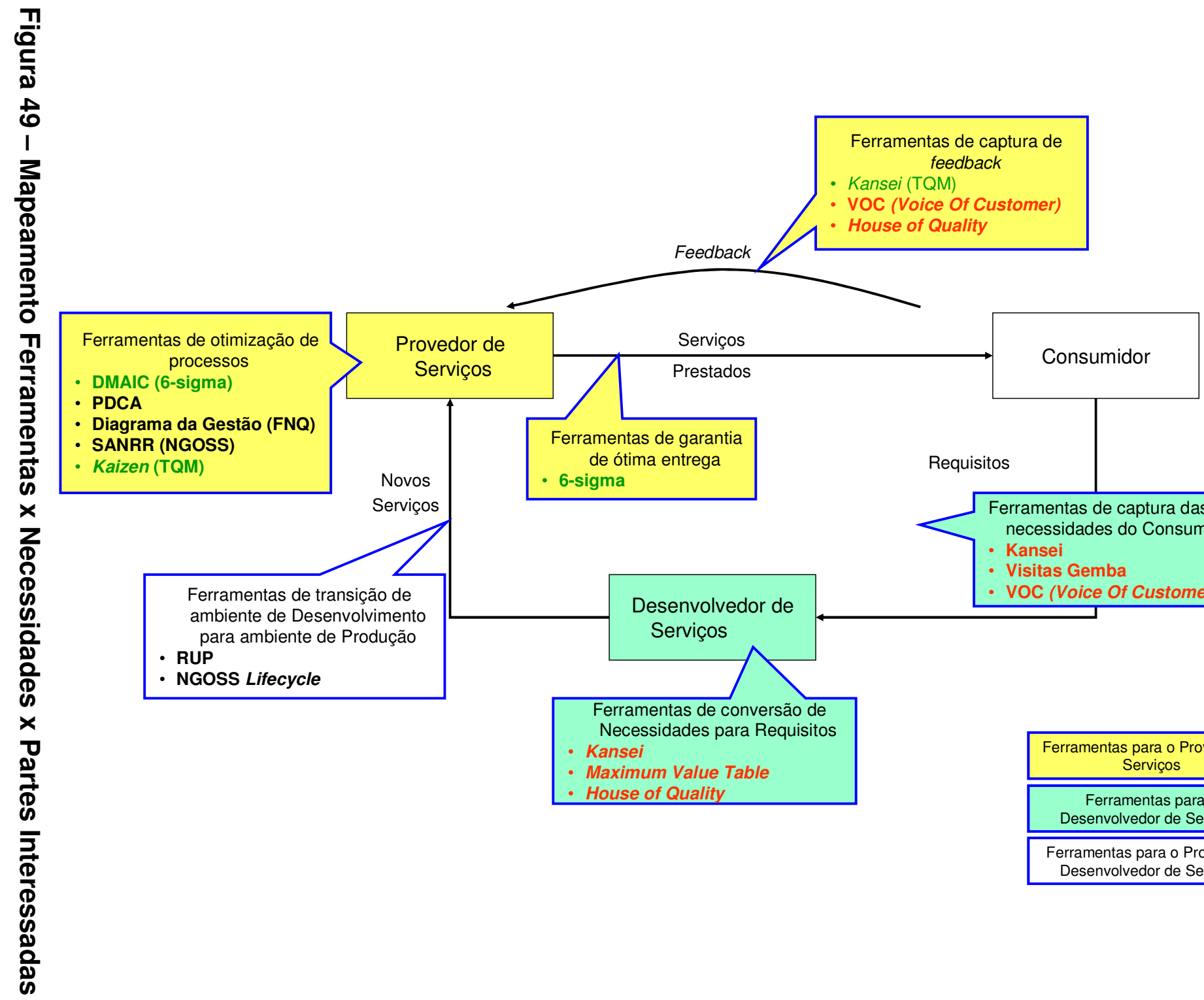

Ferramentas de transição de ambiente de Desenvolvimento

- NGOSS Lifecycle

$x$

$\frac{\mathscr{D}}{7}$

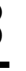

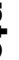

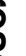

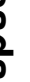

6-sigma

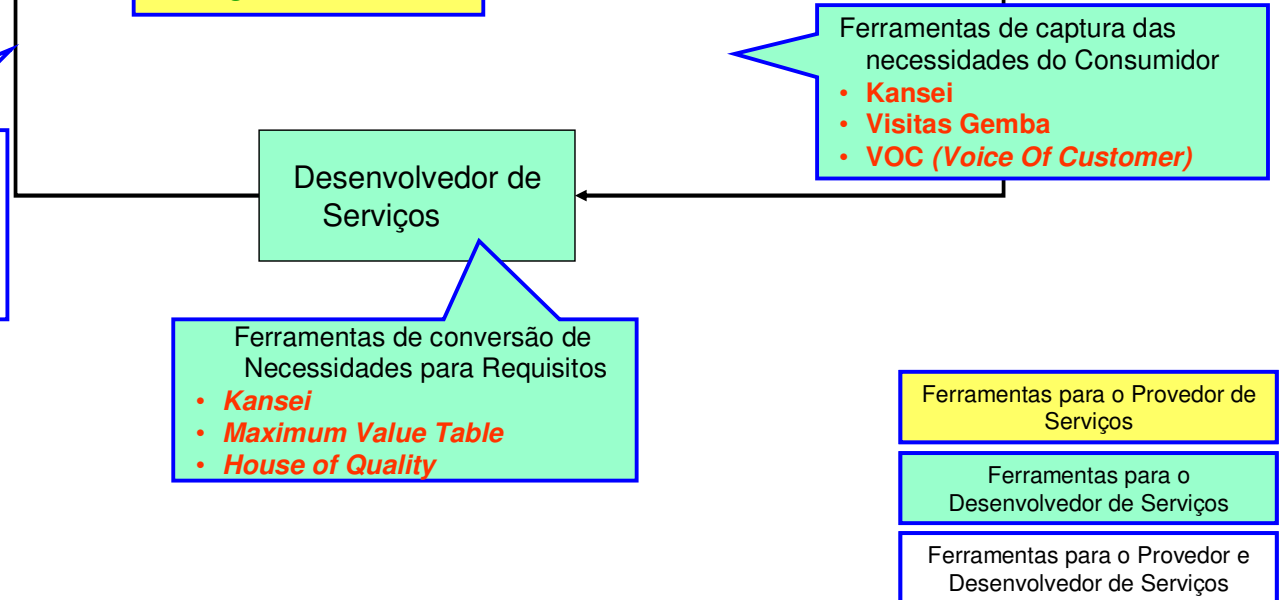

TQM (Total Quality Management)

QFD (Quality Function

Design)

Outros 


\subsection{Mapeamento na Cadeia de Prestação de Serviços}

As ferramentas identificadas no Capítulo 4 também podem ser mapeadas na Cadeia de Prestação de Serviços apresentada na seção 5.2 (Figura 47). Neste caso, ocorre alguma sobreposição no escopo de atuação das ferramentas devido à própria sobreposição dos papéis dos Desenvolvedores e Provedores de Serviço (Figura 48).

O mapeamento das ferramentas identificadas na Cadeia de Prestação de Serviços encontra-se na Figura 50, a seguir. 


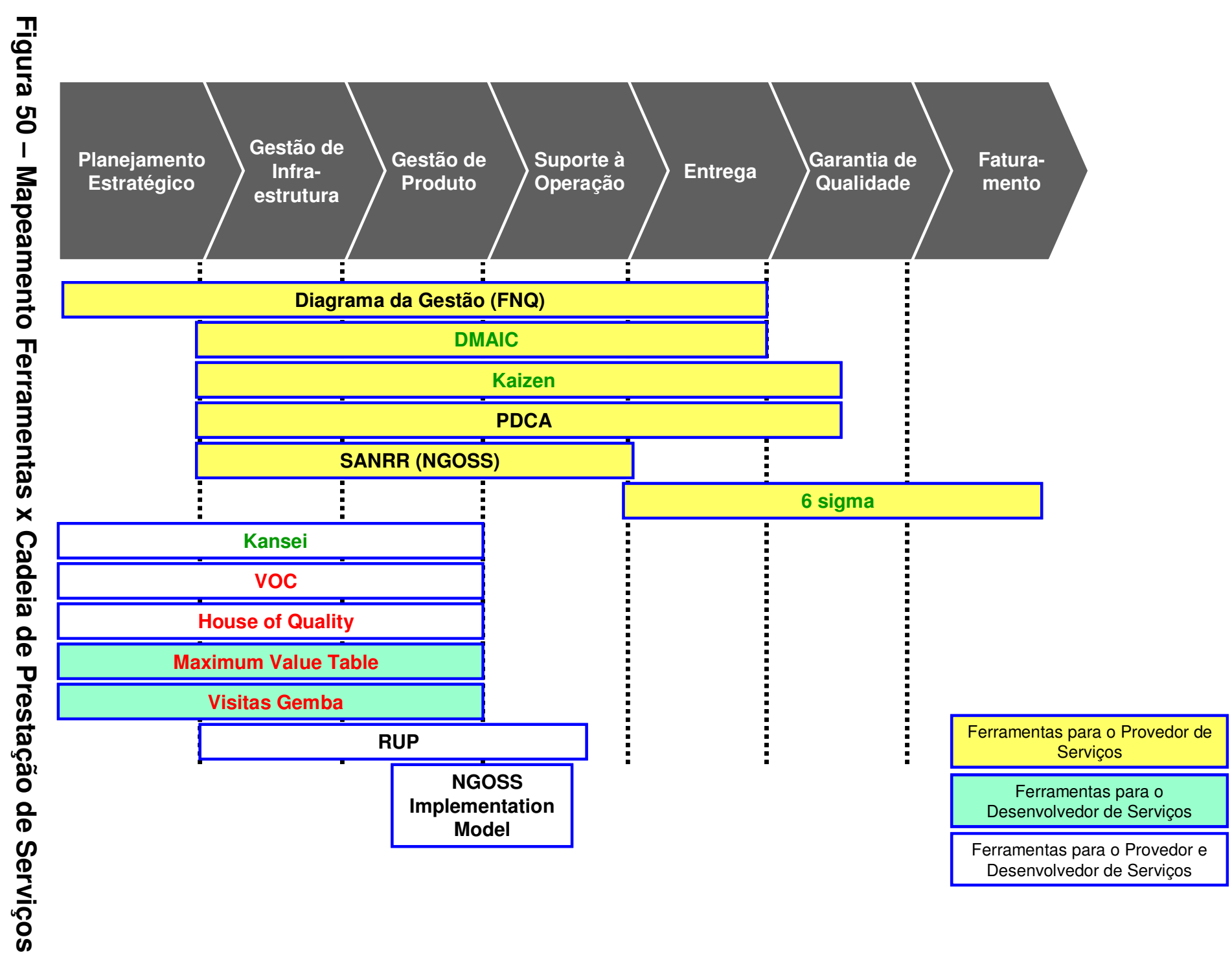

TQM (Total Quality Management)

QFD (Quality Function Design)

Outros 


\subsection{Mapeamento no eTOM}

O mapeamento apresentado na Figura 50 se baseia na Cadeia de Prestação de Serviços da Figura 47. Como ela foi extraída de uma "fatia" horizontal do eTOM (abordagem ilustrada na Figura 46), tanto a Cadeia quanto o mapeamento baseado nela são unidimensionais: as ferramentas identificadas são classificadas apenas segundo sua aplicabilidade a cada elo do ciclo de vida de um serviço de telecomunicações.

Para melhor caracterizar a aplicabilidade e adequação de cada uma dessas ferramentas à prestação de serviços de telecomunicações, é interessante introduzir mais uma dimensão no mapeamento já realizado. Assim, será adotado o eTOM como matriz bidimensional para posicionamento das ferramentas.

Para melhor visualização, o mapeamento realizado é apresentado em 2 camadas: uma contendo apenas as ferramentas utilizadas pelos Provedores de Serviços e outra com as utilizadas pelos Desenvolvedores de Serviços. As ferramentas utilizadas por ambas as entidades estão duplicadas, ou seja, aparecem em ambos os mapas.

\subsubsection{Ferramentas para Provedores de Serviços}

Para melhor visualização, as ferramentas identificadas (Tabela 6) serão posicionadas individualmente no eTOM Nível 1 (Figura 44), sendo depois superpostas num mapa consolidado que se encontra na Figura 60.

- Diagrama de Gestão da FNQ: dado seu foco na gestão corporativa e sua ênfase no alinhamento de toda a organização em torno de um conjunto único de objetivos estratégicos, o Diagrama de Gestão da FNQ se aplica a questões de negócio (ligadas a Mercado e aos Clientes, ou seja, pertencentes à camada horizontal de Marketing, Offer e Customer 
Relationship Management) em quase todo o Ciclo de Vida de um serviço (Figura 51).

- DMAIC: parte integrante do conjunto de técnicas denominado TQM, o DMAIC é a filosofia de melhoria contínua aplicada à camada de negócios do eTOM. Sua ênfase em análise e correção de tendências torna-o uma boa opção para garantir um ciclo de realimentação entre os processos de Operação (notadamente Entrega e Garantia de Qualidade) e os de Planejamento (tanto de Produto quanto de Infra-estrutura), como ilustrado na Figura 52.

- VOC: metodologia para captura de requisitos do usuário, o VOC é a ferramenta ideal para ligar os processos de Estratégia e Planejamento de Produto e Infra-estrutura, garantindo o seu alinhamento com os anseios do cliente (Figura 53).

- Kansei e House of Quality: em se tratando ambas de metodologias para tradução dos anseios subjetivos do cliente em requisitos objetivos de projeto, o papel do Kansei e da House of Quality se estende tanto na direção do mercado quanto na direção da infra-estrutura física. Assim, ambos tangenciam a camada de Mercado e Clientes e se concentram nas camadas de Serviços e Recursos (vide Figura 54), auxiliando o Provedor a entender tanto as demandas dos clientes por funcionalidades nos seus Serviços quanto o seu impacto prático nos Recursos que os implementam.

- Kaizen e PDCA: tanto o Kaizen, através de uma abordagem mais conceitual e até filosófica, quanto o PDCA, com seu pragmatismo simples, abordam o mesmo tema: o foco da empresa na melhoria contínua, entendida como um processo iterativo e sem fim. Assim, o papel de ambos está em garantir a melhora do Provedor de Serviços no Planejamento e na Operação de seus Serviços e Recursos e na interação com seus Parceiros e Fornecedores (vide mapeamento na Figura 55).

- RUP: para o Provedor de Serviços, o ponto mais importante do RUP é a gestão da implantação (apresentada na secão 4.4.1.2.2 ), que the permite assumir a operação de um novo serviço através de uma transição totalmente controlada. Assim, o RUP se posiciona entre os processos de Planejamento 
(agrupamento SIP) e os processos de Operação (agrupamento FAB) na camada horizontal de Recursos (o RUP é muito mais focado no desenvolvimento de infra-estrutura tecnológica do que no de novos serviços), como ilustrado na Figura 56.

- SANRR: embora se trate de uma metodologia iterativa como o PDCA e também contenha um componente de melhoria contínua como o Kaizen, o SANRR é focado na implementação da infra-estrutura de suporte à operação. Assim, seu papel nos processos de Planejamento se dá apenas na camada de Recursos (na medida em que o SANRR se propões a auxiliar na modelagem da infra-estrutura tecnológica que suporta o serviço); nos processos de Operação, por sua vez, o SANRR não possui papel relevante (devido ao seu já mencionado foco na implantação). Seu papel em Operações resume-se à disponibilização de plataformas de OSS e BSS, e por isso ele aparece mapeado tanto na camada de Recursos quanto na de Serviços no agrupamento de processos de Operations Support \& Readiness (Figura 57).

- NGOSS Implementation Model: como o RUP, o principal papel do NGOSS Implementation Model para o Provedor de Serviços (num cenário como o deste trabalho em que existe a figura do Desenvolvedor de Serviços) e facilitar a transição do novo serviço do ambiente de Desenvolvimento para o de Produção. No entanto, o NGOSS Implementation Model é mais focado em serviços (devido à sua origem vinculada ao eTOM - vide seção 4.2 ) do que o RUP; daí as diferenças no seu mapeamento no eTOM (Figura 58).

- Seis Sigma: a mais conhecida das metodologias para Controle Estatístico de Processos é especialmente indicada para otimizar os processos de entrega do Provedor de Serviços, reduzindo erros no aprovisionamento de novos serviços (Fulfillment), tornando a resolução de problemas mais ágil (Assurance) e reduzindo o número de erros em contas e faturas (Billing), entre outros benefícios. Seu mapeamento encontra-se na Figura 59. 


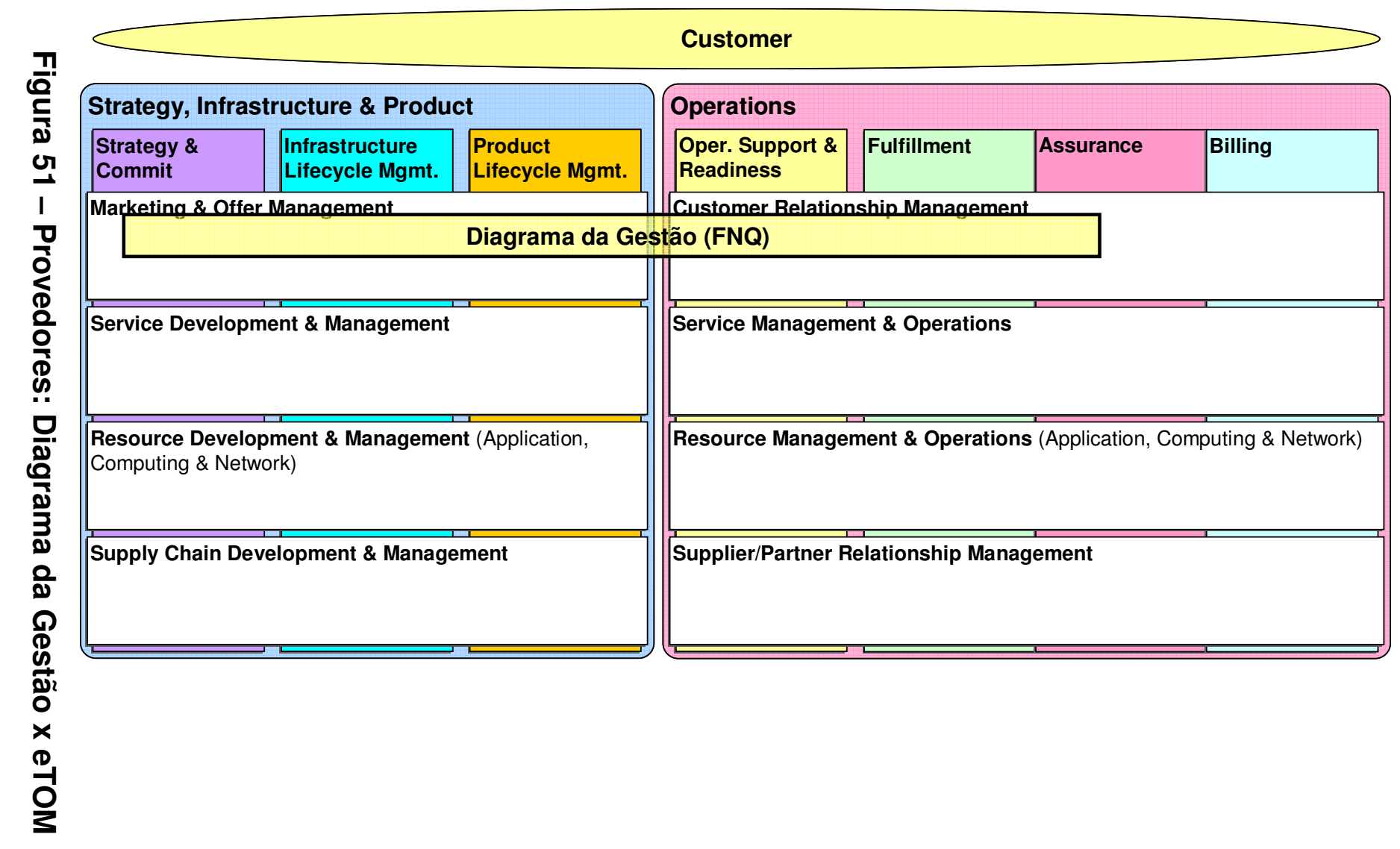

\section{TQM (Total Quality Management) \\ QFD (Quality Function Design)}

Outros 


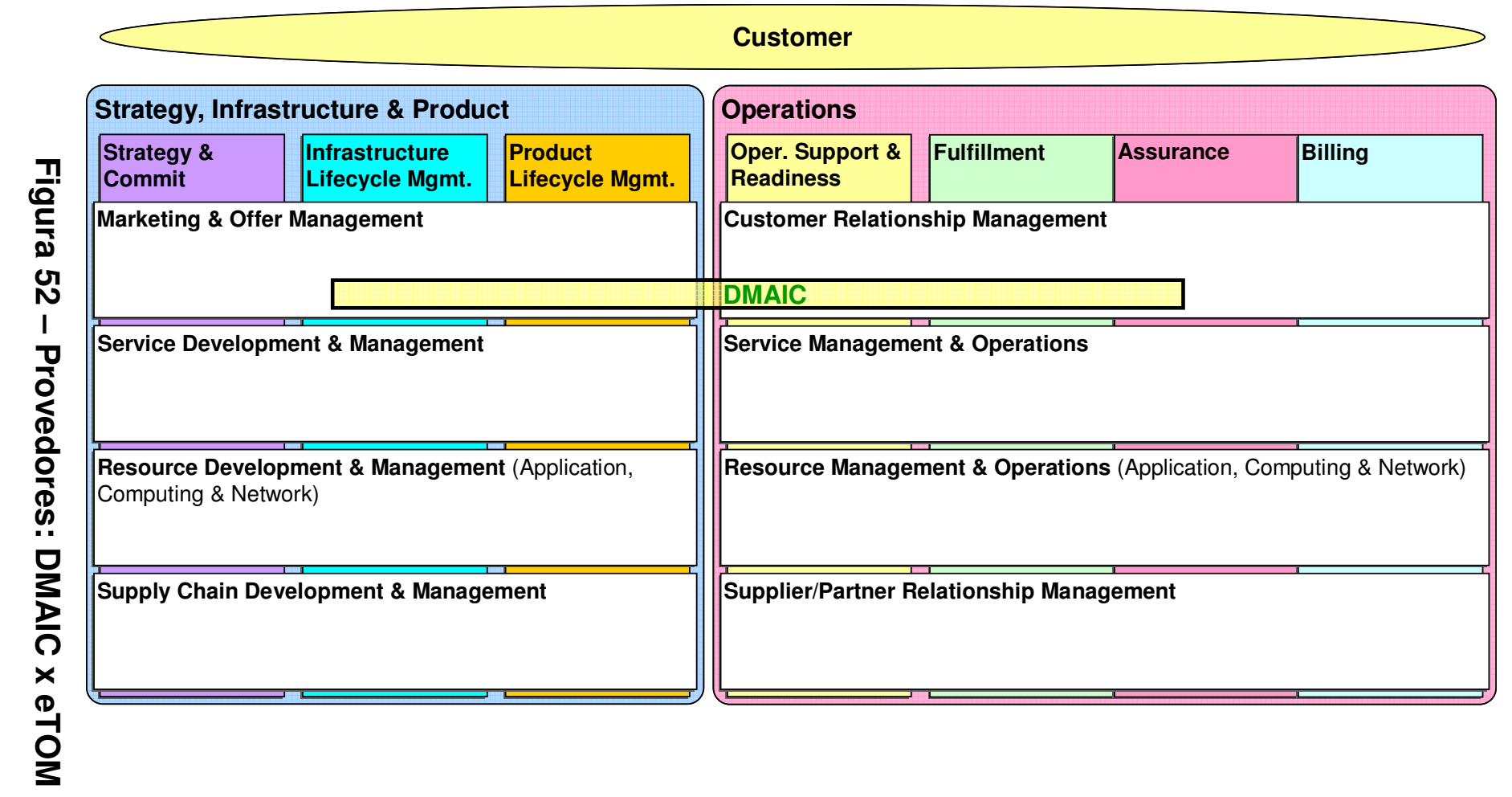

TQM (Total Quality Management)

QFD (Quality Function Design)

Outros 


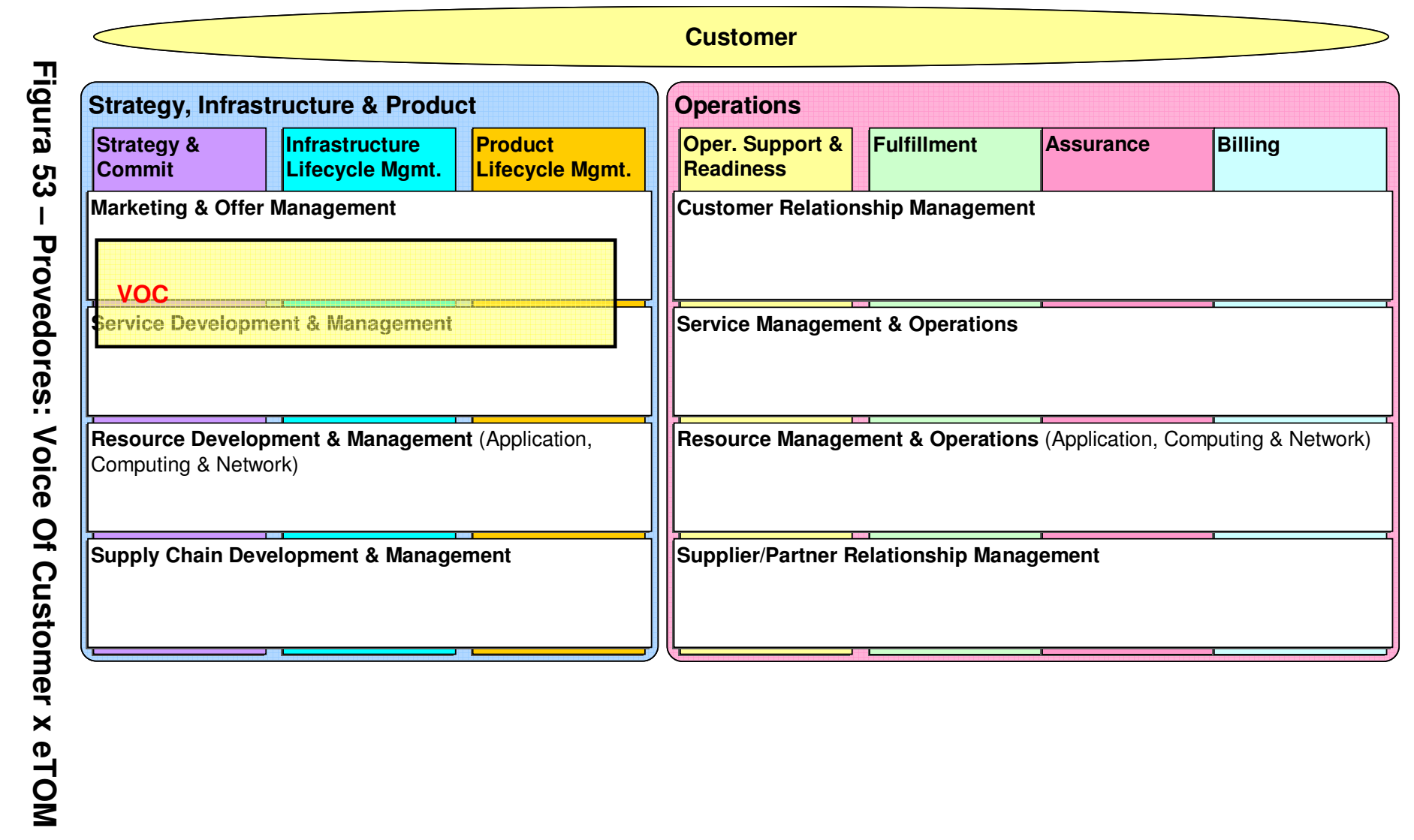

\section{TQM (Total Quality Management) \\ QFD (Quality Function Design)}




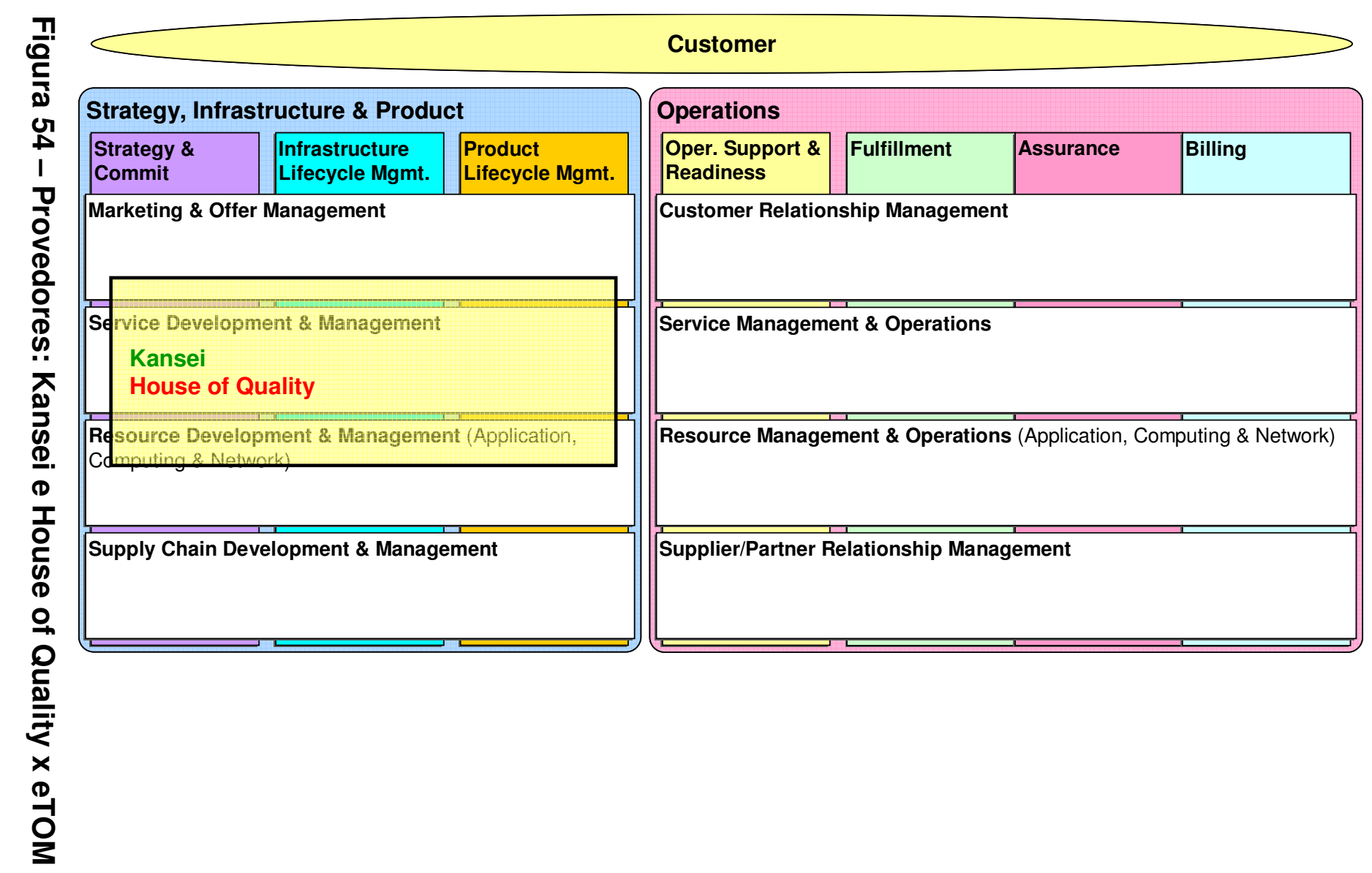

\author{
TQM (Total Quality \\ Management) \\ QFD (Quality Function \\ Design)
}

Outros 


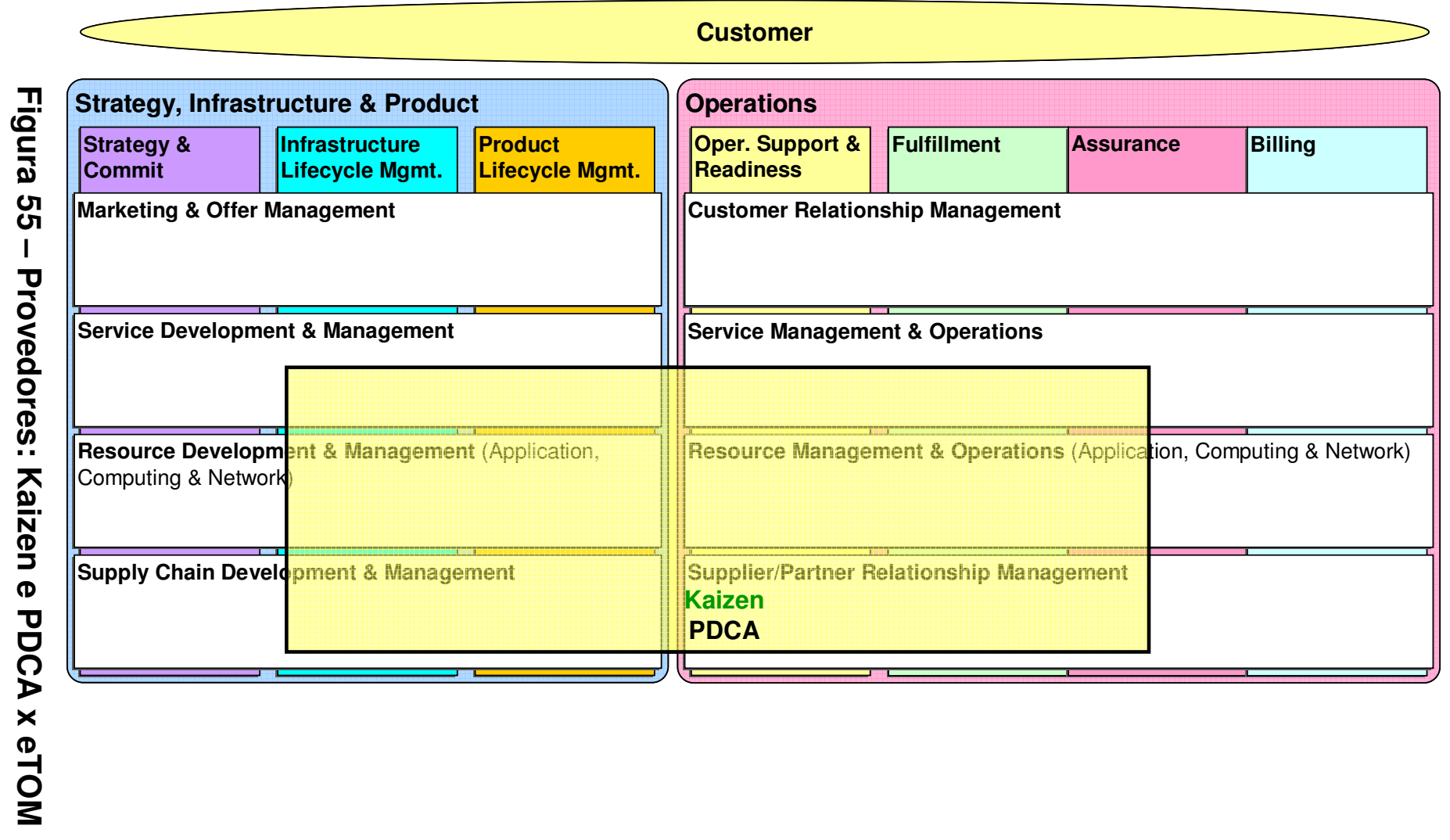
TQM (Total Quality
Management)
QFD (Quality Function Design)

Outros 


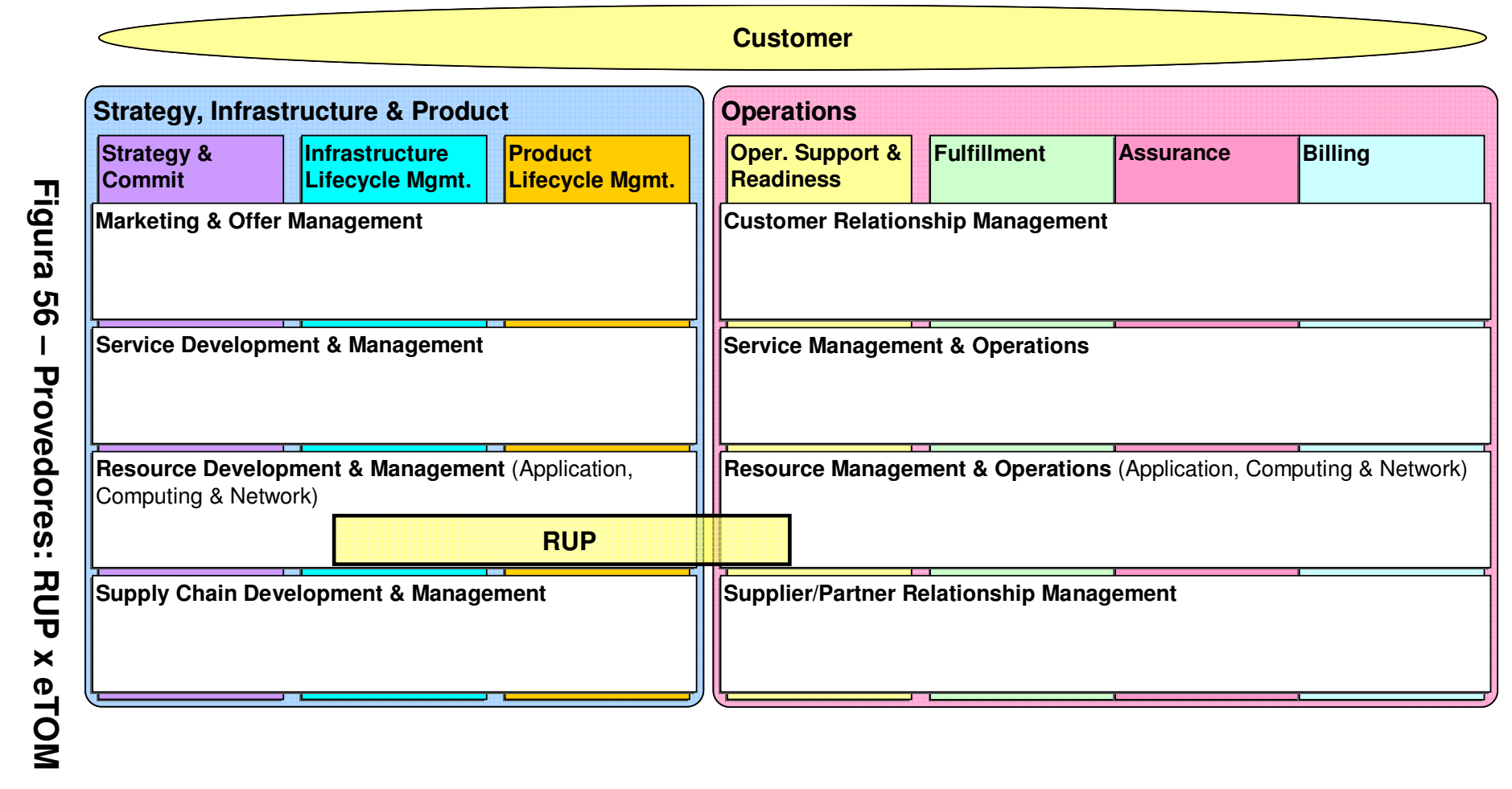
TQM (Total Quality Management)
QFD (Quality Function Design)

Outros 


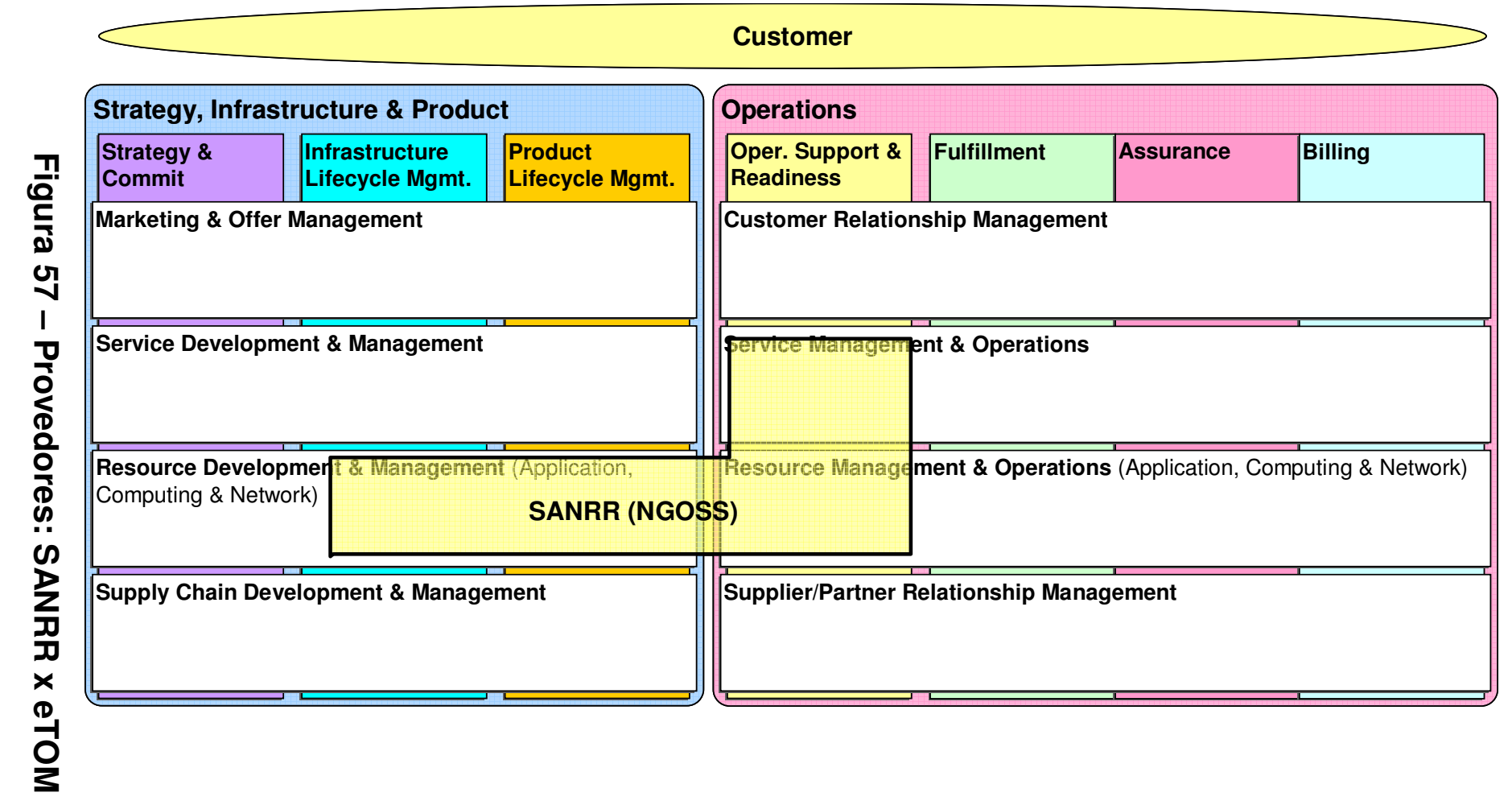
TQM (Total Quality Management)
QFD (Quality Function Design)

Outros 


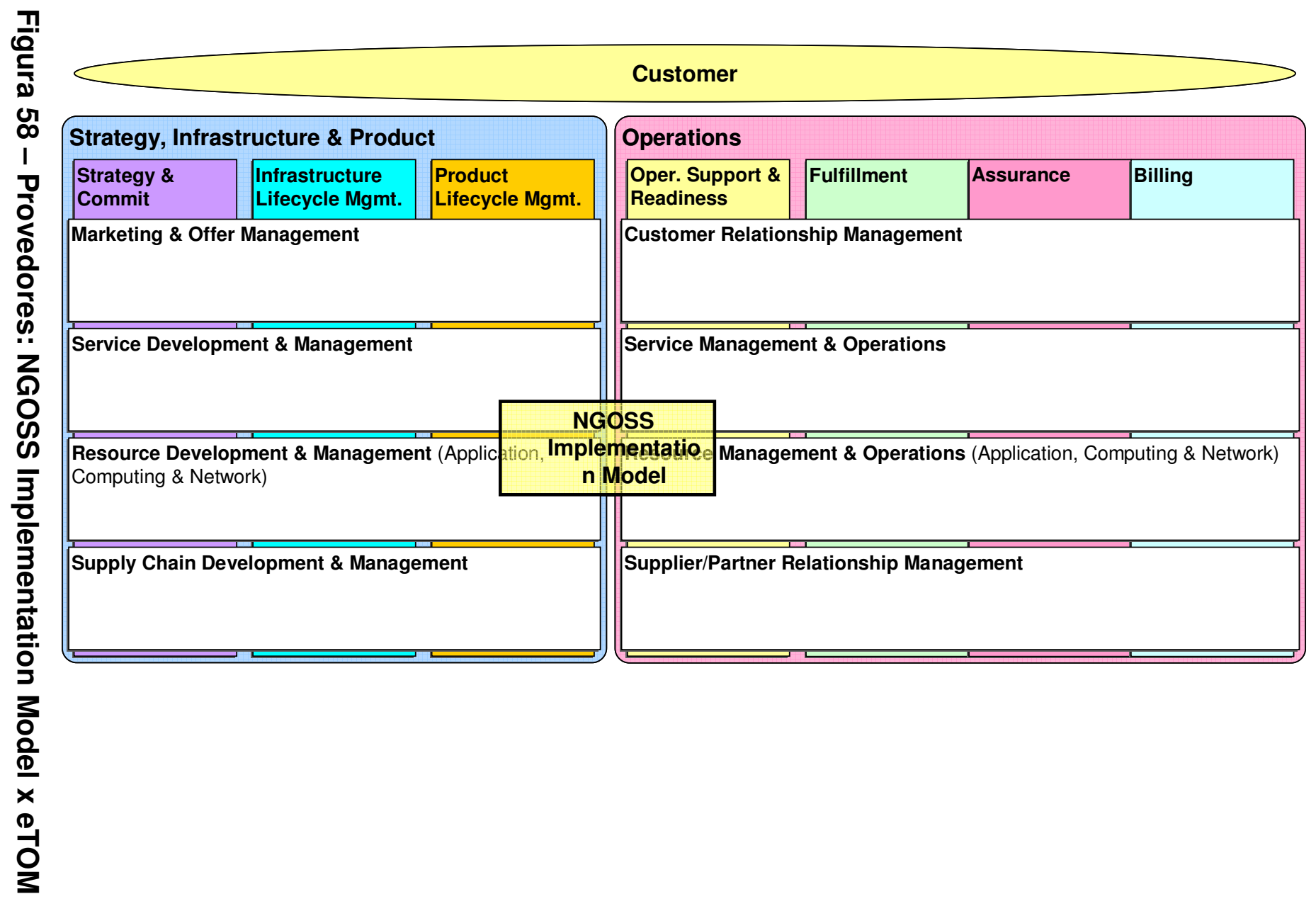




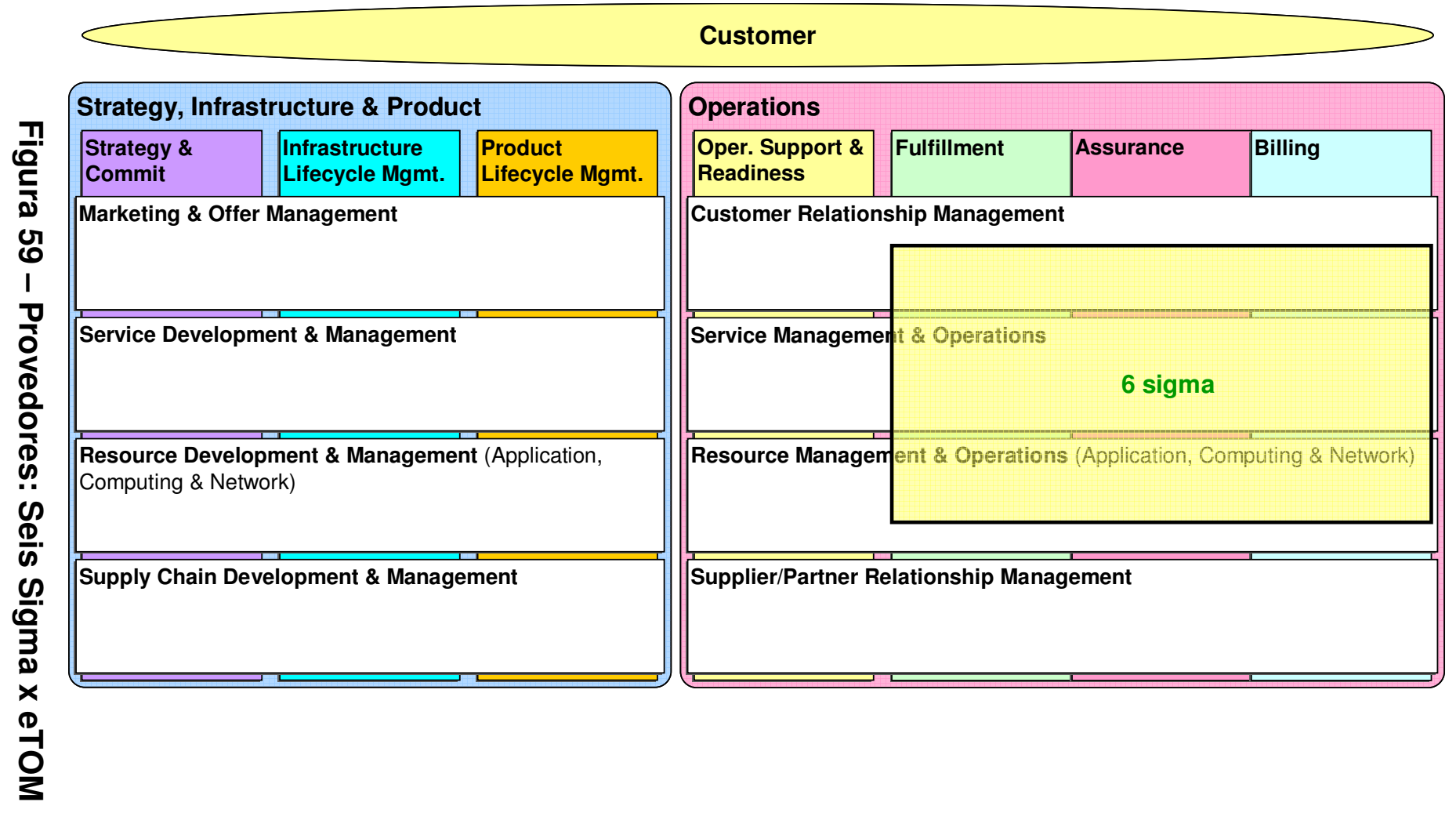
TQM (Total Quality Management)
QFD (Quality Function Design)

Outros 


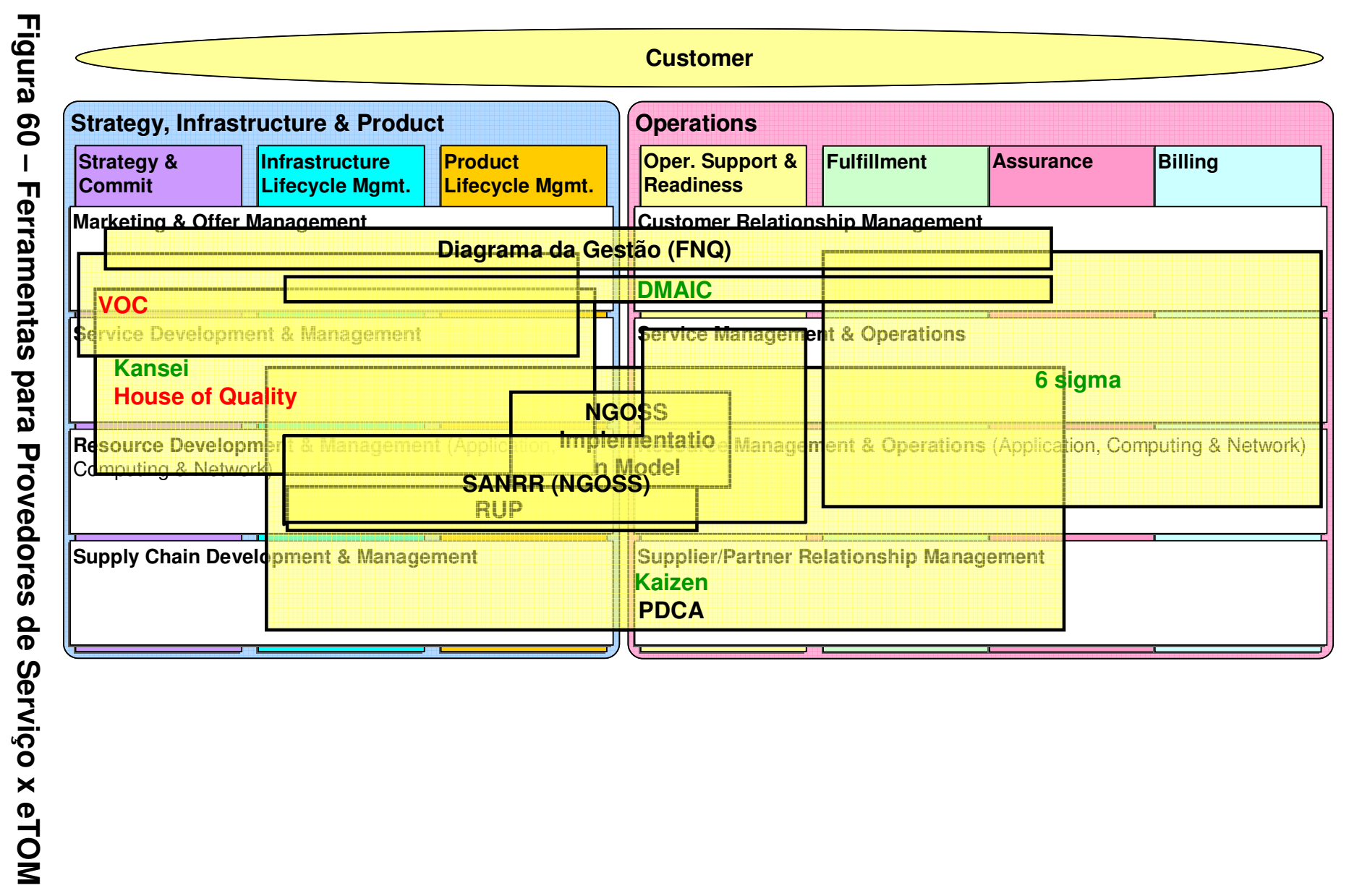

\author{
TQM (Total Quality \\ Management \\ QFD (Quality Function \\ Design)
}

Outros 


\subsubsection{Ferramentas para Desenvolvedores de Serviços}

Para melhor visualização, as ferramentas identificadas (Tabela 6) serão posicionadas individualmente no eTOM Nível 1 (Figura 44), sendo depois superpostas num mapa consolidado que se encontra na Figura 65.

- VOC: da mesma forma que para os Provedores (seção 6.3.1), o VOC é a metodologia para captura de requisitos do usuário, ou seja, pode ser utilizada para ligar os processos de Estratégia e Planejamento de Produto e Infra-estrutura, garantindo o seu alinhamento com os anseios do cliente (Figura 61).

- Kansei, House of Quality, Maximum Value Table e Visitas Gemba: todas estas ferramentas, focadas na conversão dos desejos subjetivos dos clientes em requisitos e parâmetros de projeto objetivos, se aplicam ao processo de planejamento e projeto de novos serviços (agrupamento SIP no eTOM), abrangendo de questões de mercado à interação com parceiros e fornecedores, ou seja, todas as camadas horizontais do eTOM Nível 1 (Figura 62).

- RUP: diferente de sua aplicação para um Provedor de Serviço (centrada na transição entre os ambientes de Desenvolvimento e Produção), o RUP tem um papel muito mais abrangente em um Desenvolvedor de Serviços - aqui, o RUP permeia todos os processos de trabalho ligados à especificação técnica, à construção e à implementação do serviço e da infra-estrutura tecnológica que o suporta (Figura 63).

- NGOSS Implementation Model: um Desenvolvedor de Serviços tende a favorecer o RUP no lugar do NGOSS Implementation Model como metodologia de desenvolvimento, já que este último é um padrão desenvolvido por e para Provedores de Serviço. No entanto, como os Provedores adotam o NGOSS como base para seus sistemas internos, é interessante para o Desenvolvedor adotar algumas de suas práticas com o intuito de facilitar a transição do novo serviço do ambiente de Desenvolvimento para o de Produção (Figura 64). 


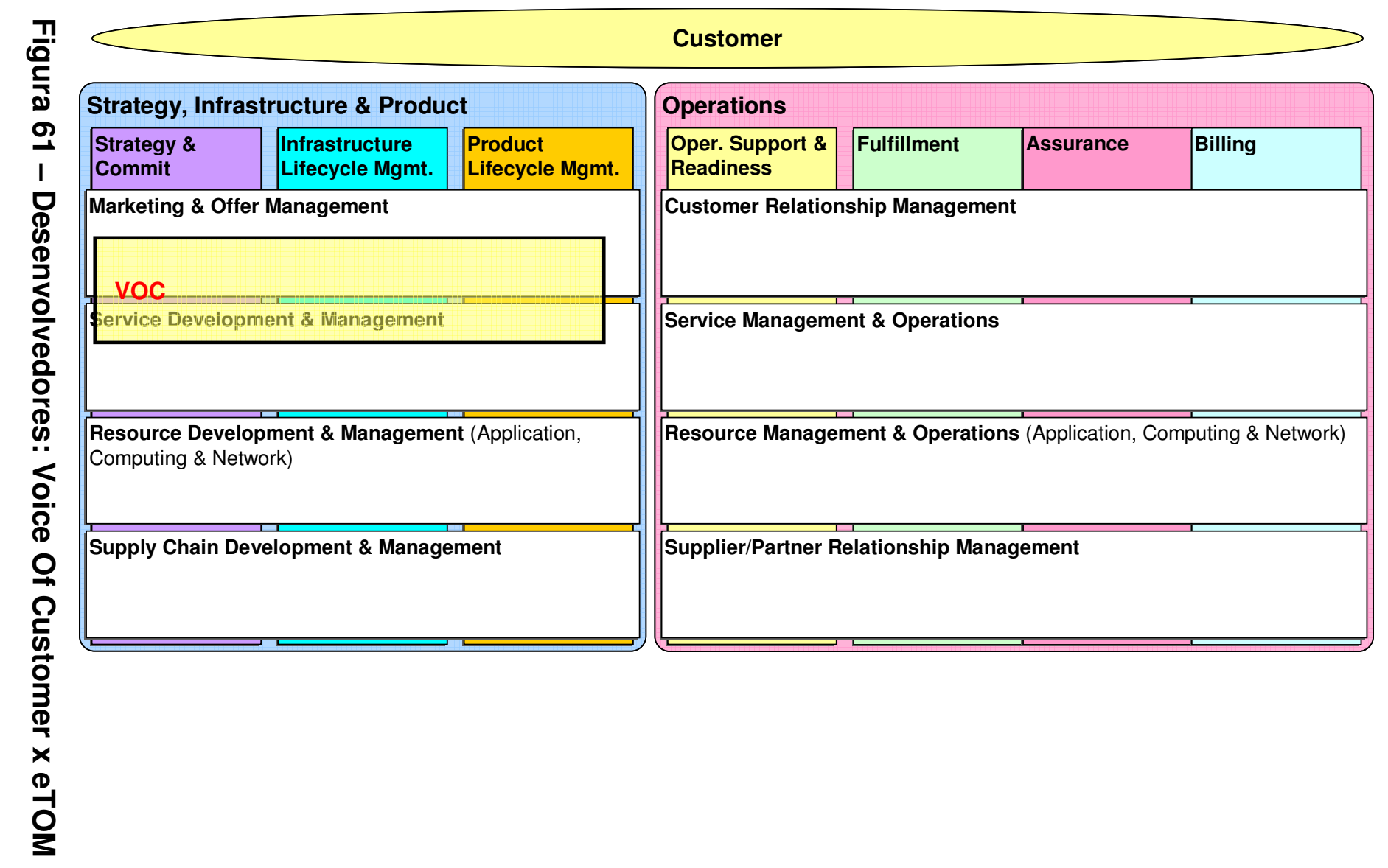

\author{
TQM (Total Quality \\ Management) \\ QFD (Quality Function \\ Design)
}

Outros 


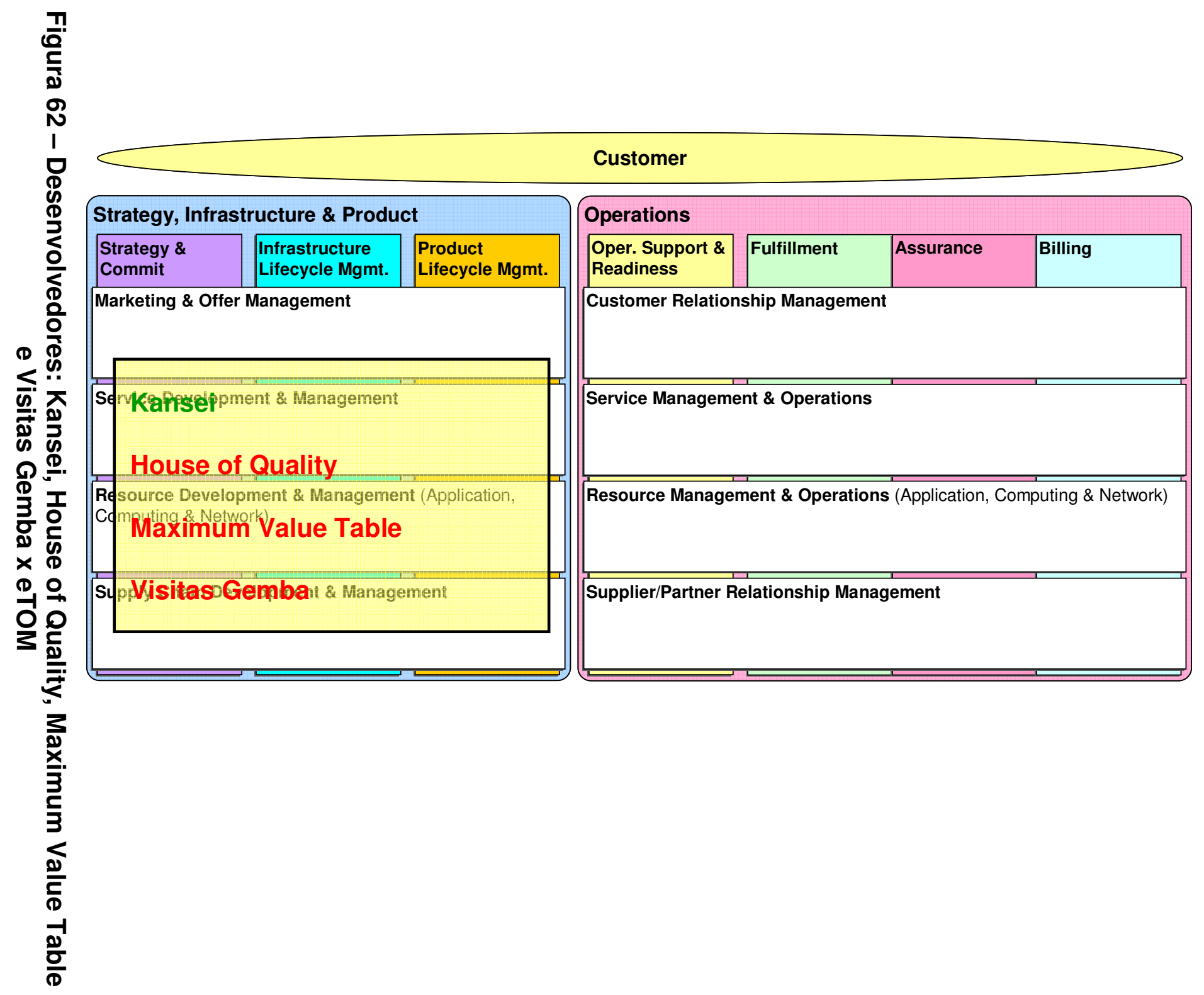
TQM (Total Quality
Management)
QFD (Quality Function Design)

Outros 


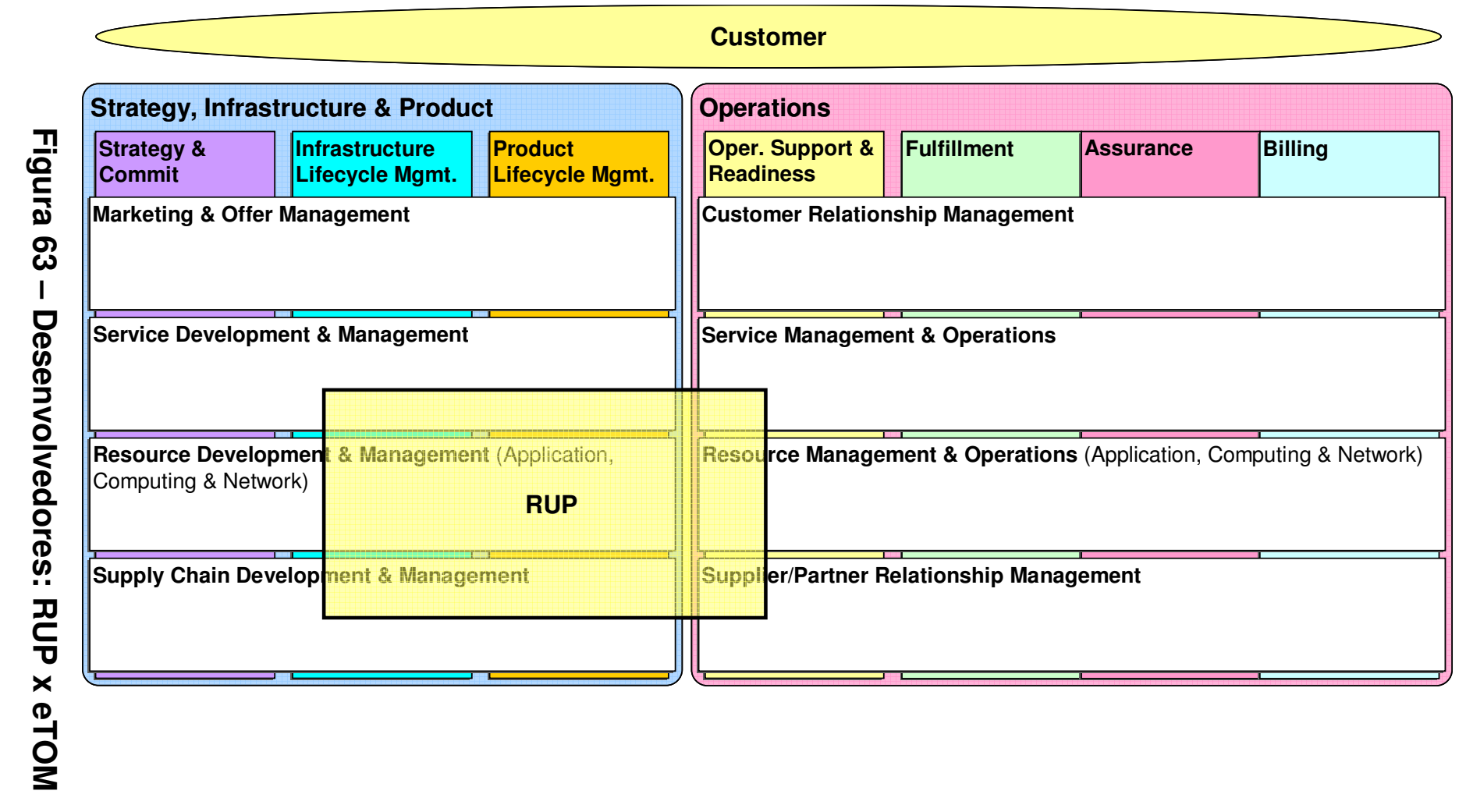
TQM (Total Quality
Management)
QFD (Quality Function Design)

Outros 


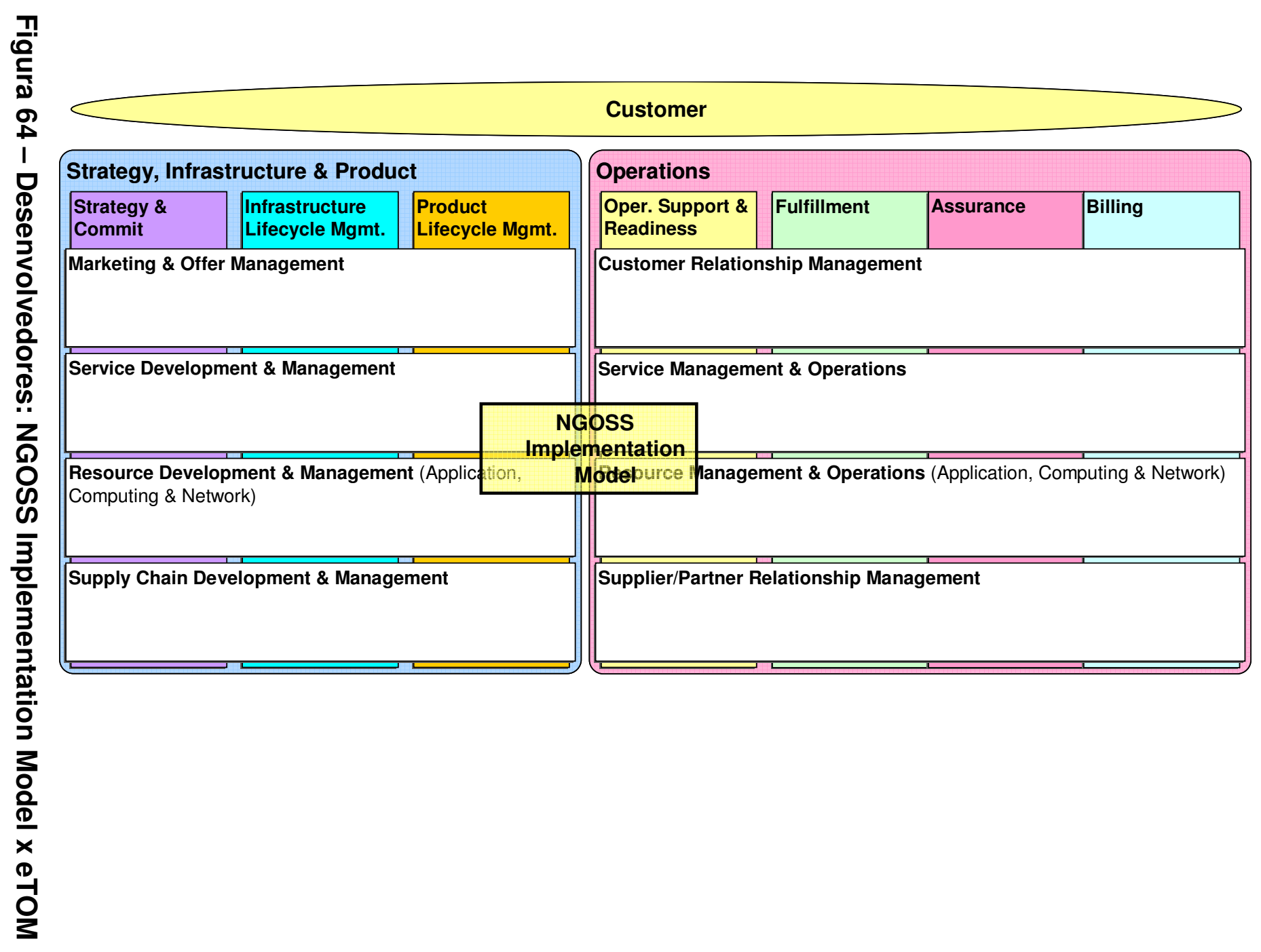

\author{
TQM (Total Quality \\ Management) \\ QFD (Quality Function \\ Design)
}

Outros 


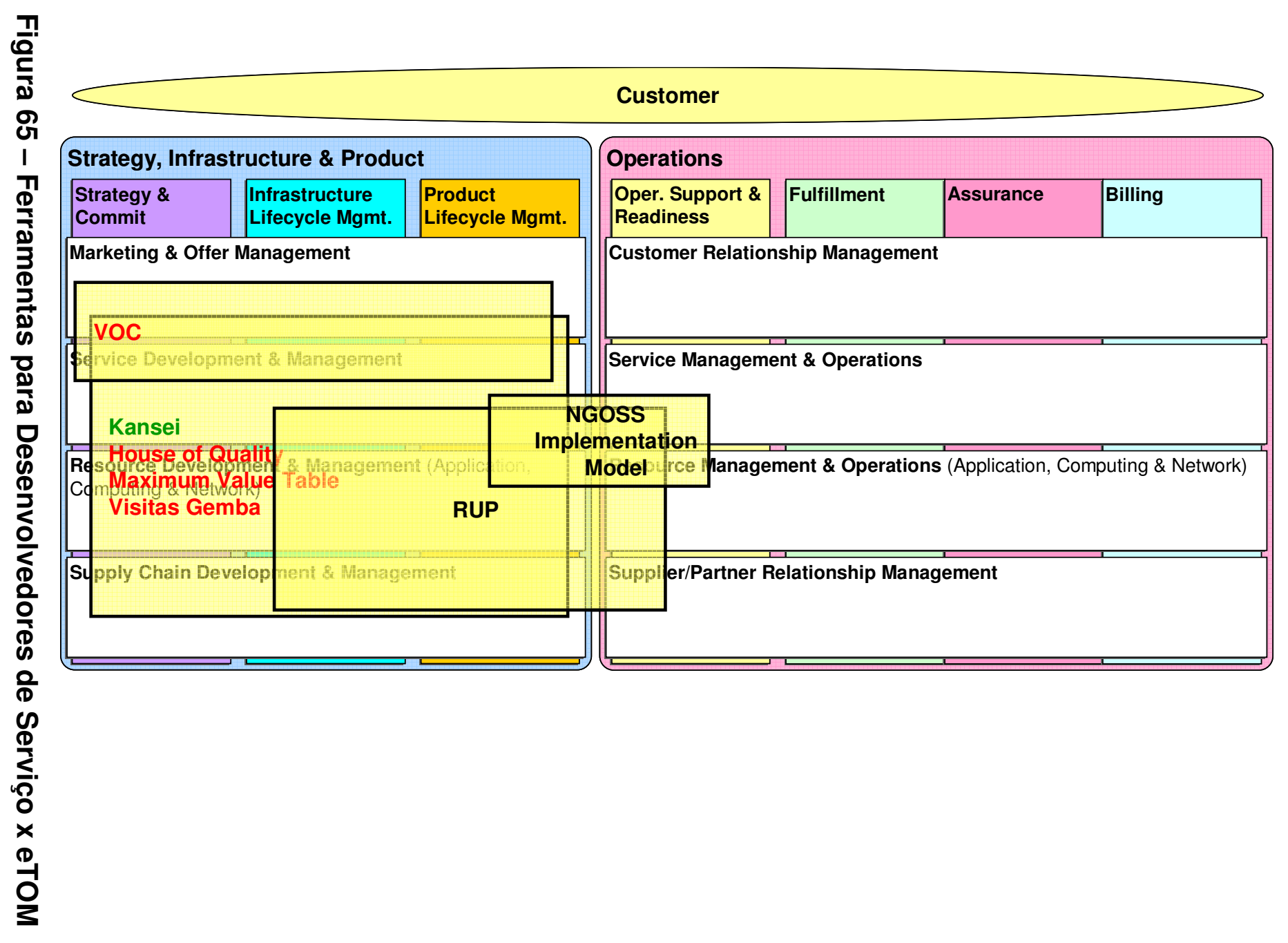

\author{
TQM (Total Quality \\ Management) \\ QFD (Quality Function \\ Design)
}

Outros 


\section{CONSIDERAÇÕES FINAIS}

\subsection{Avaliação dos Resultados}

O objetivo inicial - apresentar um conjunto de ferramentas para garantir que a voz do consumidor seja levada em consideração em todos os elos da cadeia de prestação de serviços em telecomunicações - foi atingido na forma dos mapas apresentados no capítulo 6 .

Embora a abordagem inicialmente planejada fosse a utilização direta do eTOM, o desenvolvimento de diversos mapas com complexidade e detalhamento crescentes contribui para enriquecer o resultado final, na forma de um melhor entendimento do papel e da aplicabilidade de cada ferramenta em cada atividade que compõe a prestação de um serviço de telecomunicações. Além disso, o desenvolvimento de um modelo de interação entre Desenvolvedores e Provedores de Serviço também tornou o resultado final mais interessante, pois permitiu demarcar claramente o escopo de atuação de cada entidade.

\subsection{Contribuições do Trabalho}

Mais do que tudo, este trabalho propõe uma idéia: aplicar técnicas de Engenharia de Qualidade a todas as etapas da prestação de um serviço de telecomunicações, tendo como objetivo último o atendimento das necessidades dos consumidores.

Não se trata de uma idéia nova - o Programa Lean Operator do TMForum, uma das fontes de inspiração deste trabalho - é exatamente sobre este tema.

No entanto, o mapeamento das ferramentas da Engenharia da Qualidade e da Engenharia de Produção num modelo de processos reconhecido pela indústria 
(o eTOM) torna essa idéia muito mais tangível (e, espera-se, mais exeqüível) para os Desenvolvedores e Provedores de Serviço.

Assim, as principais contribuições deste trabalho são duas:

- O Modelo de referência com ênfase em requisitos e design de serviço (apresentado na seção 3.1.2 ): a distinção entre Desenvolvedores e Provedores de Serviços e a formalização dos seus papéis, responsabilidades e necessidades pode melhorar a interação entre estas entidades;

- A aplicação das ferramentas de Gestão da Qualidade e Produção ao eTOM (apresentada no capítulo 6): ao explicitar em que processo do eTOM cada ferramenta se aplica, espera-se despertar o interesse de Desenvolvedores e Provedores de Serviços para as técnicas que possam auxiliá-los nos processos considerados mais relevantes.

\subsection{Trabalhos Futuros}

Este trabalho apresentou um conjunto de ferramentas e propôs uma abordagem integrada para a sua utilização. Esta proposta pode ser estendida em duas direções:

- Estudo de Caso: a abordagem necessita ser testada em um ambiente real, por meio de sua aplicação a um serviço de telecomunicações que esteja em uso ou em fase de desenvolvimento. Dada a proximidade do autor com este segmento de mercado, esta é uma possibilidade bastante concreta de continuidade deste trabalho.

- Adaptar ferramentas identificadas para as especificidades dos serviços de telecomunicações: como já mencionado, as ferramentas propostas têm origens bastante diversas. Enquanto as ferramentas ligadas ao TMForum e ao seu programa NGOSS foram desenvolvidas especificamente para a indústria de telecomunicações, metodologias como o Seis Sigma vieram do ambiente fabril e da produção de bens em larga escala. Adaptar estas 
ferramentas para o mundo de serviços em geral, e para o ambiente de serviços de telecomunicações em particular, seria uma ótima oportunidade de continuação para este trabalho. Um exemplo bastante específico seria adicionar ao COBIT (vide 4.5.3 ) uma dimensão centrada no consumidor, com um conjunto de objetivos focados em atender aos seus requisitos. 


\section{LISTA DE REFERÊNCIAS}

[1] HEGEDUS, Clovis E. N. A compreensão da percepção da qualidade pelo consumidor como base para a definição de estratégias pelas empresas e suas cadeias de fornecimento. 2000. 183p. Dissertação (Mestrado) Escola Politécnica da Universidade de São Paulo, Departamento de Engenharia de Produção. São Paulo.

[2] PROCON. Pesquisa sobre Telefonia Móvel. 2004. Disponível em: <http://www.procon.sp.gov.br/infpressservruins.shtml>. Acesso em: 19/12/2004.

[3] PROCON. Ranking de Má-prestação de Serviços. 2002. Disponível em: $<$ http://www.procon.sp.gov.br/infpressservcad2002.shtml>. Acesso em: 19/12/2004.

[4] CONSUMIDOR MODERNO. Prestação de serviços de telecom em pauta. 27/01/2003. Disponível em:

$<$ http://www.consumidormoderno.com.br/ler_materia.asp?id=2367>. Acesso em: 19/12/2004.

[5] COCHRAN, Craig. Leveraging Customer Complaints Into Customer Loyalty. Quality Digest Magazine. 2004. Disponível em: <http://www.qualitydigest.com/currentmag/articles/02_article.shtml>. Acesso em: 22/12/2004.

[6] NADEAU, Michel; CHALIFOUR, Sebastien. QOS in the relentless pursuit of customers. Telephony Online 2000. Disponível em: $<h t t p: / / t e l e p h o n y o n l i n e . c o m / a r / t e l e c o m \_q o s \_r e l e n t l e s s \_p u r s u i t />$. Acesso em: 05/01/2005.

[7] KARAM, Dib Junior. Modelo de negócio para mobilidade e interatividade em ambientes convergentes heterogêneos. 2006. 80 p. Tese (Doutorado) - Programa de Pós Graduação em Engenharia. Área de Concentração: 
Computação e Sistemas Digitais) - Escola Politécnica da Universidade de São Paulo. São Paulo.

[8] INTERNATIONAL TELECOMMUNICATION UNION. ITU-T

Recommendation M.3010 (02/2000) - Principles for a telecommunications management network. 2000.

[9] HONDIUS, Ewoud. The Notion of Consumer: European Union versus Member States. Sydney Law Review, Sydney, Australia, Vol 28: 89. 2006.

[10] FERREIRA, A. B. H. Dicionário Aurélio Básico da Língua Portuguesa. Rio de Janeiro: Editora Nova Fronteira, 1995. 687 p.

TMFORUM. GB921 Release 6 v6.1: Enhanced Telecom Operations Map (eTOM). The business process framework for the information and communications services industry. 2005. 81 p.

[12] ABNT NBR. ISO 9000 Sistemas de gestão da qualidade Fundamentos e vocabulário. Segunda Edição. Rio de Janeiro, Brasil, 2006. p. 8

[13] ASQ (American Society for Quality). Página institucional, glossário e documentação básica. Disponível em: <www.asq.org>.

[14] ASQ (American Society for Quality). Glossary - Definition of Quality. Disponível em: < http://www.asq.org/glossary/q.html>. Acesso em: 10/4/2006 ASQ (American Society for Quality). Basic Concepts - Customer Satisfaction. Disponível em: <http://www.asq.org/learn-aboutquality/customer-satisfaction/overview/overview.html>. Acesso em: 10/4/2006

[16] MAZUR, G. Close Encounters of the QFD Kind. In: Symposium on Service Quality Conference, 6a ${ }^{\text {, }}$ 1997. Proceedings. 1997.

[17] MAZUR, G. Voice of the Customer (Define): QFD to define Value. QFD Institute. Michigan, USA. 1997. 
[18] TeleManagement Forum. Página institucional e documentação sobre as iniciativas da entidade. Disponível em <www.tmforum.org>.

[19] FARO, L.; SPINA, E. The Need for a Customer-centric Approach for Services Development and Operation in the Brazilian Telecommunications Market. In: International Conference on the Digital Society 2007. Guadeloupe, 2007. Conference proceedings. IEEE Computer Society. ISBN 0-7695-2760-4. Disponível em $<$ http://ieeexplore.ieee.org/>.

[20] EIKELMAN, S. et al. Outsourcing trends in the European telecommunications industry. Booz Allen Hamilton. 2003. 12 p.

[21] WOMACK, J. P.; JONES, D. T. Lean Thinking Second Edition. Lean Institute. Publicado por Simon \& Schuster. 397 p. ISBN: 0-7432-4927-5.

[22] JONES, D. The Beginner's Guide to Lean. Lean Enterprise Academy. Disponível em:

$<$ http://www.lean.org/Community/Registered/Article.cfm?Articleld=379>. Acesso em: 29/11/2006.

[23] NAGAMACHI, M. Kansei engineering as a powerful consumer oriented technology for product development. 2002. Applied Ergonomics 33 , p. 289-294.

[24] NAGAMACHI, M. Workshop 2 on Kansei Engineering. In: International Conference on Affective Human Factors Design. Proceedings. Singapore, 2001.

[25] SCHÜTTE, S.; EKLUND, J. Product Development for Heart and Soul. Linköpings Universitet, Department for Human Systems Engineering. Publicado por Uni Tryck Linköping. Suécia. ISBN: 91-631-4295-3

[26] Lean Institute. Página institucional e documentação básica.

Disponível em <www.lean.org $>$. 
[27] Lean Institute Brasil. Glossário, definição de Kaizen. Disponível em: $<$ http://www.lean.org.br/bases.php?interno=thinking_vocabulario\#55>. Acesso em: 20/05/2005.

[28] FONTANINI, J. I.; REIS, D.; LEITE, M. A melhoria contínua através do kaizen como mecanismo de incorporação de inovações tecnológicas incrementais. In: Anais do Congresso Brasileiro de Gestão do Conhecimento (KM Brasil 2003). São Paulo: Sociedade Brasileira de Gestão do Conhecimento, 12 a 14 de Novembro de 2003. Disponível em: <http://www.ppgte.cefetpr.br/docentes/permanentes/dalcio/kaizen.pdf> Acesso em: 20/05/2005.

[29] HUTZINGER, J. The Roots of Lean. Training Within Industry: The Origin of Kaizen. Target Volume 18, Number 1. AME (Association for Manufacturing Excellence - <www.ame.org>). EUA, 2002.

[30] ANDRADE, Fabio F. O método de melhorias PDCA. 2003. 157 p. Dissertação (Mestrado) - Escola Politécnica da Universidade de São Paulo. Área de concentração: Engenharia de Construção Civil e Urbana. São Paulo, 11/07/2003.

[31] TAGUE, Nancy R. Quality Toolbox, $2^{\text {nd }}$ Edition. Publicado por ASQ Quality Press, EUA, 2005. 558 p. ISBN-10: 0873896394. ISBN-13: 9780873896399.

[32] ISO (International Organization for Standardization). Página institucional e glossário. Disponível em: <www.iso.org>

[33] ISO. ISO/IEC 27001 Information technology - Security techniques - Information security management systems - Requirements. Primeira edição. Suíça, 2005. 42 p.

[34] Motorola. Página institucional. Disponível em: <www.motorola.com> [35] BRICE, Zachey. Six Sigma Sharpens Services. Quality Digest Magazine, Maio de 2004. Disponível em: 
<http://www.qualitydigest.com/may04/articles/03_article.shtml>. Acesso em: 20/11/2006.

$$
\text { TRAD, Samir. Seis sigma: fatores críticos de sucesso de sua }
$$
implantação e impacto sobre desempenho organizacional. 2006. 177 p.

Dissertação (Mestrado) - Faculdade de Economia, Administração e Contabilidade da Universidade de São Paulo. Departamento de Administração. São Paulo.

[37] TONINI, A. C. A contribuição do seis sigma para a melhoria dos processos de software. 2006. 231 p. Dissertação (Mestrado) - Escola Politécnica da Universidade São Paulo. Departamento de Engenharia da Produção. São Paulo.

CABRERA JUNIOR, ALVARO. Dificuldades de implementação de programas Seis Sigma: estudos de casos em empresas com diferentes níveis de maturidade. 2006. Dissertação (Mestrado). Escola de Engenharia de São Carlos - Universidade de São Paulo. Engenharia de Produção. São Carlos.

[39] REILLY, John P.; CREANER, Martin J. NGOSS Distilled. The Lean Corporation. EUA, 2005. 215 p.

[40] QFD Institute. Página institucional e documentação básica. Disponível em <www.qfdi.org >

[41] CLARK, Kim B;. Wheelwright, Steven C. Managing New Product and Processes - Text and Cases. The Free Press, 1992. 896 p.

[42] BOLT, Andrew; MAZUR, Glenn H. Jurassic QFD - Integrating Service and Product Quality Function Deployment. QFD Institute, University of Michigan. EUA, 1999. 19 p.

[43] NAGUMO, G. K. Desdobramento da função qualidade (QFD) aplicado à produção de mudas de café (Coffea arabica L.). 200561 p. Dissertação (Mestrado) - Escola Superior de Agricultura Luiz de Queiroz. Piracicaba. 
Front-End QFD Tools, With Case Studies. 1996. In: AQC (Annual Quality Congress) 1997. Orlando, EUA, 1997. 17 p.

[45] RINGS, C.M.; BARTON, B.W.; MAZUR, G. Consumer Encounters: Improving Idea Development and Concept Optimization. In: 10th Symposium on QFD. 1998.

[46] FNQ - Fundação Nacional da Qualidade. Conceitos Fundamentais da Excelência em Gestão. Publicado pela FNQ. São Paulo, 2006. 32 p.

[47] FNQ - Fundação Nacional da Qualidade. Critérios de Excelência. Publicado pela FNQ. São Paulo, 2007. 52 p. ISBN 978-85-60362-23-3.

[48] DUTRA, Érica P. BPM - uma nova arquitetura de tecnologia da informação na gestão de processos de negócio. 2006. 142 p. Dissertação (Mestrado) - Escola Politécnica da Universidade São Paulo. Departamento de Computação e Sistemas Digitais. São Paulo, 2006.

[49] KRUCHTEN, P. The Rational Unified Process, An Introduction, Second Edition. Addison Wesley Longman. EUA, 2000.

[50] ECLIPSE PROJECT; IBM. Basic Unified Process v1.0. EUA, 2006.

[51] IT Service Management Forum. Página institucional, glossário e documentação básica. Disponível em: <www.itsmf.org >

[52] ISACA (Information Systems Audit and Control Association). Documentação oficial do COBIT. Disponível gratuitamente em: $<w w w$.isaca.org/cobit>

[53] ITGI (IT Governance Institute). Página institucional e documentação básica. Disponível em: <www.itgovernance.org> ITGI. COBIT 4.1. Estados Unidos, 2007. 213 p. ISBN 1-933284-72-2 FAGUNDES, E.M. COBIT: Um kit de ferramentas para a excelência na gestão de TI. 2004. 5 p. Disponível em 
<http://www.efagundes.com/Artigos/Arquivos_pdf/cobit.pdf>. Acesso em: 10/10/2006

[56] Project Management Institute. Página institucional. Disponível em: $<$ www.pmi.org >

[57] INTERNATIONAL TELECOMMUNICATION UNION. ITU-T Recommendation M.3200 (1997) - TMN management services and telecommunication managed areas: Overview. 1997.

[58] INTERNATIONAL TELECOMMUNICATION UNION. ITU-T Recommendation M.3400 (02/00) - TMN management functions. 2000.

[59] TANenbaum, A. Computer Networks, 4th Edition. Prentice Hall. EUA, 2002. 921 p. ISBN-10: 0130661023. ISBN-13: 978-0130661029.

[60] SAKURAI, Cledson Akio. Proposta de uma arquitetura aberta pra um sistema de suporte à operação de uma provedora de serviços de telecomunicações. 2004. 121p. Dissertação (Mestrado) - Escola Politécnica da Universidade de São Paulo.

[61] MIYATA, Cristina Mori. Gestão de qualidade de serviço na visão ODP: uma aplicação na arquitetura SLM. 2004. 120p. Dissertação (Mestrado) - Escola Politécnica da Universidade de São Paulo. São Paulo, 2004. 